\title{
Financial advice online : experiments investigating trust in an online human advisor
}

Citation for published version (APA):

Schmidt, M. (2009). Financial advice online : experiments investigating trust in an online human advisor. [Doctoral Thesis, Maastricht University]. Universitaire Pers Maastricht. https://doi.org/10.26481/dis.20091119ms

Document status and date:

Published: 01/01/2009

DOI:

10.26481/dis.20091119ms

Document Version:

Publisher's PDF, also known as Version of record

\section{Please check the document version of this publication:}

- A submitted manuscript is the version of the article upon submission and before peer-review. There can be important differences between the submitted version and the official published version of record.

People interested in the research are advised to contact the author for the final version of the publication, or visit the DOI to the publisher's website.

- The final author version and the galley proof are versions of the publication after peer review.

- The final published version features the final layout of the paper including the volume, issue and page numbers.

Link to publication

\footnotetext{
General rights rights.

- You may freely distribute the URL identifying the publication in the public portal. please follow below link for the End User Agreement:

www.umlib.nl/taverne-license

Take down policy

If you believe that this document breaches copyright please contact us at:

repository@maastrichtuniversity.nl

providing details and we will investigate your claim.
}

Copyright and moral rights for the publications made accessible in the public portal are retained by the authors and/or other copyright owners and it is a condition of accessing publications that users recognise and abide by the legal requirements associated with these

- Users may download and print one copy of any publication from the public portal for the purpose of private study or research.

- You may not further distribute the material or use it for any profit-making activity or commercial gain

If the publication is distributed under the terms of Article $25 \mathrm{fa}$ of the Dutch Copyright Act, indicated by the "Taverne" license above, 


\title{
FinANCIAL AdVICE ONLINE
}

\author{
EXPERIMENTS INVESTIGATING TRUST \\ IN AN ONLINE HUMAN ADVISOR
}

Mirjam Schmidt 
ISBN 9789052788807

Universitaire Pers Maastricht

(C) 2009, Mirjam Schmidt, Bruxelles

All rights reserved. No part of this publication may be reprinted or utilized in any form or by any electronic, mechanical, or other means, now known or thereafter invented, including photocopying and recording or in any information storage retrieval stystem, without the written permission of the copyright owner. 


\title{
FINANCIAL ADVICE ONLINE EXPERIMENTS INVESTIGATING TRUST IN AN ONLINE HUMAN ADVISOR
}

\author{
Proefschrift
}

ter verkrijging van de graad van doctor aan de Universiteit Maastricht op gezag van de Rector Magnificus, Prof. mr. G. P. M. F. Mols, volgens het besluit van het College van Decanen, in het openbaar te verdedigen op donderdag 19 november 2009 om 14.00 uur door






\section{Promotor:}

Prof. dr. J. C. de Ruyter

\section{Copromotor:}

Dr. R. M. Walczuch

\section{Beoordelingscommissie:}

Prof. dr. F. Moers (voorzitter)

Prof. dr. ir. H. W. G. M. van Heck (Erasmus Universiteit Rotterdam)

Dr. G. J. Odekerken-Schröder 
Für meine Eltern Gerhard und Christel 



\section{Acknowledgements}

In January 2006, after my graduation from the research master, I went to Venezuela to do the final internship of my life. It was from there that I applied to my master thesis supervisor Rita and to Jos Lemmink for a PhD. A subjective couple of years later, I was offered a position which I happily accepted.

A subjective couple of weeks after my first working day in August 2006, I will defend this dissertation. However, I owe this success to many people who have supported me on the (long) way, and without whom I had probably never reached the day of the defense.

The most important person to name here is Rita, my supervisor. Rita, you are actually the reason why I started my PhD at Maastricht and did not apply elsewhere. When you guided me during the master thesis process, I appreciated your inspiration and creativity already, and I knew that I would need your patience and your happy attitude during a PhD. We both know that without you I had given up long before reaching the day of the defense. Thanks for all the support you gave me during these "dark hours".

Furthermore, I am grateful that Ko was willing to be my supervisor even though we had never met before, and could not meet during the application process either. Ko, you have provided me with a unique chance to do a $\mathrm{PhD}$ in Maastricht. My work has greatly benefited from your critical questions; you identified any weak point in my ideas within seconds and made me re-think. I still remember your skeptical attitude when I prepared my second experiment; however, you never stopped me from doing exactly the studies I wanted. The result of our collaboration is described in this dissertation....

In spring 2009, I visited Elena Karahanna in Athens, GA. Elena, thank you very much for inviting me to the US, and for all your contribution to my third chapter. While we had not agreed on details of my visit before I came, you took the time to see me once a week and to read every single word in my chapter over and over again. You have enabled me to defend my work at this point of time - I doubt that I had reached this speed without you! 


\section{ii | A c know ledgements}

Frank Moers, Gaby Odekerken and Eric van Heck took the time to read and evaluate my dissertation in July and August: Thanks for being on my committee, and providing feedback to me. (Eric and me could only meet 17 hours before this dissertation was printed. This night is short...)

I would also like to thank my roommates in our ever-growing office: Marjolein and Anto (whom I asked so many questions and whose knowledge I highly appreciated), and Aga, Niek, Iraz and Anne (who made me aware that I was a "senior" PhD). I am also thankful for al US-PhDs, who welcomed me for the short period that I was there, and who took me to the supermarket in the small town of Athens, where life is impossible without a car: Thank you Adela, Ben, Seth, Ashley, Christine and Keri.

During the data collection phase, I was supported by some very motivated master students who provided me with access to their data (Silja and Gilles) or who provided me with support during the data collection (Anna, Eva, Priscilla and Emre). Thanks to all of you!

I am grateful to all service units of the University that provided me with support during this dissertation, especially the teams of the DocShop and ACO-help, who always fixed my last-minute requests.

Beste Nettie en Raymond, bedankt voor de leuke tijd in de Majolicastraat en de enorme ondersteuning! Jullie waren een waardevolle vervanging voor mijn familie die ik in Nederland heb moeten missen.

Danke auch an meine Eltern und Schwestern und alle anderen Verwandten, die mich in diesen drei Jahren unterstützt haben. An euch habe ich nur noch eine letzte Bitte: Sagt nicht “ist das Alles?” wenn ihr dieses Büchlein seht... 


\section{Table of Contents}











1.4 Theoretical Considerations .......................................................................

1.4.1 Adaptive Structuration Theory............................................................ 5





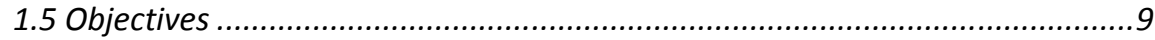





1.6 Outline of the dissertation ................................................................... 11

2 Out of sight, out of mind? - Extending the understanding of social presence and trust in an online service encounter ............................................................. 13

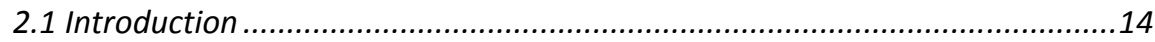



2.2.1 Social Presence Theory .....................................................................17

2.2.2 Conversational Involvement ...............................................................22

2.2.3 Increasing Social Presence in mediated conversations...........................25

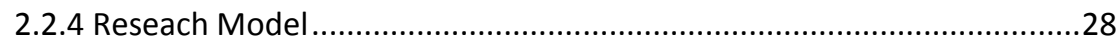

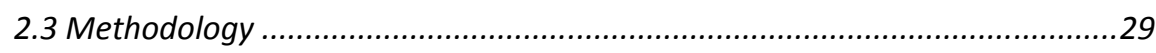

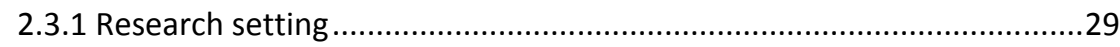

2.3.2 Selection of advisors and manipulation ..............................................29





2.3.5 Measurement Development ..............................................................










2.5 Discussion and Conclusion .......................................................................40

2.5.1 Social Presence, Trust and the role of Conversational Involvement.......40

2.5.2 Antecedents of Physical Presence........................................................41

2.5.3 Managerial implications .................................................................4

2.5.4 Limitations and Future Research...................................................42

2.6 Appendix A - Results scale development................................................45



2.8 Appendix C - Experimental scripts and handouts....................................48

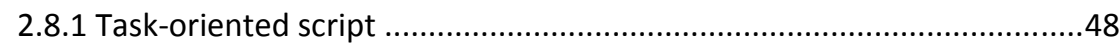



Handout 3 - Kaufkraft und Inflation ............................................................55

Handout 5 - examples of monthly payments................................................58

3 Investigating the Trust Transfer Process: The Role of Purchase Pals in Interactions With an Online Human Expert.................................................. 59



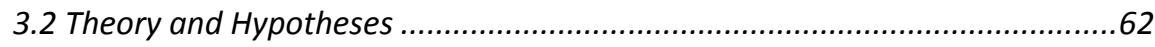

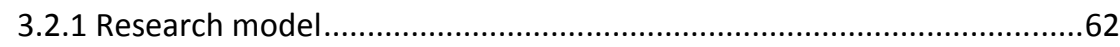



3.2.3 Decisions under uncertainty and prospect theory................................65

3.2.4 The role of presence in online trust creation .......................................66

3.2.5 Trust in purchase pal and physical presence with the online human

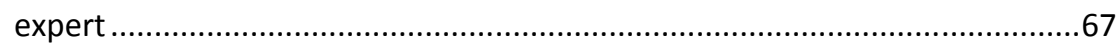

3.2.6 Trust and purchase decision ........................................................68

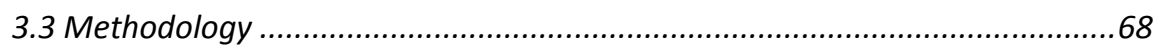

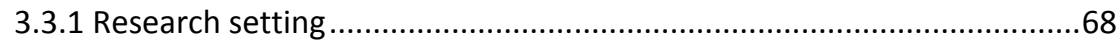

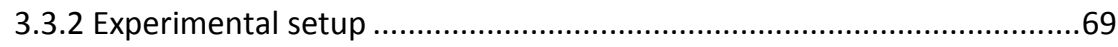

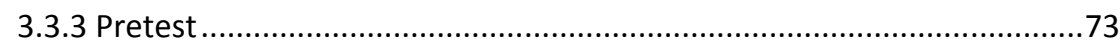

3.3.4 Measurement Development ........................................................ 74

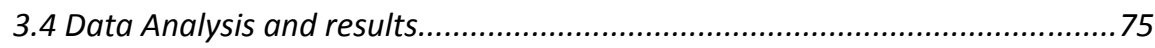

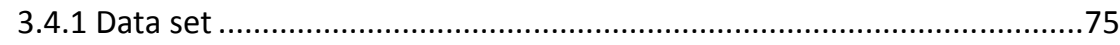

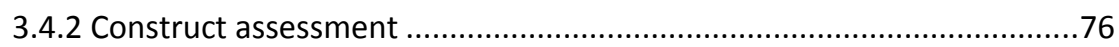

3.4.3 Structural model test .......................................................................... 79

3.4.4 Test for alternative explanations ........................................................82

3.4.5 Post-hoc test: Impact of purchase pal on customer's trust in the expert 




3.5 Discussion and Contributions to theory ............................................................ 85

3.5.1 Online trust transfer in the presence of trusted pals..............................85





3.6 Appendix A - questionnaire items ........................................................91

3.7 Appendix $B$ - experimental scripts and handouts....................................93













4.2.1 Chapter 2 ................................................................................... 114



4.3 An integrated perspective ....................................................................116

4.3.1 Maximizing the power of service encounters with online human experts 116

4.3.2 Re-defining Social Presence ..........................................................118

4.3.3 Suggestions for further research.....................................................119








\section{Figures and Tables}

Figure 1: Core elements of Adaptive Structuration Theory ...................................17

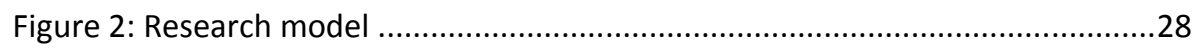



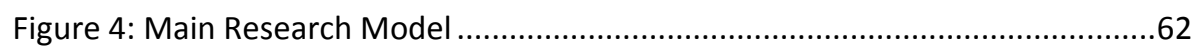



Figure 6: Results for the hypotheses ................................................................79

Figure 7: Interaction effect "pal's trust in expert" * "customer's trust in pal" .........81



Table 1: Outline of this dissertation...................................................................12

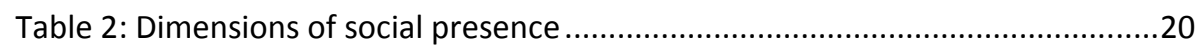

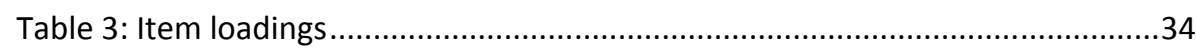



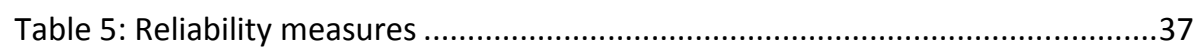

Table 6: coefficients, significance levels and interpretation of hypotheses .............38

Table 7: Basis for calculating the Goodness-of-Fit of the model. .............................39

Table 8: yields and investment alternatives for customer and purchase pal ...........70

Table 9: Weights of factor scores for trust constructs...........................................76

Table 10: Construct correlations (square root of the AVE on diagonal) ...................77

Table 11: Composite reliability, Cronbach's Alpha and Cross loading ........................78

Table 12: Mean values for customer's trust in online human expert.......................80

Table 13: Interaction effect for "pal's trust in expert" and "customer's trust in pal"



Table 14: Basis for calculating the Goodness-of-Fit of the model. ............................82

Table 15: Main characteristics of the studies ....................................................113 
Chapter 1

Introduction 


\subsection{Introduction}

The internet has penetrated most households in the developed world. According to Internet World Stats (www.internetwoldstats.com 2009), 83\% of the Dutch population has internet access at home. Likewise, $83 \%$ of all Dutch one-person-households has a telephone landline (European Commission 2008). Thus, the internet coverage has just leveled off with landline coverage in the Netherlands, and may bypass it in the very near future, especially since internet flat rates are available at lower prices than landline telephone lines. The internet enables customers not only to browse web pages and send emails, but also voice-over-IP (volP) communication is available in very good sound quality. Additionally, a volP call may be enriched with video, and thus outperforms the possibilities of a telephone landline.

As a logical consequence, companies have adapted their portfolio of communication media available to interact with their customers. For example, major Dutch banks such as ABN Amro, SNS Bank, ING or Rabobank offer video calls, chat or volP communication to advice their customers. Especially video calls seem to be a new and challenging alternative. Video calls offer the benefit of eye-to-eye contact, as it is in face-to-face communication. However, video calls also require that customers and companies have a webcam and the specific software installed that a company is using. So from a company perspective, the final question may not be which technology features are superior to another, but rather how to use technology in order to increase service performance and the sales of services.

In the remainder of this chapter we will introduce the motivation and theoretical background of this dissertation and its relevance. Then we describe the context of these studies: online service encounters and the role of initial trust formation between a customer and an online human expert. Afterwards we introduce the central problem statements and discuss the objectives of the individual studies. We conclude this chapter with an outline of the dissertation and demonstrate how the studies are related to each other. 


\subsection{Online service encounters with a human expert}

Service encounters can be defined as the moment of interaction between a customer and a firm (Bitner et al. 1994). These service encounters are "moments of truth" (Bitner et al. 2000), because they have been related to critical outcomes such as customer satisfaction (Söderlund et al. 2008), intention to repurchase (Meuter et al. 2000), word-of-mouth communications (Gremler et al. 2001; Keaveney 1995), relationship quality (Czepiel 1990), loyalty (Gremler et al. 1999) and willingness to pay more (Zeithaml et al. 1996).

Service encounters can take place face-to-face, for example when a customer is visiting an actual retail store of a company. However, they may also take place over the phone, through the mail, or over the Internet (Bitner et al. 2000). Nowadays, these service encounters are increasingly taking place online. Researchers have already studied different aspects of online service encounters. For example, there are a number of studies on service encounters via websites (Bugg Holloway et al. 2008; Gefen et al. 2004), some of them investigated the use of avatars with human-like characteristics (Qiu et al. 2005; Wang et al. 2007).

Customers evaluate not only the service outcome, but also the manner in which the service is delivered (Parasuraman et al. 1985). For online retailers that means that providing consumers with enhanced perceptions of human connection and emotional bonds have a competitive advantage (Wang et al. 2007). Therefore, companies often implement an avatar such as IKEA's Anna into their webpage to help customers with their online shopping while providing the illusion that the customer receives a personal one-toone consultation. However, Anna and other avatars are only as intelligent as the database behind, and avatars can provide little more than a search in the company's FAQs.

The fact that customers prefer human connections over browsing a website without human elements (Wang et al. 2007) indicates that customers are searching for "high touch", a term first used by Naisbitt (1982) to refer to dealing with a human being instead of a computer screen or voice response system (www.thefreedictionaory.com). And in fact, dealing with a "real" 
human instead of an avatar is possible with chat or volP programs. Thus, companies can provide online service encounters between a customer and an online human expert to enable a more advanced level of conversation and for individual answers or advices that an avatar would impossibly get from a database. Companies such as Cisco, IBM, Microsoft, Livecom or Teleportel offer chat or video solutions to enable one-to-one interactions, either integrated in websites or via specific programs or hardware. Some companies promise the feeling of "social presence" via these technologies. And while one-to-one online service encounters with a human expert have received little attention in academia, the concept of social presence has been discussed in many fields. The next paragraph will reflect some of the ideas in this field.

\subsection{Social Presence and trust}

Social presence has been defined as "the degree of salience of the other person in the interaction and the consequent salience of the interpersonal relationship" (Short et al. 1976, p.65). Other conceptualizations focus on the feeling of being physically together. Thus, social presence researchers argue that if people feel social presence, the physical distance between them is actually reduced (a detailed discussion and on overview over different definitions and uses will be provided in chapter 2). On the other hand, the lack of personal interaction or (social presence) results in a situation of high perceived risk (Grabner-Kräuter et al. 2003).

Researchers have argued that the spatial separation between customers and online retailers increases the customer's vulnerability and consequently their need for trust (Yadav et al. 2005). Trust has been defined as "the willingness of a party to be vulnerable to the actions of another party based on the expectation that the other party will perform a particular action important to the trustor irrespective of the ability to monitor or control that other party" (Mayer et al. 1995, p.712). For customers, it is important to trust a company or a consultant if they have to take decisions based on the advice or information they received. Thus, creating trust is important to companies, and it is not easy in an online setting where customer and salesperson are physically separated. 
Trust researchers have identified a number of antecedents to trust, such as seller reputation (Jarvenpaa et al. 1999), familiarity with the online vendor (Yoon 2002) or other factors that assume some kind of experience or knowledge of the vendor (Gupta et al. 2009). However, if a customer cannot rely on any of these things because in a first-time interaction with an unknown salesperson none of this information is present, customers will still form some kind of initial trust (McKnight et al. 1998). To form this initial trust, customers will evaluate other cues they have.

Since social presence reduces the perceived distance and risk, trust will arise more easily. Social presence thus facilitates the development of trust, yet may not be the only antecedent. In this dissertation, we will investigate social presence and other factors that are relevant in first-time interactions. In the next section, our theoretical motivation to extract these factors are described. A variety of theories are used to explain how a customer's trust is created in a service encounter with an online human expert.

\subsection{Theoretical Considerations}

Apart from Social Presence theory, this dissertation applies and empirically tests additional theories. This chapter will shortly introduce the three major theories used in this dissertation, and discuss how they are relevant to the topic of trust and social presence.

\subsubsection{Adaptive Structuration Theory}

The way technology influences an interaction is far from simple. DeSanctis and Poole (1994) developed their adaptive structuration theory to account for the complexity of technology-mediated interactions. According to them, several sources of structure influence an interaction simultaneously. These sources of structure are the technology used, the task, the organizational environment and the group who engages in the interaction. While these sources of structure are very broad, each one including many different elements, we will here discuss the technology and the group more in details.

Technology is one source of structure because it directly impacts the interaction by facilitating or limiting the speed of information exchange and the availability of information. For example, information can be exchanged 
faster if it is exchanged synchronously in a chat or telephone call than if the technology only allows for asynchronous information exchange such as email or voice mail. Additionally, most people can speak faster than they can write, as such information is exchanged faster if it is spoken. Also the availability of information can be facilitated by the structure of the technology. While a video call allows for the exchange of non-verbal cues such as a smile, a text chat does not display the emotions of the other party other than explicitly stated in the text or by tolls such as a smiley. This second feature of information availability has been investigated by media richness theory (Daft et al. 1987) and is currently the only factor investigated by social presence researchers (Bente et al. 2008; Biocca et al. 2003; Short et al. 1976). However, within adaptive structuration theory, technology is only one source of structure.

A second important source of structure is related to the group engaging in an interaction. This category includes elements such as the interaction styles used within the group, the common history a group has or the group size, all of which are assumed to impact the interaction. Interaction styles for example can vary in terms of their interactivity and thus are related to how much content or involvement each person can bring into an interaction. If one person speaks without interruption, the others cannot speak at the same time. A common history relates to the experience one has with other members of the group. After a first interaction, one has a perception of e.g. the other's knowledge or personality that one did not have before. The group size relates to the number of people involved in the interaction. Communication within a dyad is different from communicating within a triad, because only one can speak at a time. A third person added to a dyad would change the interaction history inherent to the dyad, because he or she may or may not be closer to one than to the other member of a dyad.

Thus, adaptive structuration theory argues that not only the technology itself, but also the different features of a group are relevant to technologymediated communication. As such, they may extend social presence theory and our understanding of trust formation within an online setting. In this dissertation, we will focus on different elements of the group as a source of 
structure, namely on the interaction styles, the interaction history, and the group constellations of dyads and triads.

A shortcoming of adaptive structuration theory is that there is no detailed reasoning provided as to how the different features within each source of structure impact an interaction. We will thus refer to additional theories to understand the specific effects of the group features.

\subsubsection{SIDE model}

The Social Identity model of Deindividuation Effects (SIDE) explains why small cues in an online interaction can have a very large impact (Tanis et al. 2003). The authors of this model show that if people lack information on another party, they will take whatever information available to form their impression. In its effect, very basic information such as basic biographical information or a portrait photo can be interpreted as to whether one wants to collaborate with a person in an area not even covered by the biographical information available. While these irrelevant cues should then actually mean very little, in the absence of more relevant information people will form their impression based on the cues they have, instead of ignoring the cues because they are irrelevant to the decision that has to be taken. Thus, it seems that people grasp at straws to form an impression on another person in the absence of perfect information.

In a service encounter, a customer will not have perfect information on the expert and the topic that is presented by him because the customer does now know the true intentions of the expert, and often the customer cannot fully know or understand all features of a service product. Thus, a service encounter is a setting in which customers are very likely to interpret any cue available. This is exacerbated if the encounter takes place online.

The group features mentioned in the section on adaptive structuration theory include the interaction history, the interaction styles as well as the group size. All of these may provide cues relevant to the customer's perception of social presence or trust.

One characteristic of an online service encounter is that the customer is physically separated from the online human expert, thus social distance is 


\section{I Chapter 1}

likely to arise (Williams et al. 2008). To overcome the social distance and to create the illusion of a "normal, face-to-face interaction", customers thus search for cues that cause this illusion. A common interaction history may create this illusion, because people will replace the missing physical closeness with a memory of a previous interaction. Also a very interactive style of communication, and in the case of an advice, adapting the advice to the customer by inviting the customer to provide knowledge in his or her personal situation may be a cue as of being in a real face-to-face conversation with no physical separation (chapter 2).

One feature of a group is the number of people participating in an interaction. In dyadic communication, the customer can only deduct the trustworthiness of the online human expert from the expert himself. However, if a customer engages in an interaction with an online human expert in the presence of a third person (triadic interaction), a customer is likely to interpret any cues transmitted by this third person that refer to the online expert's trustworthiness. Thus, a third person added to an interaction may provide additional cues for the customer, and the third person's perceptions of the expert may transfer to the customer (chapter 3 ).

The SIDE model adds to adaptive structuration theory by reasoning that imperfect information is a reason why the group features impact an interaction and the outcome thereof. Taken both theories together, it becomes clear that the problem of imperfect information cannot be fully overcome by providing richer media, because the insecurity on the trustworthiness of the online human expert or the physical separation cannot be overcome by any media. Nonetheless, media richness is up to now the only main antecedent discussed in social presence theory. Thus, combining adaptive structuration theory with the SIDE model extends social presence theory by providing reasoning to why the different group features may impact social presence in addition to media richness.

While the SIDE model helps to explain why any cue is relevant and thus provides a reason to expect a trust transfer within a triad, it does not provide any indication as to how people deal with inconsistent cues. In the next section, prospect theory will be used to discuss this specific case. 


\subsubsection{Prospect Theory}

Prospect theory (Tversky et al. 1991) argues that losses loom greater than gains. That is, a loss of a certain size will have a larger negative impact than a gain of the same size would have in terms of a positive impact.

In an online service encounter, customers have a lot to lose if they trust an expert and take a decision based on the advice that was actually inappropriate for the customer's situation. In the setting of financial services, a bad advice is often directly linked to a loss of money if the customer buys shares of a company and the advisor did not know or reveal information on financial problems with the company. A customer will thus be very hesitating in placing trust into a financial advisor if he or she receives negative cues on the expert's trustworthiness, because the customer wants to avoid a loss by any means.

In a triad, there are several cues available which may help the customer to form his own impression of the online expert's trustworthiness. First of all, a customer may perceive a third person's perception of the expert's trustworthiness, and second, a customer will have an own opinion as to whether this third person is actually trustworthy himself. Thus, if either of the two cues is negative, a customer may decide not to trust the online human expert to exclude potential losses that can result from trusting and acting based on the expert's advice. Chapter 3 will pay more attention to prospect theory and the trust transference when mixed cues are available.

\subsection{Objectives}

In this study, we focus on trust creation during online service encounters of customers with human experts. The encounters under study were initial interactions in which online human experts advised customers with whom they did not have any prior online experience. The separate chapters related to these encounters address different aspects of trust creation, each one clearly discusses the objectives, relevant literature as well as contributions to theory and practice. Together they contribute to the overall objective of this dissertation. The aim of this dissertation is to uncover antecedents that are important in enhancing customer trust in initial encounters 
with online human experts in the context of complex services. Previous research has identified the importance of media richness in this context. However, often companies cannot influence the availability of the medium the customer possesses. Thus, an online consultation may take place with non-optimal video- or sound quality, or even without video. This dissertation will thus look into ways how companies may adapt processes to achieve trust other than changing the media richness. Framed differently, we will investigate how a given medium in an online service encounter should be used to maximize the initial trust felt by a customer.

To gain in-depth insights into these encounters and to address this aim appropriately based on a variety of theories from different fields, we develop more specific aims for the different chapters.

\subsubsection{Objective chapter 2}

In chapter 2, we study the impact of social presence on trust in dyadic online service encounters and evaluate new triggers for social presence. Past research on social presence has identified that media richness is the major antecedent for social presence which subsequently increases the level of trust. However, adaptive structuration theory (DeSanctis et al. 1994) leads to the assumption that media richness inherent to a technology is only one cause of a given outcome such as trust. The objective of this chapter is twofold: Firstly, alternative ways to create social presence are explored based on adaptive structuration theory, and second, the process by which social presence leads to trust is investigated in detail. This second objective includes the development of a clear definition and measurement scale for social presence applicable in dyadic online encounters.

\subsubsection{Objective chapter 3}

In chapter 3 , we study the impact of a purchase pal who sits next to the customer and shares one computer screen with her while they jointly interact with an online human expert. Specifically we are interested in whether trust can be transferred from the purchase pal to the customer. While trust transfer has been researched in the context of word-of-mouth referrals or online reviews systems, in which a purchase pal or peers have first-hand experience with a specific online vendor, this study aims to investigate 
whether trust can be transferred even if the purchase pal does not have any prior experience with the vendor. In order to address this objective, a number of theories from different fields of research, such as trust transfer theory, prospect theory, the social identity model of deindividuation effects (SIDE) and construal level theory, are used to explain why and under which conditions trust in the online human expert transfers from the purchase pal to the customer.

\subsection{Outline of the dissertation}

This dissertation applies an inter-disciplinary approach and uses a variety of theories to investigate the creation of trust in technology-mediated interactions between an online human expert and a customer. Given that previous research in the field has often focused on avatars or websites instead of human beings, and that many studies in the area of social presence have only focused on media richness to explain trust creation between humans, we were guided by the idea of adaptive structuration theory. As a consequence, we put the emphasis of this study on human-to-human interactions and studied specifically factors inherent in the relationship of the dyad or triad, and on their interaction styles. Two different experiments were executed to measure trust in different consultations on a complex service product.

In chapter 2, we investigate in great detail how social presence leads to trust in a one-to-one video consultation between an online human expert and a customer. Additionally, adaptive strucutration theory is used as an inspiration to investigate new antecedent to social presence that have not been investigated yet. Specifically, the effect of the interaction styles applied by the online human expert, and the interaction history of the dyad is manipulated to measure subsequent effects on social presence and trust.

In contrast to a dyad as studied in chapter 2, chapter 3 focuses on whether trust can be transferred. This means that the customer is being advised in a somewhat less ordinary situation of a triad in which the customer has a purchase pal being co-located and sharing the same screen, while the customer interacts with the online human expert. While the customer is faceto-face with the purchase pal, the online human consultant is only available 
via audio. Thus, a cue-lean environment is created to whether trust can be transferred under these circumstances. Figure 1 gives an overview over the topic of each study, the medium used, and the manipulated factors in the experiment (i.e., the sources of structure).

The execution of the experiments in both chapters was driven by the ambition to create a real atmosphere for the participants, so that the subsequent data collection was under the influence of an almost real online consultation. While in chapter 2 a real company provides advice on age retirement and customers could provide their contact details to meet the company representatives again, in chapter 3 participants had to invest real money based on an advice received by a financial advisor and received a payment four weeks after the study based on how well their investment had performed.

Chapter 4 presents a summary of the main conclusions of the chapters, as well as an outlook for further research.

\begin{tabular}{|c|c|c|c|}
\hline & & \multicolumn{2}{|c|}{ Medium used } \\
\hline & & VIDEO & AUDIO \\
\hline $\begin{array}{l}\text { Sources of } \\
\text { structure }\end{array}$ & $\begin{array}{c}\text { Interaction style } \\
\text { (dyad) } \\
\text { Interaction history } \\
\text { (dyad) }\end{array}$ & $\begin{array}{c}\text { Chapter 2: } \\
\text { How to create so- } \\
\text { cial presence and } \\
\text { trust? }\end{array}$ & \\
\hline $\begin{array}{l}\text { inter-relationship } \\
\text { of the actors }\end{array}$ & $\begin{array}{l}\text { Purchase Pal } \\
\text { present } \\
\text { (triad) }\end{array}$ & & $\begin{array}{c}\text { Chapter 3: } \\
\text { Can trust be trans- } \\
\text { ferred? }\end{array}$ \\
\hline
\end{tabular}




\title{
Chapter 2
}

\section{Out of sight, out of mind?}

\author{
Extending the understanding of social presence and trust \\ in an online service encounter
}

It is commonly known that social presence helps to build up trust in technology-mediated communication, and that social presence is facilitated by increasing media richness. In this context, we see two aspects which deserve more attention: Firstly, alternative ways to create social presence have not been researched sufficiently, and secondly the process by which social presence leads to trust is still not understood in detail. This research addresses both aspects. Based on an extensive literature review, we define social presence as a two-dimensional construct consisting of physical presence and emotional presence.

In a controlled experiment, financial advisors consulted 129 customers via video calls on retirement provisions. Results show that customers feel a higher level of physical presence when they had met the advisor face-to-face beforehand, and/or when the advisor applies an interaction-oriented conversational style (as opposed to a task-oriented style). We also find that physical presence has a positive effect on emotional presence, and emotional presence has a positive impact on conversational involvement and consequently on trust.

These findings show that even when media richness is low, communication partners still have great potential to raise social presence, conversational involvement and ultimately trust of the other party.

Keywords: social presence, video conferencing, conversational style, task-oriented, interaction-oriented, trust 


\subsection{Introduction}

Across many industries, companies are now maintaining technologymediated relationships with their customers via call centers or the internet and are replacing personal service with self-service technologies (SSTs) and online shops. The digitization of customer contact has been found to lead to better financial performance of a company (Barua et al. 2004), whereas customers profit from time savings, extended business hours and geographical independence (Meuter et al. 2000). Despite the benefits for either side, customers mainly adopt remote services for simple tasks (Sarel et al. 2003; Selnes et al. 2001). For complex services such as a mortgage, customers prefer personal meetings (Howcroft et al. 2003). This causes service providers to bear extra costs for travelling, time inefficiencies and several representative offices; these costs could be reduced if advisors could maintain some customer contact from a central location. Especially in banks, where salaries are high and products very complex, a lot of money could be saved for both parties if customers and salesperson found a way to interact more efficiently via technology-mediated communication channels.

Big IT companies such as IBM and Cisco Systems have recognized customers wish to meet a salesperson, and offer costly video-call solutions which are specifically targeted to retail banks (Bielski 2008; Cisco 2008; IBM 2006). These technologies cause the illusion of being in the same room and sitting on the same table with life-sized video which is integrated in a table, and some technologies even give the illusion of a three-dimensional image of the communication partner (Teleportel 2009). Banks are now starting to experiment with these technologies (ABN.AMRO 2004; Mensink 2007).

It has been argued that trust formation is a problem in mediated environments mainly because of low media richness (Qiu et al. 2005). When media richness is high, people are more likely to experience social presence, which is the feeling of being together with another person even though this person is at a remote place (Short et al. 1976). Social presence has been identified as an important antecedent to trust in the context of online shops (Cyr et al. 2007; Gefen et al. 2004; Hassanein et al. 2006). Gefen et al. (2008) mention in their research agenda on trust in online environments that trust 
frameworks for experience products are potentially very different from products that can be easily described. Therefore the social presence-trust relationship needs to be revisited in the context of experience products such as complex services, which are sold via a personal, technologymediated interaction. An experience product is difficult to evaluate for customers and therefore trust towards the salesperson may play an even more important role. Therefore social presence, which may play a crucial role in creating trust, deserves major attention when attempting to understand how to mediated customer-salesperson relationships.

Surprisingly little attention has been paid to the antecedents of social presence and its impact on trust in the communication partner. This is astonishing because social presence may cause the illusion that people are "together" in the same room, and consequently stimulate trust in a way that mirrors a real face-to-face contact. The interesting question then is how to increase social presence in a mediated environment, and specifically, which factors impact social presence.

This research contributes to knowledge in three important ways. Firstly, it attempts to identify antecedents of social presence in a communication. While media richness has been identified as an antecedent already (Short et al. 1976), other important factors such as the relationship between the communication partners or the behaviour of the salesperson have been neglected. That means that social presence can vary within the same medium in different contexts. For companies, thus, it is important to know how to increase social presence by reaping the maximum benefit from salespersons and the organizational setup: While the medium can often not be changed, the salesperson can be trained or specifically selected, and the allocation of customers to random advisors may be replaced by assigning customers to a fixed advisor or a small team. Therefore the role of the salesperson's behaviour and the relationship between the customer and the salesperson on creating social presence will receive major attention in this study.

Although it is well-known that social presence influences trust, the exact process underlying this relationship has never been researched. The second 
main contribution will thus be to open the black box of the social presencetrust relationship. Therefore social presence itself will be clearly defined empirically and conceptually. Currently, it is unclear which dimensions the construct consists of, and whether all of the dimensions happen simultaneously or consecutively. Third, much of the concepts available are formulated in a way that they cannot be used to evaluate social presence with a human, or they cannot be used across different media. We propose a definition and develop a short scale to measure social presence in conversations between humans across all media. After that the new concepts will be used to improve our understanding of the process from social presence to trust.

The chapter is organized as follows: First existing literature on social presence and trust is reviewed, followed by the development of a scale for measuring social presence in human-to-human interactions. Next, the research model is developed, and the experimental setting and results are described. Finally, the findings are discussed.

\subsection{Theory and Hypotheses}

One framework to investigate a technology-mediated relationship is adaptive structuration theory (AST) (DeSanctis et al. 1994), which assumes that several sources of structure (technology, task and the group itself) influence the interaction while it is ongoing (see figure 1). In the specific context of a customer-salesperson relationship, the "group" would typically be a dyad of one salesperson and one customer. At the end of the interaction, the outcome is achieved. In this chapter, the outcome under investigation is trust. Therefore, the social interaction needs to be analyzed to understand how the sources of structure can be used to create trust.

Adaptive Structuration Theory does not provide a specific answer to what happens during the social interaction. While social interaction is a very complex process, this chapter will focus on one dimension which is different between face-to-face and technology-mediated communication and which could impact trust: the physical distance between the communication partners. This can create an emotional distance which is detrimental to the creation of trust. Thus this study will investigate how we can decrease the 
emotional distance in mediated communication environments. This phenomenon has been addressed in social presence research.

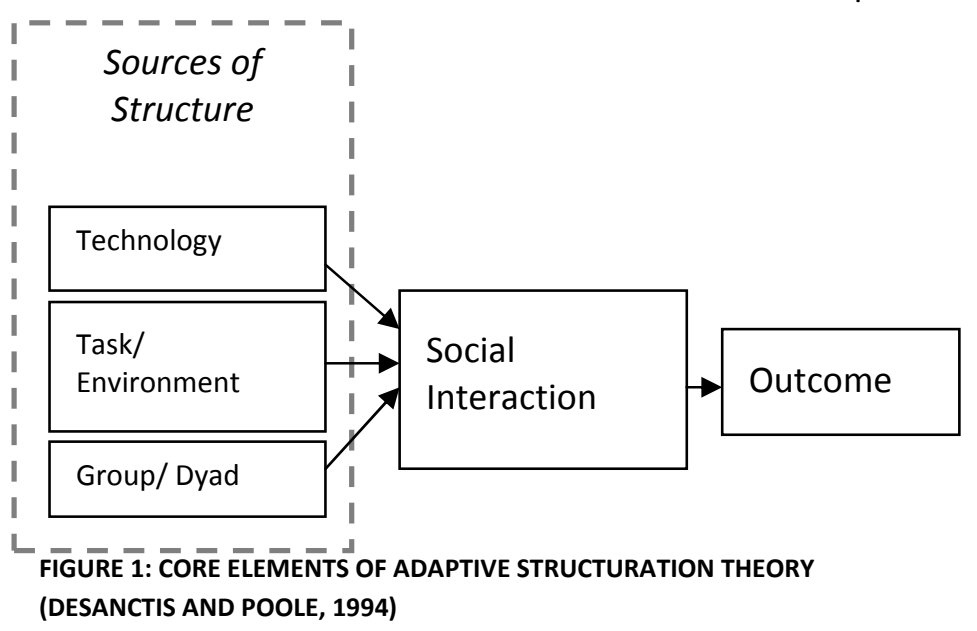

\subsubsection{Social Presence Theory}

Social presence has been defined as the "degree of salience of the other person in the interaction and the consequent salience of the interpersonal relationships" (Short et al. 1976, p.65.) This concept has been discussed widely, though inconsistently, for many years (Biocca et al. 2003; Heeter 1992; Lombard et al. 1997).

During the last decade, the concept of social presence has been used to investigate new technologies such as e-commerce, help interfaces, and mediated collaborative work environments (for details we refer to the literature review of Biocca et al. 2003). But not only new technologies were added, also the focus of social presence has been expanded from a feeling between humans within mediated communication to a broader concept of a feeling which can occur while browsing websites, when interacting with an avatar or when visiting virtual worlds (Gefen et al. 2004; Hassanein et al. 2006; Kumar et al. 2002; Lombard et al. 1997; Qiu et al. 2005). Today, social presence is used in many research areas such as marketing (Coyle et al. 2001; Li et al. 2002), communication research (Bente et al. 2008), distance learning and information management (Yoo et al. 2001). Even though the importance of mediated communication increased and the opportunities 
media provide to communicate have expanded tremendously, research has paid little attention to social presence in human to human communication.

Although much IS literature typically defines social presence as one concept, previous research recognizes that social presence consists of several dimensions (Harms et al. 2004; Heeter 1992; Lessiter et al. 2001; Lombard et al. 2000; Schubert et al. 2001a; Witmer et al. 2005; Witmer et al. 1998). Table 2 presents an overview of the proposed sub-dimensions of social presence. We have attempted to group the sub-dimensions under recurring themes, namely physical presence, emotional presence and conversational involvement. Physical presence and emotional presence are used in research settings in which the focus is on human-to-human communication. For the purpose of this research, we define physical presence and emotional presence as sub-dimensions of social presence. We consider conversational involvement to be conceptually different from - albeit related to social presence. Therefore we will first discuss social presence, and in the next section define involvement in the context of a conversation.

Most social presence researchers have covered the aspect of physical presence (see table 2). This construct has also been commonly defined as copresence (Hwang et al. 2007) or telepresence (Kim et al. 1997; Steuer 1995). Physical presence covers the aspect of "being [physically] together" (Lombard et al. 1997), and can occur with any medium, ranging from virtual worlds to telephone to even a letter (Steuer 1995).

Several researchers have recognized that in a communication between humans, the aspect of emotions is crucial (Biocca et al. 2001a; Biocca et al. 2003; Derks et al. 2008; Maguire et al. 2006). This component has also been described as social richness by Lombard and Ditton (1997), who mention that this aspect comes into play when human communication is the topic of interest. Also Maguire and Connaughton (2006) have realized that the human-to-human "connection" is poorly covered by current definitions and propose a construct called "relational presence" which consists of dimensions related to physical and emotional presence, to capture the presence of the relationship with a human being. Within the field of IS, first studies exist that separate the physical from the human/emotional aspect (Ijssel- 
steijn et al. 2003; Khalifa et al. 2004; Ou et al. 2008; Venkatesh et al. 2002). It seems that after 30 years of social presence research, researchers across fields are moving towards interpreting Short et al.'s (1976) original definition of social presence as including a physical (salience of the person) and an emotional (salience of the relationship) component. Therefore we propose the following definition of social presence:

Social Presence (SP) is the degree of salience of another person in a technology-mediated interaction. It consists of two sub-concepts: "physical presence" deals with the perception of being physically together, and "emotional presence" reflects the possibility to perceive the other person's emotions.

Physical and emotional presence are clearly related. The question that arises is whether they are causally related or simply correlated. And if they are causally related, which direction does the causality have? Studies that used both dimensions have used at least three approaches in the past. Firstly, many researchers see social presence as one concept which includes both aspects, without specifying how they are related, often by referring back to Short et al. (Short et al. 1976; Straub et al. 1998; Yoo et al. 2001). A second approach is to reflect the two dimensions in a second-order construct. Ou et al. (2008) have chosen this approach, and their data clearly reveal that both dimensions have discriminant validity (AVE is higher than the correlation, see Fornell et al. 1981). Thirdly, the same scale that Ou et al. (2008) used as a second-order formative construct has earlier been used by Venkatesh and Johnson (2002) and by Khalifa and Shen (2004) to measure both dimensions as separated constructs. 


\begin{tabular}{|c|c|c|c|c|c|c|c|c|c|c|c|c|c|}
\hline 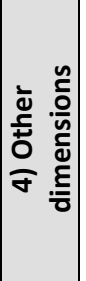 & & & & & & & & & 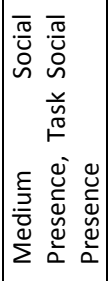 & 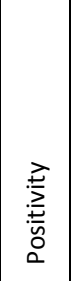 & & & \\
\hline 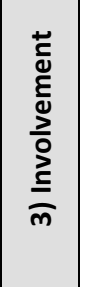 & & & 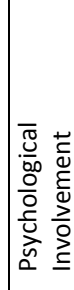 & & & & 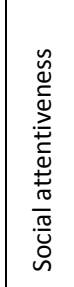 & & & 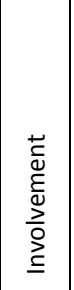 & & & \\
\hline 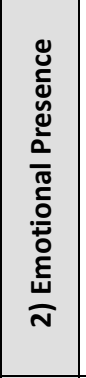 & 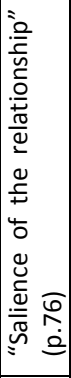 & 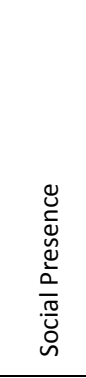 & 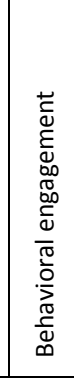 & 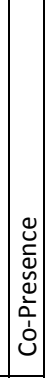 & & 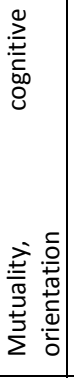 &  & 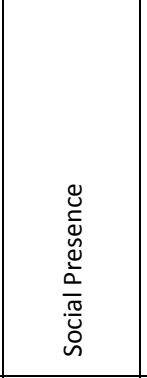 & & 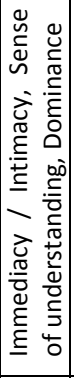 & 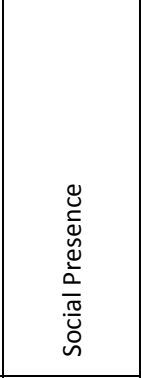 & 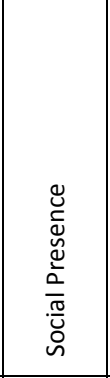 & \\
\hline 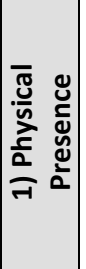 & 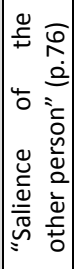 & & 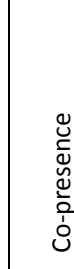 & 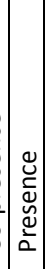 & 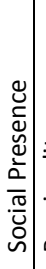 & 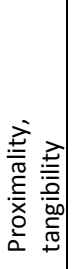 & 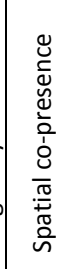 & 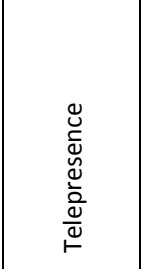 & & & & 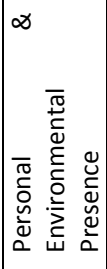 & 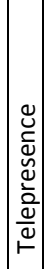 \\
\hline 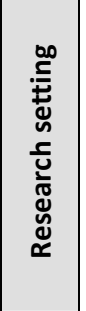 & 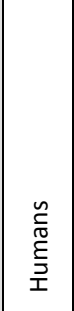 & & 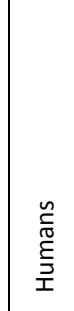 & 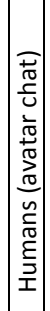 & 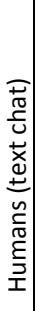 & 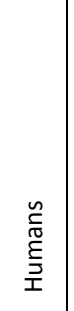 & 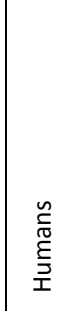 & 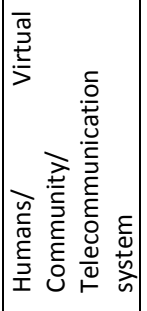 & 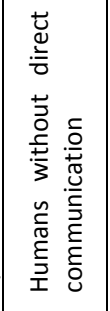 & 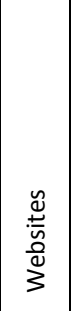 & $\begin{array}{l}\stackrel{y}{0} \\
\stackrel{+}{n} \\
\stackrel{0}{0} \\
3\end{array}$ & $\begin{array}{l}\frac{n}{0} \\
\frac{0}{0} \\
\frac{3}{0} \\
\frac{3}{5} \\
\frac{3}{5}\end{array}$ & 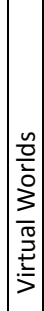 \\
\hline 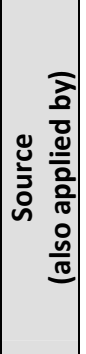 & 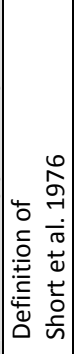 & 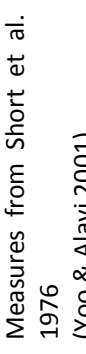 & 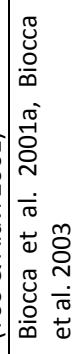 & 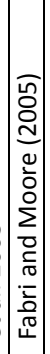 & & 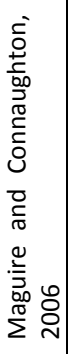 & 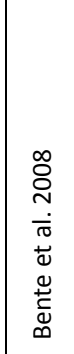 & 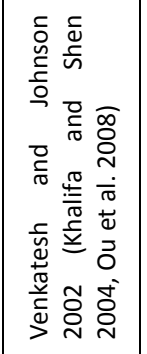 & 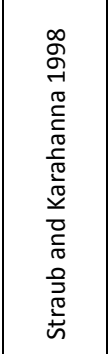 & 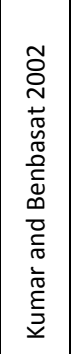 & 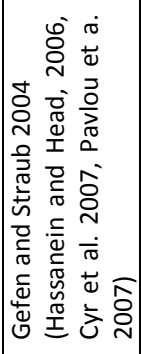 & 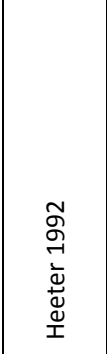 & 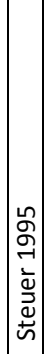 \\
\hline
\end{tabular}




\begin{tabular}{|c|c|c|c|c|c|c|c|c|c|c|c|c|}
\hline 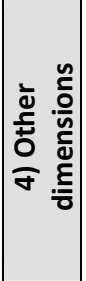 & & & 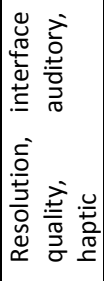 & 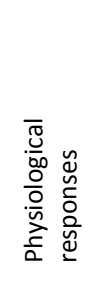 & & 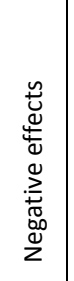 & 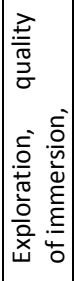 & 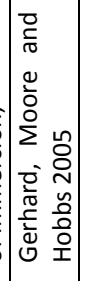 & 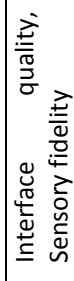 & & 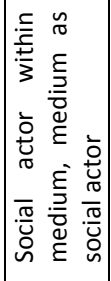 & \\
\hline 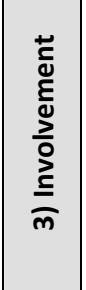 & & 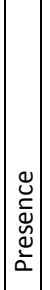 & 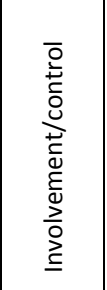 & 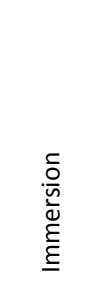 & & 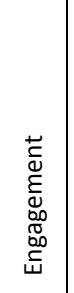 & 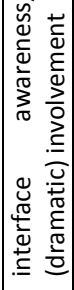 & & 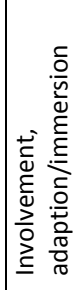 & & 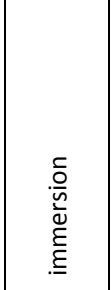 & \\
\hline 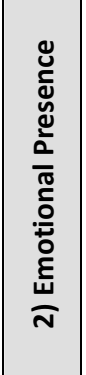 & & & & 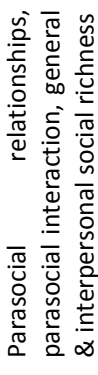 & & & & & & 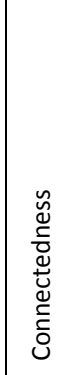 & 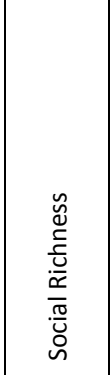 & 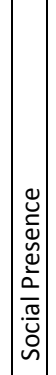 \\
\hline 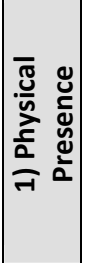 & 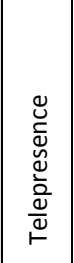 & 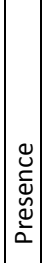 & $\begin{array}{l}\bar{\Gamma} \\
\stackrel{2}{2} \\
\frac{\pi}{2}\end{array}$ & 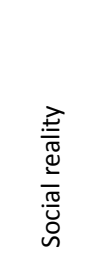 & 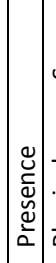 & 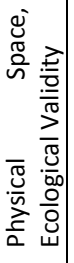 & 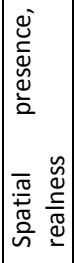 & 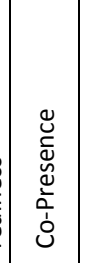 & & 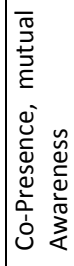 & 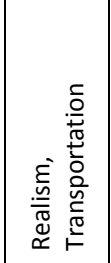 & 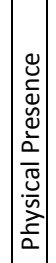 \\
\hline 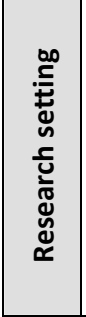 & 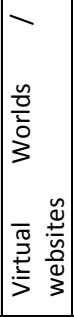 & 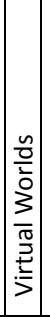 & $\begin{array}{l}\frac{n}{\frac{n}{2}} \\
\frac{3}{3} \\
\frac{0}{3} \\
\frac{3}{5}\end{array}$ & 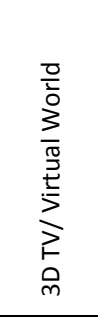 & 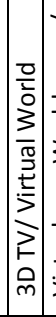 & 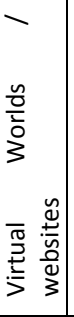 & 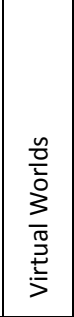 & $\frac{\frac{n}{0}}{\frac{0}{0}}$ & $\begin{array}{l}\frac{n}{0} \\
\frac{0}{0} \\
\frac{3}{3} \\
\frac{0}{3} \\
\frac{n}{5}\end{array}$ & $\begin{array}{l}\frac{n}{0} \\
\frac{0}{2} \\
\frac{3}{3} \\
\frac{0}{3} \\
\frac{0}{5}\end{array}$ & $\overline{\bar{\sigma}}$ & $\overline{\bar{\pi}}$ \\
\hline 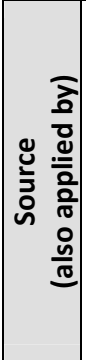 & 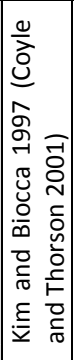 & 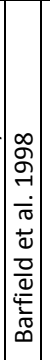 & 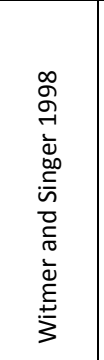 & 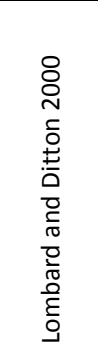 & 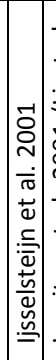 & 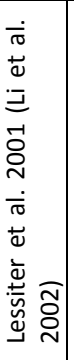 & 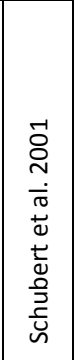 & 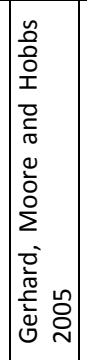 & 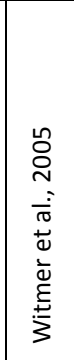 & 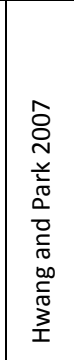 & 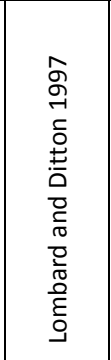 & 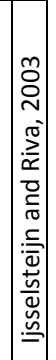 \\
\hline
\end{tabular}


In psychology, the link between physical an emotional distance has been established (Rosch 1975). By means of the so-called "doll placement technique", people can represent the emotional distance they feel in terms of physical distance by placing dolls further or closer from each other (Gerber 1973; Villeneuve et al. 1984). Researchers now started to discuss the causal relationship between these constructs. In experimental research it could be shown that when physical distance was increased, subjects reported weaker bonds to their family members (Williams et al. 2008).

We believe that there exists a causal relationship between physical presence and emotional presence. Specifically, we argue that physical presence is a necessary condition for emotional presence. Steuer (1995) discusses a situation in which presence happens: When receiving a phone call, and the person who calls you does not say anything, you feel that there is no one. As soon as the other party speaks, one feels that he or she is present. Only thereafter it is possible to perceive emotions of the other party. A broader discussion on ways how physical presence impacts emotional presence can be found in Williams and Bargh (2008).

However, it is also possible that while two people interact and feel physically present, for various reasons they do not feel the emotional presence of the other party. In that sense, physical presence is a necessary, though not sufficient condition for emotional presence. Therefore we formulate the following hypothesis.

$H_{1}$ : Physical Presence has a positive impact on Emotional Presence

\subsubsection{Conversational Involvement}

Many social presence studies discovered a dimension of involvement in the construct of presence (Biocca et al. 2003; Biocca et al. 2001b; Lessiter et al. 2001; Schubert et al. 2001b; Witmer et al. 2005). The methods that were applied, however, have been criticized for use of factor analyses excessively to determine the dimensions of the construct (Waller et al. 2006). This has severe consequences, because one cannot distinguish between antecedents, dimensions or consequences of social presence with this technique. One of the few exceptions in this stream of research is a study of ljsselsteijn et al. (2001), in which presence and involvement are two different con- 
cepts, and in where antecedents of presence have no direct impact on involvement. The incorporation of involvement as a dimension of social presence needs to be reviewed against this background.

The concept of involvement has been long discussed across many fields, such as marketing (Zaichkowsky 1985), information management (Barki et al. 1989), psychology (Schwyhart et al. 1972) and communication science (Cegala et al. 1982). However, the term involvement refers to different things, such as participating in something or being involved with a product, and can be a personality trait or a state (Barki et al. 1989; Havitz et al. 2005).

In the context of this research, we are specifically interested in involvement during a conversation. Research on conversational involvement originated more than 25 years ago in communication sciences (Cegala et al. 1982) and thereafter been applied and refined in face-to-face studies within the field (Burgoon et al. 1999; Coker et al. 1987). We propose the following definition for conversational involvement, which is adapted from Coker and Burgoon (1987):

Conversational involvement $(\mathrm{Cl})$ refers to the degree to which participants in a communicative exchange focus their interest and attention on the topic, relationship and/or situation.

The fact that conversational involvement has often been identified as a dimension of social presence indicates that there may be a relationship. However, only a limited number of studies have investigated a causal link between involvement and social presence: Gerhard et al. (2005) have found that higher levels of physical presence lead to more involvement in a virtual environment. Fabri and Moore (2005) researched humans using a messaging programme and found that the possibility to express emotions with an avatar resulted in much higher levels of involvement and considered it to be the key to create trustful distant relationships. For customer-salesperson interactions, Siehl et al. (1992) expect that the expressiveness of emotions of the salesperson also causes the customer to perceive her to be more involved in the interaction. Humans only want to get involved in a conversation when they feel the other party's emotions (Burgoon et al. 1999). 
Therefore we conclude that sensing emotions is positively linked to conversational involvement and hence formulate the following hypothesis:

$\mathrm{H}_{2}$ : Emotional Presence has a positive impact on Conversational Involvement

The final goal that a company or salesperson strives to achieve in a service encounter is to create trust and subsequent trusting behaviour on part of the customer. Social presence has been linked directly to trust in the context of websites (Gefen et al. 2004; Hassanein et al. 2006), avatars (Qiu et al. 2005) and human-to-human contact (Bekkering et al. 2006; Bos et al. 2002).

However, as this research attempts to open the black box of how higher levels of social presence can lead to more trust, the assumption that social presence leads to trust deserves closer attention. We would like to recall that psychologists such as Williams and Bargh (2008) argue that physical presence increases emotional presence (hypothesis 1 in this research), and emotional presence causes conversational involvement (hypothesis 2). If conversational involvement can be linked to trust, then an important extension to our understanding of the social presence-trust relationship is made. Social presence and trust may be only the first and the last elements of a complex process, which is mediated by emotional presence and conversational involvement.

The missing link can be found in communication research, where involvement could be linked to trust (Burgoon et al. 2000; Burgoon et al. 1989). More importantly, Bente et al. (2008) found that conversational involvement (which the authors called attentiveness) is related to competencebased trust, but that it is not related to social presence. In other words, physical or emotional presence alone do not cause the customer to trust the salesperson. Rather, the customer must be involved and fully focus attention on the communication in order to build up trust during the interaction. That makes sense, because if a customer does not focus on the conversation, and therefore misses parts of the talk, how can she in the end trust the advice she received from the sales person? Therefore we formulate the following hypothesis: 
$\mathrm{H}_{3}$ : Conversational Involvement has a positive impact on Trust

Trust has a positive impact on trusting intention (McKnight et al. 2002). The more trust people feel, the less they are concerned about their information privacy or information security (Pavlou et al. 2007). This relationship is reflected in the following hypothesis:

$H_{4}$ : Trust has a positive impact on Trusting Intentions

\subsubsection{Increasing Social Presence in mediated conversa- tions}

Adaptive Strucutration Theory names three sources of structure that impact a social interaction: Technology, task/environment and the group (i.e. the dyad). Since trust formation is an important issue for practitioners and researchers alike, knowing how these factors impact trust is of great importance. Technology, and specifically media richness, has been researched extensively during the last 30 years (Barfield et al. 1998; Bekkering et al. 2006; Short et al. 1976). In this study, we will focus mainly on the salesperson-customer dyad as a source of structure.

The styles of interaction (DeSanctis et al. 1994) and the interaction history (Stewart et al. 2002) are two aspects which are assumed to impact the interaction. Both of them can be influenced in a customer-salesperson dyad by training company representatives to use a certain conversational style, or by making sure that customers are matched to the same person instead of different ones each time they interact with a company.

\section{The influence of the Interaction History on Social Presence}

The importance of interaction history and previous meetings has been researched in the field of IS (Yoo et al. 2001), communication (Walther et al. 1992), management (Levin et al. 2004) and economics (Bohnet et al. 1999; Brosig et al. 2003; Frey et al. 1996; Schmidt et al. 2005). It became evident that people prefer to know their interaction partner (Frey et al. 1996), and that the knowledge of the other person even outweighs the impact of the communication medium (Brosig et al. 2003; Yoo et al. 2001). 
In structuration theory terms, this means that previous conversations of a dyad serve as structure for the following conversations, and should therefore impact the level of social presence that evolves during the interaction (DeSanctis et al. 1994; Stewart et al. 2002). For example, if friends or groups with a common history communicate with each other via any communication channel, they will perceive more social presence than if speaking with a foreigner they have not met before (Harms 2004; Yoo et al. 2001). Therefore, focusing on media richness as the sole antecedent to social presence is insufficient. Instead of the visual representation of the communication, which can be transferred in rich media, knowledge of the communication partner may be the clue to understand social presence: One can easier imagine the other person to be physically close if one knows the movements, mimics and gestures of a person. If the communication partner sends an emoticon in a chat conversation, one can "hear" the other's voice and "see" the facial expression of the communication partner. In that sense, the relationship compensates for cues that are not transmitted in a mediated communication. Therefore we summarize:

$H_{5}$ : A previous face-to-face meeting of the dyad has a positive impact on the level of Physical Presence perceived during a technology-mediated conversation.

\section{The influence of Styles of Interaction on Social Presence}

When people interact, they can apply different communication styles (also referred to as interaction styles). Communication styles have been discussed in many areas in which humans interact, such as psychology and medicine (Bradley et al. 2001; Buller et al. 1987; Slingsby et al. 2006), communication (Norton et al. 1975), marketing (Dion et al. 1992; Williams et al. 1985) and information management (Derks et al. 2007). One way to classify communication styles is to group them into task-oriented versus interaction-oriented (Derks et al. 2007; Williams et al. 1985). In a task-oriented communication, the communication partners speak about the task only, it is a goal-oriented and purposeful communication and is concerned with efficiency. The interaction-oriented conversational style is more personal, where especially the salesperson shows an interest in the customer and attempts to integrate the information received by the customer in adapting 
the information. The focus of this style is the customer and his or her needs.

Interaction-oriented conversations have been reported to outweigh the effect of media richness (Walther et al. 2005). In the marketing literature, the importance of communication in general and interaction-oriented sales behaviour is a core element of a good relationship: Duncan and Moriarty state that "if relationships are the objective, then impersonal mass communication must be supplemented, especially in [...] service categories, by personal customized communication that [...] is interactive" (Duncan et al. 1998, p.8). Dion and Notarantonio (1992) show that interaction-oriented conversations have a positive impact on sales outcome. Additionally, lack of interaction is a reason for customers not to use self-service technologies (Meuter et al. 2005).

Therefore, we argue that communication style has an impact on physical presence. Concretely, we believe that as the salesperson applies an interaction-oriented communication style, the customer feels more physical presence and can easier imagine the salesperson to be in the same room. On the other hand, if the salesperson applies a task-oriented conversational style and speaks about the product only, the customer might feel more like listening to the TV rather than having a conversation with a human being. The following hypotheses shall be tested:

$H_{6}$ : Compared to a task-oriented conversational style, an interactionoriented conversational style has a positive impact on the level of physical presence perceived during a technology-mediated conversation. 
$\mathbf{2 8 | C h a p t e r 2}$

\subsubsection{Research model}

The hypotheses can be summarized in the following research model.

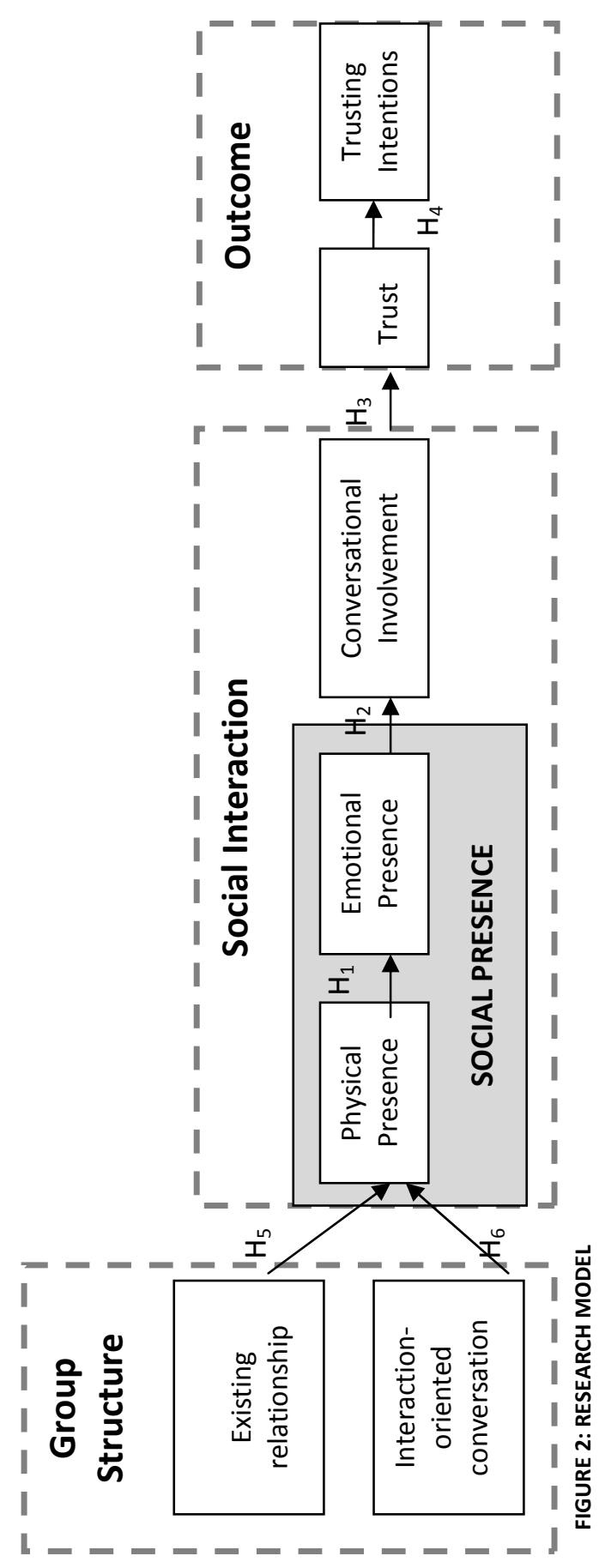




\subsection{Methodology}

\subsubsection{Research setting}

A well-known German financial service provider (MLP) was invited on campus to advice students on saving plans for retirement provisions and financial incentives offered by the government for these saving plans. This topic was chosen because the German pension system relies more and more on private retirement provisions (Queisser 1996). Nearly $60 \%$ of the Germans aged below 30 expect to have less money once they are retired. However, most do not even know the most basic products that are promoted with financial incentives by the government (FocusMoney 2007). Financial products have been described as being an important purchase for customers that require elaborate decision (Heaney et al. 1999). Concluding, private retirement provision products were considered of high relevance, sufficiently complex and new for the participants. Professional advisors from an existing company presented real information on retirement provisions to the participants.

\subsubsection{Selection of advisors and manipulation}

The company MLP was chosen, as they specialize on advising students and academics on retirement provisions. All advisors have passed a selection by the company and possess an extremely persuasive, extrovert and friendly personality. In addition, they receive the same product training. Thus, they represent a rather homogenous group of advisors with the same knowledge base. Six of the senior advisors participated.

\subsubsection{Experimental setup}

To test the hypotheses, a $2 \times 2$ between-subjects experiment was designed, in which conversational style and existing relationship were manipulated. Participants were invited on a voluntary basis to receive financial advice in a "video call research project", and were awarded with the information they received plus an assessment center training (worth EUR 70) or 10 EUR in cash.

The participants were randomly assigned to any of the four conditions. When entering the lab, they received the business card of the advisor, and 
consequently had a video-advice session of about 10-15 minutes via Skype in individual cabins. After the session, a link to a questionnaire appeared.

\section{Manipulation 1: Existing relationship}

From thin slicing theory, we know that about half a minute is sufficient to get a strong first impression (Ambady et al. 1993). In order to achieve the effect of a previous meeting, some participants were assigned to have a chat with their future advisor and had a drink together before the experiment, while the others did not. The purpose of this meeting was disguised. The participants were told that their advisor was already available but that the conversation could not yet start as some participants of the previous session still had their conversation in the lab. We arranged for meetings which lasted five minutes. The advisors were instructed not to talk about any financial issues yet, but rather focus on introducing themselves and getting to know the participant. During the five minute meeting, participants of the previous session would one by one come out after having finished their questionnaires, and would cross the first room and the waiting area. This supported our claim that the computer room was indeed still taken while they had to wait. The advisors would then go to room 3, and the participants of the waiting area and the participant who had the meeting would enter room 2 (see figure 3 ).

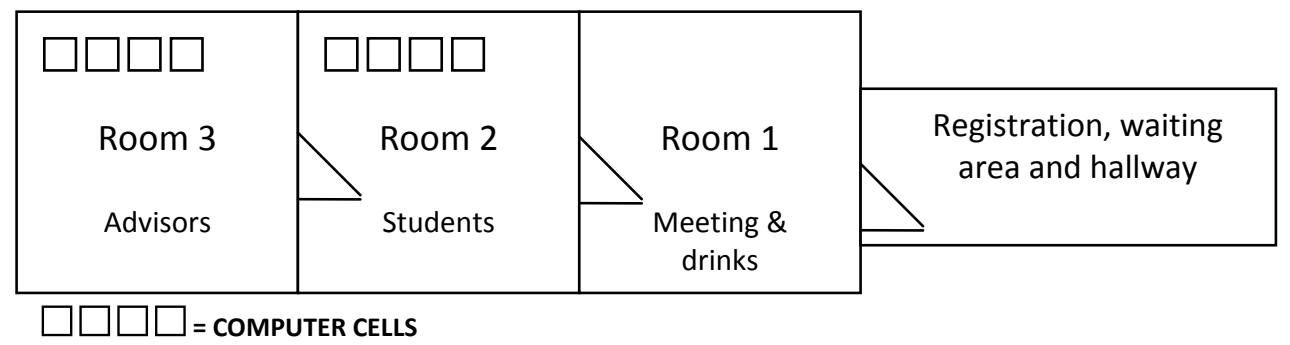

FIGURE 3: FLOOR PLAN OF THE COMPUTER LAB

\section{Manipulation 2: Interaction Style}

In order to influence the interactivity, two different interaction styles will be compared. When advising a customer on a service product, a sales employee can do so by actively consulting the customer and adapting the products to the customer's needs (interaction-oriented), or by merely in- 
forming the customer on the products and its benefits, independent of whether or not the products fits the customer (task-oriented). The advisors understood the difference between the two interaction styles easily and recognized that many retail banks apply the task-oriented style, because employees get incentives to sell a certain product. The advisors of the chosen company were trained to use the interaction-oriented style, but agreed to follow the assigned script in the experimental sessions.

The content of each style was discussed in mutual agreement between researchers and the consultants, to make sure that the information given was correct, the conversation could be done in a natural way and would last about equally long. Also both conversations ended with the same sentence in which the advisors invited the participants to leave their contact details for a follow-up conversation in the company's office. Finally the content of both styles was scripted, and advisors were asked to stick with the script as much as possible. The script can be found in the attachment of this chapter. Manipulation checks in the questionnaire investigated whether the correct interaction style was identified.

\subsubsection{Pretest}

Nine PhD students participated in the pre-test. All manipulations were confirmed. The task-oriented conversation was considerably shorter than 15 minutes. The scripts were adapted so that both were approximately equal in length, while conveying about the same information. Furthermore, the advisors were asked to answer all questions the participant might raise in a natural way, to prevent that one condition was more unfriendly. In that sense, there is a chance that the task-oriented style could become more interactive if the customer asked a lot of questions.

\subsubsection{Measurement Development}

All principal constructs in this study were statements that could be answered on a 7-point Likert scale anchored at $1=$ Strongly disagree, $4=\mathrm{Neu}$ tral and $7=$ Strongly agree. 


\section{Physical Presence, Emotional Presence, Conversational Involve- ment}

The existing inventories for social presence were often very long (e.g. Lessiter et al 2001 include 44 items), dependent on one media (by e.g. referring to a display) and did not include items which were appropriate to measure communication between humans. Therefore we developed scales containing questions that could be answered independent of the medium, for measuring physical presence, emotional presence and conversation involvement in inter-human communication following Churchill (1979).

Based on the definition which was developed earlier in this chapter, 48 statements on social presence and conversational involvement (out of which 35 from existing scales) are included in a paper-based questionnaire. Participants are second year Bachelor students who have to refer to their last chat conversation when filling it out $(n=334)$. After deletion of some items, three factors are extracted. To confirm the three factors, a second data collection is performed among 125 second year bachelor students (see appendix A). The findings of the first analysis are unconditionally confirmed.

Both analyses indicate that social presence can be discriminated from conversational involvement and that two dimensions of social presence can be statistically verified. This short questionnaire provides us with a tool to measure social presence and conversational involvement by means of a survey with only four questions for each construct.

\section{Trust and Trusting Intentions}

The participants' trust in the advisor is measured with 12 questions to cover the aspects of benevolence, competence and integrity. Furthermore, respondents are asked in how far they are willing to depend on the advisor's recommendation, follow the advice, or give up private information such as their address. This construct is called trusting intention. Both constructs are taken from McKnight et al. (2002).

However, participant's answers to hypothetical questions on trusting intentions may not reflect their actual behavior, as several researchers have noted discrepancies between self-reported intentions and actual behavior (Chandon et al. 2005; Weijzen et al. 2008). Therefore the participants have 
the opportunity to indicate whether they are interested in a second conversation with the same advisor, and they can leave their contact details in the questionnaire. In this case, the respondents are asked to declare whether they allowed the researchers to forward their contact details to the advisors.

\section{Additional control variables}

In an interaction, each person has the possibility to influence the process by his own behavior. An extrovert person may take more influence on the process than an introvert person. Therefore control questions for extraversion were included. Additionally, the feeling of social presence is rather subjective. It may be that a person who is more open to new experiences is also more likely to imagine another person being present in the same room. We controlled for this by including questions for openness to experience.

Both of these constructs were taken from the Big Five personality scale (Benet-Martinez et al. 1998). The items were selected based on whether they were included in the reduced version BFI-10 (Rammstedt et al. 2007), plus two additional items which loaded well in the English version and among a German sample (Benet-Martinez et al. 1998; Lang et al. 2001). Since one of the BFI-10 items loads poorly among Germans in previous studies (Lang et al. 2001), one additional item from the BFI personality scale was picked for openness which has good fit among Germans in the study of Lang et al. (2001). So both constructs are measured with four items.

Since trust is known to be influenced by the level of institutional trust a person has into to institution that an individual person represents, this construct was included as a control variable as proposed by McKnight et al. (2002). We used nine questions that cover competence, benevolence and integrity. In this study, it was decided to use institutional trust in financial advisors in general as the level for which the control variable was measured, as opposed to institutional trust in the specific company. This wording ensured that also participants who had not know the company beforehand could answer the question. 


\subsection{Data Analysis and results}

\subsubsection{Data set}

A total of 129 participants from a Dutch university took part in the study, $47 \%$ of them being female. The average age was 22.6 years, ranging from 18 to 35 ( $S D=2.23)$. None of the cases had to be excluded.

\begin{tabular}{|c|c|c|c|}
\hline Physical Presence & & Trusting Beliefs & \\
\hline PP1 & 0.7873 & Benevolence & \\
\hline PP2 & 0.7565 & TBBen1 & 0.813 \\
\hline PP3 & 0.884 & TBBen2 & 0.8573 \\
\hline PP4 & 0.8484 & $\begin{array}{l}\text { TBBen3 } \\
\text { TBBen4 }\end{array}$ & $\begin{array}{l}0.8363 \\
0.8366\end{array}$ \\
\hline \multicolumn{4}{|l|}{ Emotional Presence } \\
\hline EP1 & 0.8634 & Competence & \\
\hline EP2 & 0.5312 & TBComp1 & 0.8475 \\
\hline EP3 & 0.8946 & TBComp2 & 0.7789 \\
\hline \multirow[t]{2}{*}{ EP4 } & 0.9055 & TBComp3 & 0.8509 \\
\hline & & TBComp4 & 0.8192 \\
\hline \multicolumn{4}{|l|}{ Conversational Involvement } \\
\hline $\mathrm{Cl} 1$ reversely coded & 0.8808 & Institutional Trust & \\
\hline $\mathrm{Cl} 2$ & 0.9037 & $\overline{\text { Benevolence }}$ & \\
\hline $\mathrm{Cl} 3$ reversely coded & 0.6069 & IBen1 & 0.8065 \\
\hline \multirow[t]{2}{*}{$\mathrm{Cl} 4$} & 0.8919 & IBen2 & 0.7915 \\
\hline & & IBen3 & 0.8354 \\
\hline \multicolumn{4}{|l|}{ Trusting Intentions } \\
\hline Willingness to depend & & Competence & \\
\hline TIWillDep1 & 0.8818 & IComp1 & 0.8731 \\
\hline TIWillDep2 & 0.8801 & IComp2 & 0.8384 \\
\hline TIWillDep3 & 0.8001 & IComp3 & 0.7976 \\
\hline Follow advice & & Extraversion & \\
\hline TIFollowAdv2 & 0.9102 & BFIExtr1 & 0.6505 \\
\hline TIFollowAdv3 & 0.8137 & BFIExtr2 & 0.7719 \\
\hline TIFollowAdv4 & 0.8391 & BFIExtr4 reversely coded & 0.8699 \\
\hline Give Information & & Openness & \\
\hline Givelnfo1 & 0.8603 & BFIOpen1 & 0.7934 \\
\hline Givelnfo2 & 0.8939 & BFIOpen2 & 0.6983 \\
\hline Givelnfo3 & 0.8421 & BFIOpen4 & 0.8283 \\
\hline & & BFIOpen4 & 0.6837 \\
\hline
\end{tabular}

TABLE 3: ITEM LOADINGS 


\subsubsection{Construct assessment}

\section{Trust and Institutional Trust - revision of sub-dimensions}

Trust has been proposed to consist of three sub-dimensions. However, a principal axis factor analysis revealed that the proposed sub-dimensions of benevolence, integrity and competence would not load on clear factors. Specifically, the dimension of "integrity" cross-loads and cannot be distinguished from benevolence. McKnight et al. (2002) also found that the constructs of benevolence and integrity suffer from high correlations of .9 or .88 for the individual and institutional constructs respectively. Therefore, it was decided to exclude integrity and use benevolence and competence exclusively. These two dimensions were also used by other authors with similar questionnaire items (e.g. Cho 2006; Levin et al. 2004). Likewise, the dimension of integrity was removed from the institutional trust scale.

\section{Construct assessment of the overall model}

We used partial least squares (PLS) analysis as implemented in SmartPLS (Ringle et al. 2005). This technique makes is robust against small sample sizes (Sheng-Hsun et al. 2006) and a number of other problems (Cassel et al. 1999).The model fit is evaluated in two steps. First the construct validity and the reliability of the measures is assessed (measurement model), afterwards the hypotheses will be tested (structural model).

Validity and reliability: The constructs used in this study are evaluated on their convergent and discriminant validity, as well as on their internal consistency reliability.

Convergent validity: All items apart from Extraversion loaded very well on their respective constructs with a SL>0.5 (Hulland 1999; Tenenhaus et al. 2005). We removed the item BFIExtr3, and consequently loadings greater 0.5 were achieved (see table 3 ).

Discriminant validity: Good discriminant validity is achieved if the average variance extracted (AVE) per constructs exceeds the correlation shared between the construct and all other constructs (Fornell et al. 1981). This criterion was fulfilled for all correlations (see table 4). 


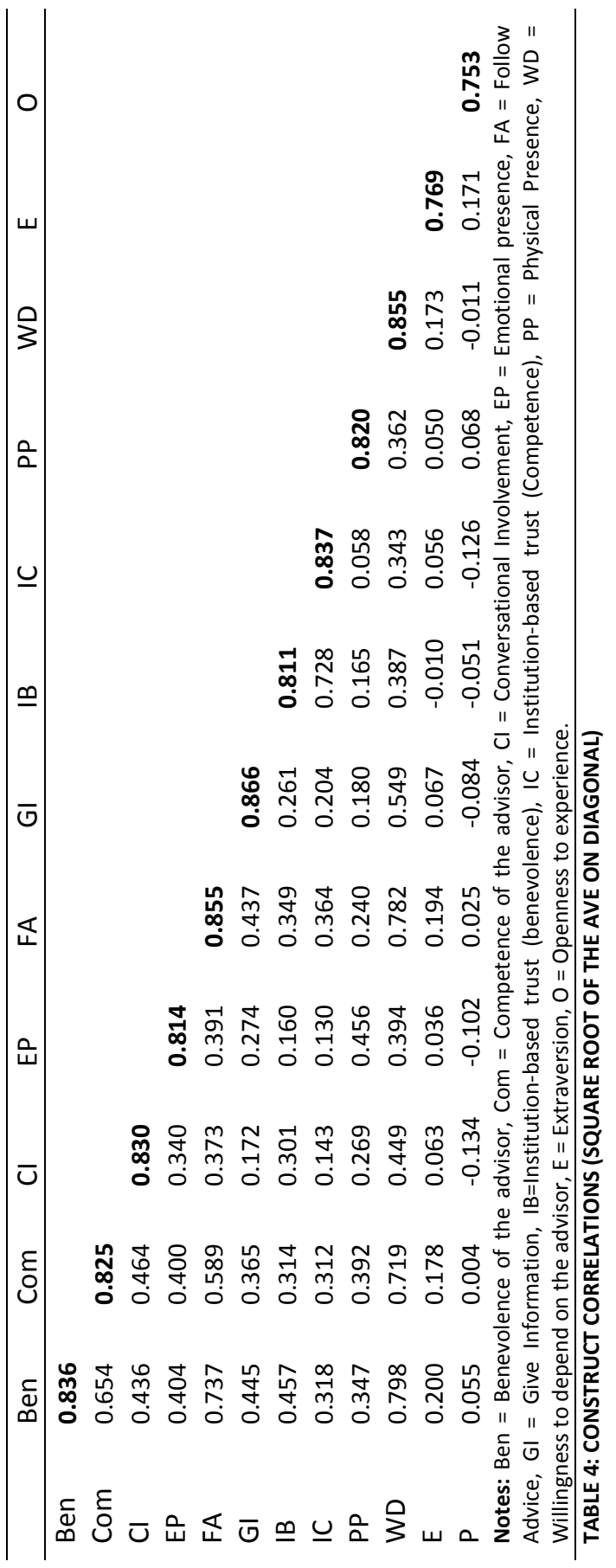




\begin{tabular}{|l|c|c|}
\hline & Composite Reliability & Cronbach's Alpha \\
\hline Conversational Involvement & 0.8966 & 0.8528 \\
Physical Presence & 0.8914 & 0.8370 \\
Emotional Presence & 0.8830 & 0.8253 \\
\hline Benevolence of the advisor & 0.9027 & 0.8565 \\
Competence of the advisor & 0.8946 & 0.8427 \\
Trust in the advisor overall & 0.9131 & 0.8908 \\
\hline Institution-based trust - Ben. & 0.8524 & 0.7411 \\
Institution-based trust - Comp. & 0.8751 & 0.7859 \\
Institution based trust overall & 0.8937 & 0.8564 \\
\hline Follow advice & 0.8908 & 0.8167 \\
Give Information & 0.8997 & 0.8329 \\
Willingness to depend & 0.8904 & 0.8160 \\
\hline Extraversion & 0.8111 & 0.7230 \\
Openness & 0.8387 & 0.7626 \\
\hline
\end{tabular}

TABLE 5: RELIABILITY MEASURES

Reliability: A reliability analysis was conducted by measuring Cronbach's $\alpha$ and the composite reliability. The threshold for both measures is 0.7 , with higher numbers indicating good reliability (Hair et al. 2006). This value was very well exceeded for all measures, indicating a good internal consistency of all constructs (table 5 ) .

\subsubsection{Structural model test}

Hypotheses testing: The results of the hypotheses testing are summarized in table 6. To obtain the t-values, the bootstrap procedure with 500 resamples was applied. The results support all the hypotheses of the research model. If communication partner had seen each other in a previous conversation, they feel more physical presence towards each other. Likewise, if the salesperson used an interactive communication style, the customer felt more social presence. The beta coefficients are .166 and .159 respectively at the 0.05 significance level. The relatively smaller betas can be explained due to the scale of the variable: Both were binary variables. Therefore, hypotheses 5 and 6 were supported.

The positive impact of physical presence on emotional presence $\left(H_{1}\right)$, from emotional presence to conversational involvement $\left(\mathrm{H}_{2}\right)$ and from conversational involvement to trust $\left(\mathrm{H}_{3}\right)$ could also be supported with strong betas (all > .3) at highly significant $p$-values $(p=0.0001)$. Additionally, trust result in 
concrete intentions to depend on the advisor $(\beta=.837, p=.0001)$ and to follow the advice $(\beta=.736, p=.0001)$. Furthermore the customer has the intention to give up private information $(\beta=.449, p=.0001)$, and customers who feel more trust are more likely to provide their real email address to the advisor $(\beta=.332, p=.0001)$. These findings fully support $\mathrm{H}_{4}$.

\begin{tabular}{|c|c|c|c|c|}
\hline & Coefficient & $t$-value & $p$-value & Conclusion \\
\hline Physical Presence -> Emotional Presence & 0.456 & 6.277 & 0.0000 & Supporting $\mathrm{H} 1$ \\
\hline Emotional Presence -> Conv. Involvement & 0.340 & 3.784 & 0.0001 & Supporting $\mathrm{H} 2$ \\
\hline Conversational Involvement -> Trust & 0.420 & 5.397 & 0.0000 & Supporting $\mathrm{H} 3$ \\
\hline Relationship -> Physical Presence & 0.166 & 1.797 & 0.0373 & Supporting H5 \\
\hline Interaction Style -> Physical Presence & 0.159 & 1.859 & 0.0326 & Supporting $\mathrm{H} 6$ \\
\hline Trust -> Follow advice & 0.736 & 18.966 & 0.0000 & Supporting $\mathrm{H} 4$ \\
\hline Trust -> Give Info & 0.449 & 5.536 & 0.0000 & Supporting $\mathrm{H} 4$ \\
\hline Trust $->$ Willingness to depend & 0.837 & 32.419 & 0.0000 & Supporting $\mathrm{H} 4$ \\
\hline Trust $->$ Real data provided & 0.332 & 4.359 & 0.0000 & Supporting $\mathrm{H} 4$ \\
\hline \multicolumn{5}{|l|}{ Control variables } \\
\hline extraversion -> Physical Presence & 0.030 & 0.223 & 0.4121 & n.s. \\
\hline openness -> Physical Presence & 0.035 & 0.252 & 0.4007 & n.s. \\
\hline Institution based trust -> Trust & 0.318 & 4.762 & 0.0000 & significant \\
\hline
\end{tabular}

TABLE 6: COEFFICIENTS, SIGNIFICANCE LEVELS AND INTERPRETATION OF HYPOTHESES

Control variables: The personality traits for extraversion and openness has no effect on physical presence $(p>.4)$. Institutional trust has a highly significant impact on trust $(\beta=.318, p=.0000)$.

Model fit: While there is no single goodness-of-fit measure, the $R^{2}$ values of the endogenous constructs provide an indication on how much variance can be explained with the model. Cohen (1988) categorizes $R^{2}$ effect sizes into small $(>0.02)$, medium $(>0.13)$ and large $(>0.26)$. According to this categorization, the effects of trust (0.342), willingness to depend (0.701) and follow advice (0.542) are large, the effects of emotional presence (0.208) and willingness to give up information (0.201) are medium, and conversational involvement $(0.118)$, real data provided $(0.110)$ and physical presence $(0.057)$ have a small $R^{2}$, however, the latter two are either explained by or measured by binary variables. Therefore, high $\mathrm{R}^{2}$ values are not likely to be expected 
A global Goodness-of-Fit measure was calculated as the square root of the product of the average communality and the average $\mathrm{R}^{2}$ (Tenenhaus et al. 2005).

While the average communality is formed of all constructs in the model, the average $R^{2}$ is formed of the endogenous constructs only (Schepers et al. 2005). Cohen (1988) proposes that Goodness-of-Fit criteria for small, medium and large effect sizes are $0.1,0.25$ and 0.36 respectively. For the current model, the goodness of fit is $\mathbf{0 . 4 3 4}$, indicating a good fit of the model to the data (see table 7).

\begin{tabular}{|c|c|c|}
\hline & $\begin{array}{c}\text { AVE / } \\
\text { communality }\end{array}$ & $\mathbf{R}^{2}$ \\
\hline $\begin{array}{l}\text { Relationship } \\
\text { Conversational Style }\end{array}$ & $\begin{array}{l}1,000^{*} \\
1,000^{*}\end{array}$ & $\begin{array}{l}0^{*} \\
0^{*}\end{array}$ \\
\hline $\begin{array}{l}\text { Physical Presence } \\
\text { Emotional Presence } \\
\text { Conversational Involvement }\end{array}$ & $\begin{array}{l}0,673 \\
0,662 \\
0,689\end{array}$ & $\begin{array}{l}0,0568 \\
0,2083 \\
0,1157\end{array}$ \\
\hline $\begin{array}{l}\text { Trust - Benevolence } \\
\text { Trust - Competence } \\
\text { Trust } 2^{\text {nd }} \text { order construct } \\
\end{array}$ & $\begin{array}{l}0,699 \\
0,680 \\
0,569 \\
\end{array}$ & $\begin{array}{l}0,8457^{*} \\
0,8069 * \\
0,3415\end{array}$ \\
\hline $\begin{array}{l}\text { Follow advice } \\
\text { Give Info } \\
\text { Willingness to depend } \\
\text { Real data provided }\end{array}$ & $\begin{array}{l}0,732 \\
0,749 \\
0,731 \\
1,000^{*}\end{array}$ & $\begin{array}{l}0,5415 \\
0,2011 \\
0,7009 \\
0,1103\end{array}$ \\
\hline $\begin{array}{l}\text { Institution based trust - Benevolence } \\
\text { Institution based trust Competence } \\
\text { Institution based trust } 2^{\text {nd }} \text { order construct }\end{array}$ & $\begin{array}{l}0,658 \\
0,701 \\
0,585 \\
\end{array}$ & $\begin{array}{l}0,8582^{*} \\
0,8691^{*} \\
0^{*}\end{array}$ \\
\hline $\begin{array}{l}\text { Extraversion } \\
\text { Openness }\end{array}$ & $\begin{array}{l}0,592 \\
0,567 \\
\end{array}$ & $\begin{array}{l}0^{*} \\
0 * \\
\end{array}$ \\
\hline Average & 0.6633 & 0.285 \\
\hline GoF & \multicolumn{2}{|c|}{$=\mathrm{V}(0.663 * 0.285)=0.434$} \\
\hline
\end{tabular}

Note: Values marked with $a^{*}$ are not included in calculating the average.

TABLE 7: BASIS FOR CALCULATING THE GOODNESS-OF-FIT OF THE MODEL.

A customer needs to trust in a sales representative before she enters into a business relationship with a company (Morgan et al. 1994; Reynolds et al. 1999). While this trust formation traditionally took place in face-to-face meetings between customer and sales person, today even complex interaction are transacted via online chats or call centres. Therefore, companies can only be successful if they understand how to create trust between the 
customer-sales person dyad in a technology-mediated environment where the actors have no possibility to meet face-to-face.

\subsection{Discussion and Conclusion}

\subsubsection{Social Presence, Trust and the role of Conversa- tional Involvement}

This chapter investigates the concept of social presence and it's relationship to trust. First, an overview of how social presence has been defined and applied in different research areas during the last 30 years is given. The focus of this comparison was social presence between humans in mediated communication. We conclude that social presence is a construct which consists of two sub-concepts, namely physical presence and emotional presence. We also find theoretical support that involvement is not part of social presence. New definitions are formulated which sharpen the concept of social presence and conversational involvement.

Afterwards two scale development studies are executed. The goal is to create a short measurement tool which can be used with any communication medium to measure both physical and emotional presence, as well as conversational involvement. Both studies confirmed the same factors and provide full support for all three concepts. Each concept is measured with four questions.

While the impact of social presence on trust is a well-established assumption (Bos et al. 2002; Gefen et al. 2004), the exact process on how this effect works in detail has not been researched yet. By drawing upon recent research from psychology (Williams et al. 2008), information management (Fabri et al. 2005) and communication research (Bente et al. 2008), we find support for our hypotheses that physical presence has a positive impact on emotional presence $\left(H_{1}\right)$, emotional presence has a positive influence on conversational involvement $\left(\mathrm{H}_{2}\right)$, which in turn leads to lead trust $\left(\mathrm{H}_{3}\right)$. The illumination of this causal chain leads to a better theoretical understanding of how trust is developed in a mediated communication. This improved understanding enables researchers and practitioners to better observe and / 
or influence the individual steps in the process from social presence to trust.

\subsubsection{Antecedents of Physical Presence}

The second major contribution of this chapter is the inclusion of antecedents that have received no or minor attention in social presence research. While the focus of previous studies has often been around the media richness aspect, we find that also factor inherent in the dyad increase social presence. Specifically, we show that the interaction history of a dyad and the conversational style which is imposed by one member of the dyad can change the level of physical presence felt by the other party. Dyads that have met before and/or dyads in which the financial advisor has applied an interaction-oriented conversational style (as opposed to a task-oriented style) will lead to a significant higher level of physical presence felt by the customer.

This is important for other researchers in the field. Factors beyond media richness have an impact on the development of physical presence, and may be controlled for or manipulated in future studies.

\subsubsection{Managerial implications}

Managers will often be confronted with the decision on whether or not to invest in new and better technologies. Since previous research has shown that media richness leads to more social presence, the manager will conclude that an upgrade from phone to video call, or from poor video quality to higher video quality leads ultimately to more trust.

Our research sheds a different light on expensive technology investments. We identify two practical ways of how a manager can raise physical presence and ultimately trust without investing a single dollar into technology.

First of all, managers should train and select salespeople that will interact with customers via technology-mediated channels. Our results show that if a salesperson applies a very interaction-oriented conversational style, in which the advice is adapted around the customer's needs and the customers is actively integrated in designing the advice, then the customers feel a much higher level of physical presence, emotional presence, conversational 
involvement and trust, and we could also show that customers are more likely to share sensitive information with the salesperson. In our case, the customers left their contact details and specifically agreed upon being contacted by the salesperson for a second meeting. We recommend that training of salespeople should include practicing the interaction-oriented conversational style in technology-mediated communication. This may not be a very expensive part in a typical sales training, but results immediately in higher sales.

Second, this study showed that a technology-mediated interaction is likely to be more successful if the customer knows the salesperson from a previous interaction. This clearly appeals to managers to reconsider the current implementations of technology-mediated interactions, in which customers are randomly assigned to advisors they do not know. A solution here may be to assign customers to one advisor or a small team of e.g. three advisors. The customers should be clearly informed that this (team of) advisor(s) is available for him or her. That way they can clearly connect each experience they have with the service provider with their individual advisor(s). This helps to build up a common history (Mesch et al. 2006), and research has shown that after three technology-mediated meetings, there are hardly any differences as compared to a dyad which had face-to-face contact (Hian et al. 2004; Walther et al. 1992).

\subsubsection{Limitations and Future Research}

Several directions for future research emerge from our study.

First, the existing relationship which is manipulated during the experiment was operationalized as a short face-to-face meeting preceding the video interaction. It would have been desirable to also compare relationships that had been established a longer time ago. We would expect stronger effects the closer the relationship is. Future research may apply a longitudinal setting in which different kind of relationships that have developed online or offline are compared and which are followed through several technologymediated interactions. This approach would allow to measure physical and emotional presence, as well as conversational involvement after each session, and would consequently allow to draw conclusions on how social 
presence in dyads with different previous relationships develop over time when interacting via technology.

Second, the data are collected by means of a questionnaire, and thus subjectively. Some researchers have started to investigate more objective measures of presence such as behavior, brain activity or physiological reactions (Insko 2003; Meehan 2001; Mikropoulos et al. 2004). However, these measures have only been applied yet to virtual environments. Future research may investigate whether these methods can be applied to measure physical and emotional presence in a technology-mediated communication between humans.

Third, our research took place using a relatively new technology (Skype). This technology is not yet very commonly used to provide financial advice. That means that the participants - while being familiar with Skype as such had no experience with using Skype in a business setting. We can therefore draw no conclusions as to how experience would influence the use of these technologies. However, previous research indicates that the first episode of adaption is the most crucial one to predict adaptation at a later stage (Tyre et al. 1994). In that sense, we expect to observe the differences found in this study also after the phase of initial adaption. However, a longitudinal study may provide more detailed insights.

Fourth, this study only investigated the use of video communication. However, many chat programs allow using several channels simultaneously. It is possible that during the conversation one person sends a link to a webpage to the communication partner, with relevant information that is consequently discussed during the interaction. Or a conversation may start with chatting, and during the chat the dyad decides to continue the interaction via voice or video call. We propose that multi channel conversations deserve more attention in future research.

Fifth, given that both conversational style and interaction history impact the level of physical presence, future research should investigate other factors that are inherent in the dyad, and interaction effects with other wellknown antecedent of physical presence, such as media richness. Adaptive Structuration Theory (DeSanctis et al. 1994) proposes to also include the 


\section{4 | Ch a pter 2}

organizational environment, the task and sources of structure that emerge during the interaction. Our study provides insight into a typical advice task on a complex service, but findings may not be generalizable to all other tasks and countries. Future research should investigate alternative tasks, such as a medical advice, therapeutic sessions or technical support lines, and also different organizational environments or cultural background should be investigated. 


\subsection{Appendix A - Results scale development}

Results of the factor analysis / scale development $(n=125)$

\begin{tabular}{|c|c|c|c|}
\hline & EP & $\mathrm{Cl}$ & PP \\
\hline 1) I was able to sense the feelings of my communication partner. [A] & .856 & & \\
\hline 2) I could tell how my communication partner felt. [B] & .834 & & \\
\hline 3) I was able to sense the emotions of my communication partner. [A] & .760 & & \\
\hline 4) I was influenced by the mood of my communication partner. [A] & .644 & & \\
\hline 6) I was distracted during the conversation. [C] & & -.860 & \\
\hline 7) I was focused during the conversation. [C] & & .850 & \\
\hline 5) My communication partner did not receive my full attention. [B] & & -.849 & \\
\hline $\begin{array}{l}\text { 8) I remained focused on my communication partner throughout our interac- } \\
\text { tion. [B] }\end{array}$ & & .768 & \\
\hline $\begin{array}{l}\text { 9) I felt as if my communication partner and I were located in the same room. } \\
\text { [D] }\end{array}$ & & & .879 \\
\hline 10) I forgot that my communication partner was not in the same room as I. [A] & & & .843 \\
\hline $\begin{array}{l}\text { 11) When we ended the conversation, it felt as if my communication partner } \\
\text { had left the room. [A] }\end{array}$ & & & .807 \\
\hline $\begin{array}{l}\text { 12) When we started the conversation, it felt as if my communication partner } \\
\text { had entered the room. [A] }\end{array}$ & & & .792 \\
\hline
\end{tabular}

Sources of items: A (own design); B = (Harms et al. 2004); C = (Coker et al. 1987); D = (Hwang et al. 2006; Mühlbach et al. 1995);

*EP = Emotional Presence; $\mathrm{Cl}=$ Conversational Involvement; $\mathrm{PP}=$ Physical Presence

Factor Analysis ( $n=125)$, Extraction Method: Principal Component Analysis, Rotation Method: Oblimin with Kaiser Normalization, Criteria to determine number of factors: Eigenvalue $>=1$, Sorted by size. Loadings below .350 are not indicated

\subsection{Appendix B - Questionnaire items}

(Items with a * are reversely coded)

\section{Physical Presence (Social Presence 1)}

1. When we started the conversation, it felt as if my communication partner had entered the room. My communication partner did not receive my full attention.

2. I forgot that my communication partner was not in the same room as I

3. I felt as if my communication partner and I were located in the same room.

4. When we ended the conversation, it felt as if my communication partner had left the room.

\section{Emotional Presence (Social Presence 2)}

1. I could tell how my communication partner felt.

2. I was influenced by the mood of my communication partner.

3. I was able to sense the emotions of my communication partner

4. I was able to sense the feelings of my communication partner. 


\section{Conversational involvement}

1. I was distracted during the conversation.*

2. I remained focused on my communication partner throughout our interaction.

3. My communication partner did not receive my full attention. ${ }^{*}$

4. I was focused during the conversation.

\section{Trusting beliefs (McKnight et al. 2002)}

\section{Benevolence}

1. I believe that this MLP advisor acts in my best interest.

2. If I required help, this MLP advisor would do his best to help me.

3. This MLP advisor is interested in my well-being.

4. This MLP advisor cares for me (Ganesan 1994; Ganesan et al. 1997) Integrity

1. This MLP advisor is truthful in his dealings with me.

2. I would characterize this MLP advisor as honest.

3. This MLP advisor would keep his commitments.

4. This MLP advisor is sincere and genuine.

Competence

1. This MLP advisor is competent and effective in providing financial advice.

2. This MLP advisor performs his role of giving financial advice very well.

3. Overall, this MLP advisor is a capable and proficient financial advisor.

4. In general, this MLP advisor is very knowledgeable about financial products.

\section{Institution-Based Trust (McKnight et al. 2002)}

\section{Benevolence}

1. I feel that most financial advisors would act in the customer's best interest

2. If a customer required help, most financial advisors would do their best to help

3. Most financial advisors are interested in customer well-being, not just their own well-being

Integrity

1. I am comfortable relying on financial advisors to meet their obligations

2. I feel confident that I can rely on financial advisors since financial advisors generally fulfill their agreements

3. I feel confident that I can rely on financial advisors to do their part when I interact with them

\section{Competence}

1. In general, most financial advisors are competent in serving their customers

2. Most financial advisors do a capable job at meeting customer needs

3. I feel that most financial advisors are good at what they do 


\section{Trusting intentions (McKnight et al. 2002)}

** In order to reduce the total questionnaire length, only 3 items per construct were chosen, based on how well they would fit to the context. The numbers indicated below correspond with the numbers used in McKnight et al. 2002.

\section{Willingness to Depend**}

1. When an important financial issue arises, I would feel comfortable depending on the information provided by this MLP advisor

3. I feel that I could count on this MLP advisor to help with a crucial financial problem

4. Faced with a difficult financial issue that requires me to speak with a financial advisor, I would contact this MLP advisor

Subjective probability of Depending - Follow advice**

2. I would feel comfortable acting on the information on Altersvorsorge [retirement provisions] given to me by this MLP advisor

3. I would not hesitate to use the information on Altersvorsorge this MLP advisor supplied me

4. I would confidently act on the advice I was given by this MLP advisor

Subjective Probability of Depending - Give Information

Suppose you want more information on Staatliche Förderungen [state subsidies] and Altersvorsorge and you could contact this MLP advisor once more. For this service, please answer the following

1. I would be willing to provide my email address to this MLP advisor

2. I would be willing to provide information on my address and phone number to this MLP advisor

3. I would be willing to share details of my financial situation with this MLP advisor Subjective probability of Depending - make a purchase

1. If I would by an Altersvorsorge product, I would do so with X

\section{Permission to reveal contact data:}

I allow XXX University to provide MLP with my student email address: Yes/No.

I provide MLP with the following additional contact details:

My phone number:

My postal address:

Alternative email:

Big Five Inventory (Benet-Martinez et al. 1998)

Openness to experience

1. I am inventive

2. I like to reflect, play with ideas

3. I come up with new ideas, am original

4. I have an active imagination

Extraversion

1. I am talkative

2. I am outgoing, sociable 
3. I tend to be quiet* - (excluded in the analysis)

4. I am reserved*

\section{Manipulation check}

Which of the following statements fits best to the advice you received by this MLP advisor?

a) This MLP advisor gave me a lot of information, but did not take into account my personal needs

b) This MLP advisor adapted his advice to my personal needs by asking questions on my specific situation

\subsection{Appendix C - Experimental scripts and handouts}

\subsubsection{Task-oriented script}

Schönen guten Tag Herr/Frau

unser heutiges Thema ist die Altersvorsorge.

\section{Generationenvertrag}

Ich möchte Ihnen dazu kurz erklären, wie die gesetzliche Rente in Deutschland funktioniert. Jeder Arbeitnehmer in Deutschland fast $20 \%$ von seinem Bruttolohn in die gesetzliche Rentenversicherung. Dieses Geld wird aber nicht für den Arbeitnehmer gespart, sondern wird direkt and die heutigen Rentner ausgezahlt. Diese Vorgehensweise heisst Generationenvertrag. Die Bundesregierung hat bei diesem Generationenvertrag aber viel versäumt. Die Renter werden älter, die Arbeitslosigkeit ist höher, und es werden viel weniger Kinder geboren. Deswegen werden die Renten schon seit Jahren nicht mehr erhöht - durch die Inflation bedeutet das also, dass Renter jedes Jahr weniger Geld in der Tasche haben. Das heisst auch, dass Ihre Rente auf keinen Fall ausreicht, um ihren Lebensstandard zu erhalten!

\section{Inflation}

Um Ihnen mal kurz ein Beispiel zur Bedeutung der Inflation zu geben: Im Janaur hatten wir eine Inflation von $2,8 \%$. Wenn wir im Durchschnitt eine Inflation von 2,5\% annehmen, dann bedeutet dass innerhalb von 45 Jahren alles 3 mal so teuer wird. Wer heute mit 1.000 eur im Monat leben kann, brauch also 3000 eur im Monat bei Rentenbeginn. Das geht natürlich nicht, wenn die Renten nicht mehr ansteigen weil der Generationenvertrag nicht mehr funktioniert.

\section{Einleitung Basisrente}

Daher hat der Gesetzgeber verschiedene Möglichkeiten geschaffen, um steuerbegünstigt selbst fürs Alter vorzusorgen. Für Studenten bietet sich optimaler Weise 
die Basisrente an. Diese Anlageform ist auch unter dem Namen Rürup-Rente bekannt. Sie ist deswegen besonders für Studenten geeignet, da Sie durch ihr junges Alter einen sehr grossen Zinseszinseffekt erzielen und direkt ab Berufsstart von den staatlichen Förderungen zu profitieren.

Die Basisrente würde vom Wirtschaftsweisen Bert Rürop entwickelt und wird seit 4 Jahren von der Bundesregierung gefördert. Ziel dieser Anlage ist es, eine sichere Rente aufzubauen. Diese Rente wird lebenslang gezahlt und ist geschützt vor einer Pfändung oder vor Harz IV.

\section{Wie funktioniert die Basisrente?}

Die Basisrente ist eine Ergänzung zu Ihrer gesetzlichen Rente und soll mit dieser zusammen die Basis Ihrer Rente bilden. Sie wird genauso wie Ihre gesetzliche Rente bei Auszahlung mit einem geringen Steuersatz versteuert und beinhaltet die Sicherheit, dass sie lebenslang gezahlt wird.

In der Ansparphase erhalten Sie zusätzlich zu Ihren Eigenbeiträgen eine steuerliche Förderung. Ausserdem bestimmen Sie die Art der Geldanlage - Sie können wählen, ob Sie lieber chancenorientiert oder sicherheitsorientiert anlegen möchten. Bei einer sicherheitsorientierten Geldanlage wird Ihr Geld in festverzinsliche Wertpapieren angelegt. Bei einem chancenorientierten Fonds können Sie in einen oder mehrere Investmentfonds Ihrer Wohl investieren.

Die staatliche Förderung lässt sich am besten mit einem Beispiel erklären, das auf der Grundlage eines Jahresbruttoeinkommens von 45.000,- € gerechnet ist.

(Handout 1 - Basisrente besprechen)

Ohne Basisrente würden bei einer Sparrate von 100,- $€$ auch nur 100,- $€$ angelegt. Durch die steuerliche Förderung der Basisrente bekommen Sie zu Ihren 100,- € einen Betrag von 60,- $€$ hinzu, d.h. Sie erhöhen dadurch Ihre Gesamt-Sparrate auf 160 ,- $€$. Dies entspricht einer Förderquote von durchschnittlich $60 \%$. Das bedeutet: Jedes mal, wenn Sie 100,- $€$ einzahlen, zahlt der Vater Staat 60,- $€$ hinzu.

Was halten Sie davon?

(Kunde wird das in der Regel gut finden.)

\section{Auszahlungsphase}

Wenn Sie dann das Rentenalter erreicht haben, wird die Basisrente genau wie die gesetzliche Rente bei Auszahlung mit einem geringeren Steuersatz versteuert. Der Steuersatz ist deswegen gering, weil das Einkommen natürlich in der Rentenzeit niedriger ist. Das hat natürlich 2 Vorteile - zum ist der persönliche Steuersatz niedriger. Und zum anderen zahlen Sie diese Steuern viele Jahre später 
Ich kann Ihnen gerne vorrechnen, wie sich der Zinseszinseffekt auswirkt. Dazu haben Sie 3 Beispielrechnungen von Studenten vorliegen.

Nun ist es so, dass die meisten Ihrer Kommilitonen ca. $90 €$ sparen, einige liegen darunter bei ca. 50-60 € und einige, denen das Thema sehr wichtig ist, liegen sogar bei ca. $120,-€$.

Dann schauen wir uns diese Varianten nun im einzelnen mal genauer an.

(Handout 2 besprechen)

Haben Sie noch Fragen über die Basisrente?

Bitte sehen Sie dieses Gespräch als erste Vorab-Information. Zu einem umfangreichen, persönlichen Analysegespräch, lade ich Sie recht herzlich ein. Sie können auf dem Online-Feedbackbogen gerne Ihren Namen und Ihre Telefonnummer hinterlassen, dann werde ich mich zwecks Terminabsprache in den nächsten Wochen mit Ihnen in Verbindung setzen. Meine Kontaktdaten finden Sie auf der Visitenkarte.

Ich bedanke mich für das Gespräch mit Ihnen, auf Wiedersehen. 


\section{Handout 1}

\section{Basisrente}

\begin{tabular}{|l|r|r|}
\hline & \multicolumn{1}{|c|}{$\begin{array}{c}\text { ohne } \\
\text { Basisrente }\end{array}$} & \multicolumn{1}{c|}{$\begin{array}{c}\text { mit } \\
\text { Basisrente }\end{array}$} \\
\hline Eigenbeitrag & 100 EUR & 100 EUR \\
\hline Staatliche Förderung & - EUR & 60 EUR \\
\hline Gesamtsparbetrag & 100 EUR & 160 EUR \\
\hline Förderquote & $0 \%$ & $60 \%$ \\
\hline
\end{tabular}

Als Beispiel 45.000 zu versteuerndes Jahreseinkommen, Steuerklasse I/O

\section{Handout 2}

DATEN DER VBRSICHERUNG

Geburtsdatum to versicherte Person Huster Ma

08.08 .1985

Versicherungsheginn

01. 03.2008

Beginn der Rentenzahlung

01.03 .2052

Aufschub-/Beitragszahlungsdauer

44 Jahre

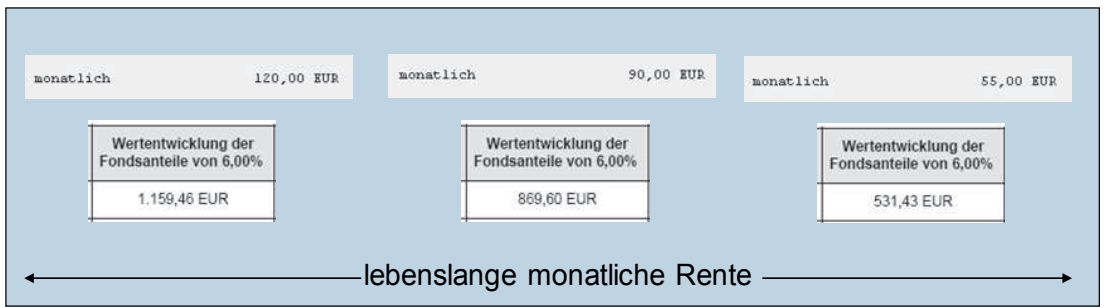




\subsubsection{Interaction-oriented script}

Schönen guten Tag Herr/Frau

unser heutiges Thema ist die Altersvorsorge.

Bevor wir uns konkret damit beschäftigen, wie Sie optimalerweise für Ihr Alter vorsorgen, ist es wichtig, dass wir zuerst einmal gemeinsam ermitteln, wie hoch $\mathrm{hr}$ individueller Bedarf ist.

(Handout 3 - Kaufkraft und Inflation besprechen)

Sparrate ermittelt

\section{Fragen:}

1) Wieviel sparen Sie denn heute schon für Ihre Unabhängigkeit im Alter?

2) Was ist Ihnen bei Ihrem Altersvorsorge-Sparen wichtig ? (mögliche Antworten: Flexibilität, Rendite)

3) Wollen Sie auch staatliche Förderungen nutzen ?

4) Ist es Ihnen wichtig, dass Sie Ihre Sparrate an Ihr steigendes Einkommen anpassen können ?

5) Würden Sie sich eher zu den sicherheitsorientierten, ausgewogenen oder chancenorientierten Anlegern zählen?

6) Planen Sie, nach dem Studium längere Zeit ausserhalb Deutschlands zu leben oder arbeiten?

\section{(Handout 4 - 3 Schichtenmodell besprechen)}

.... mit einer hier getroffenen Entscheidung schauen wir uns nun die verschiedenen Sparmöglichkeiten an, die wir zum Aufbau Ihrer Altersvorsorge nutzen können.

Wie Sie anhand der vorliegenden Folie erkennen, gibt es drei verschiedenen Schichten (Farben), die sich nach der Ansparphase (links) und Entnahmenphase (rechts) unterscheiden.

Schicht $1+2$ sind in der Ansparphase steuerlich gefördert, d.h. dass in der Ansparphase unter bestimmten Voraussetzungen der Staat bis zu 93\% Ihres eigenen Beitrages noch mal hinzuzahlt. Wenn sie zum Beispiel $100 €$ in den Vertrag zahlen gibt der Staat $93 €$ dazu.

Dafür wird die erreichte Rente in der Entnahmephase komplett mit Ihrem dann gültigen Steuersatz versteuert. 
Schicht 3 ist eine auszahlungsgeförderte Variante. Diese wird in der Ansparphase nicht gefördert, dafür wird die erreichte Rente in der Entnahmephase nur teilweise versteuert.

Um jetzt für Sie die optimale Lösung zu entwickeln, ist es wichtig, dass wir Ihre Sparfähigkeit analysieren:

Nun ist es so, dass die meisten Ihrer Kommilitonen ca. $90 €$ sparen, einige liegen darunter bei ca. 50-60 € und einige, denen das Thema sehr wichtig ist, liegen sogar bei ca. $120,-€$.

\section{(Handout 5 besprechen)}

Wo würden Sie sich eingruppieren?

a) Insgesamt ist aufgrund der Förderung des Staates und Ihres jungen Alters die Nachsteuerrendite in Schicht $1+2$ höher als in Schicht 3 und bietet heute für Sie den höchsten Nutzen.

(Sie ist ausserdem flexibel an Ihr steigendes Einkommen anpassbar. Sie haben auch die Möglichkeit, in sicherheits/ chancenorientierten Anlagen anzulegen. Daher sollten Sie über eine Riester- oder Rüruprente nachdenken.)

- oder -

b) Aufgrund Ihres geplanten Auslandaufenthaltes kommt fuer Sie eine Loesung aus der Schicht 3 optimalerweise in Frage. Denn die Förderungen aus Schicht 1 und erhalten Sie nur, wenn Sie in Deutschland arbeiten. Das heisst, Sie sollten jetzt mit einer privaten Rentenversicherung beginnen, um so Ihre Versorgungslücke auszugleichen. Diese Versicherung ist flexibel an Ihr steigendes Einkommen anpassbar. Sie haben auch die Möglichkeit, in sicherheits/ chancenorientierten Anlagen anzulegen Die Riester- order Rüruprente ist dann interessant, wenn Sie aus dem Ausland wieder zurückkommen.

Haben Sie noch Fragen zu diesem Thema?

Bitte sehen Sie dieses Gespräch als erste Vorab-Information. Zu einem umfangreichen, persönlichen Analysegespräch, lade ich Sie recht herzlich ein. Sie können auf dem Online-Feedbackbogen gerne Ihren Namen und Ihre Telefonnummer hinterlassen, dann werde ich mich zwecks Terminabsprache in den nächsten Wochen mit Ihnen in Verbindung setzen. Meine Kontaktdaten finden Sie auf der Visitenkarte. 
4 | Chapter 2

Nach der Analyse ist es möglich, ein maßgeschneidertes Konzept für Sie zu entwickeln. Wir stellen beispielsweise fest, wie flexibel Ihre Altersvorsorge sein sollte, welche Förderungen Sie nutzen können etc.

Ich bedanke mich für das Gespräch mit Ihnen, auf Wiedersehen. 


\section{Handout 3 - Kaufkraft und Inflation}
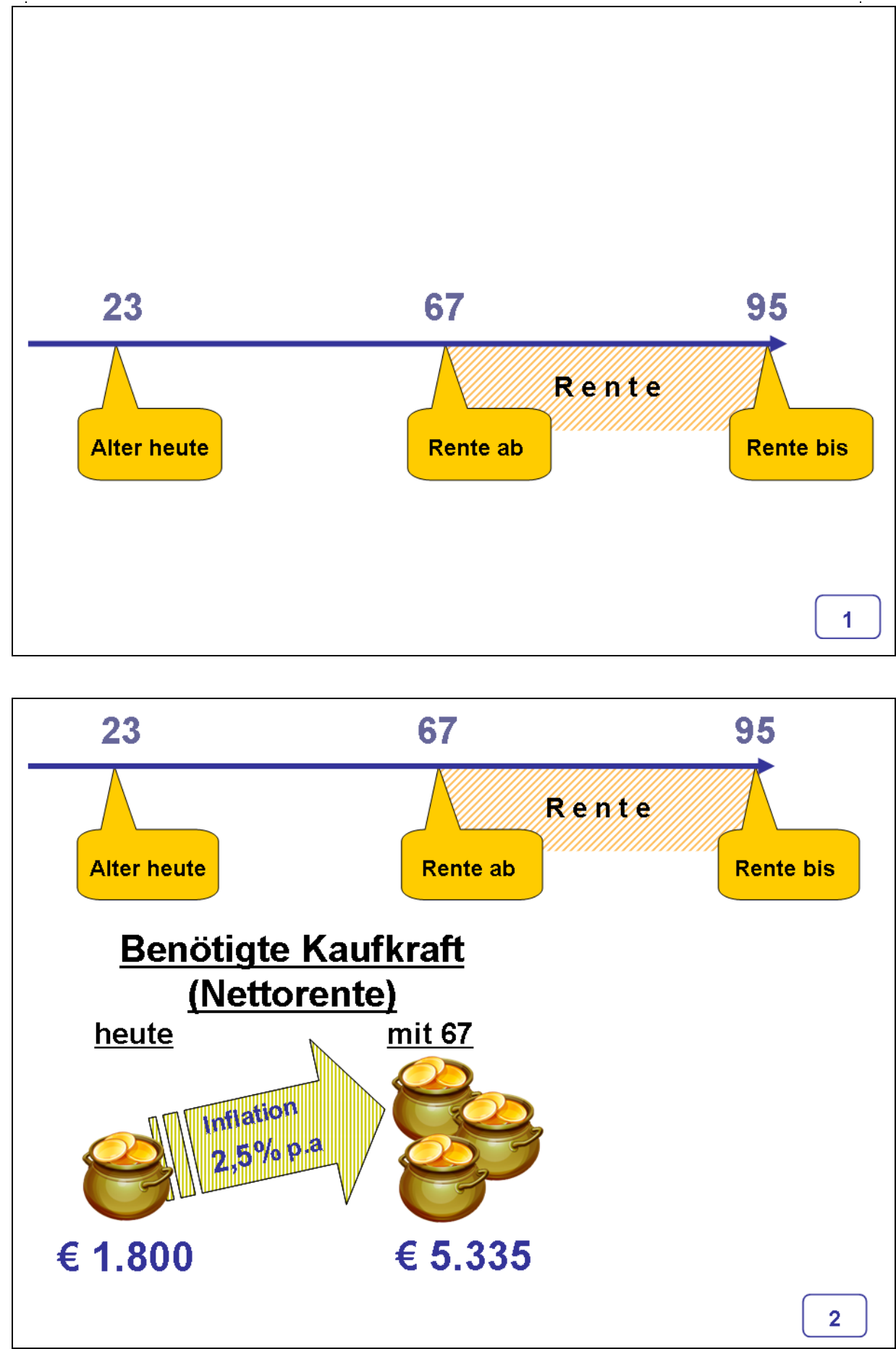


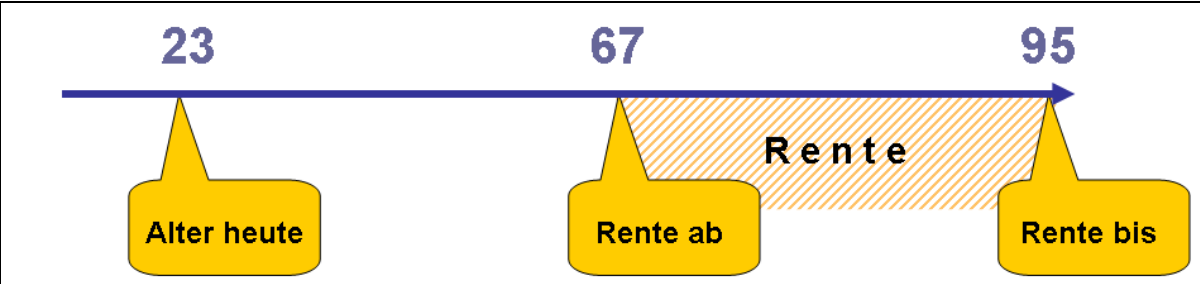

\section{Gesetzliche Rentenversicherung}
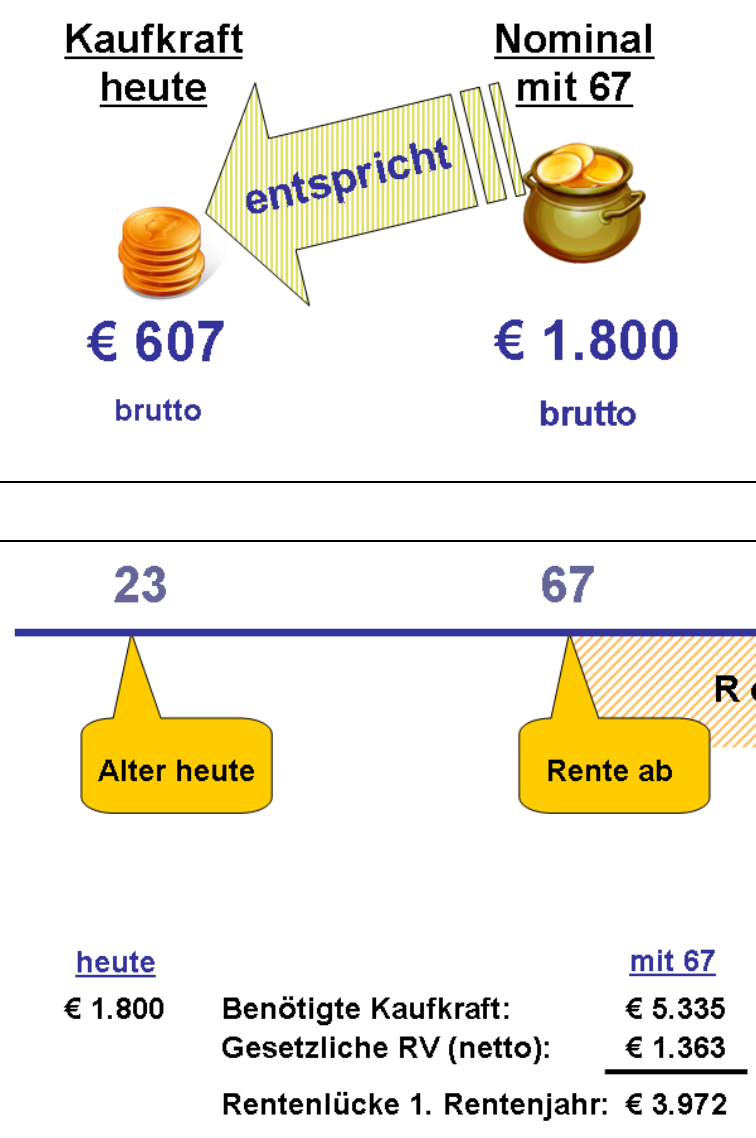

$€ 564$ heutige fehlende Sparrate / Monat 
Handout 4 - 3 Schichtenmodell

\section{Altersvorsorge}

Ansparphase

Entnahmephase

gefördert

1.

Rürup-

(Basis)rente

gefördert

nicht

gefördert

betriebliche

Altersvorsorge

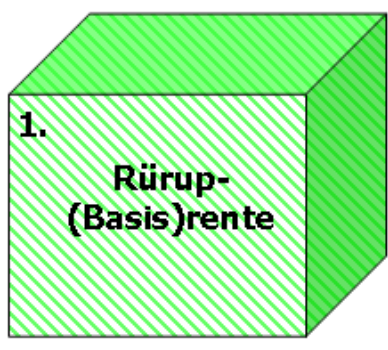

komplett

versteuert

komplett

versteuert

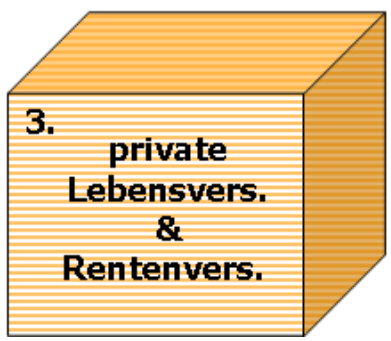

gefördert versteuert 
58 | Chapter 2

\section{Handout 5 - examples of monthly payments}

DATEN DER VERSTCHERUNG

Geburtsdatum 1. versicherte Person Huster Max

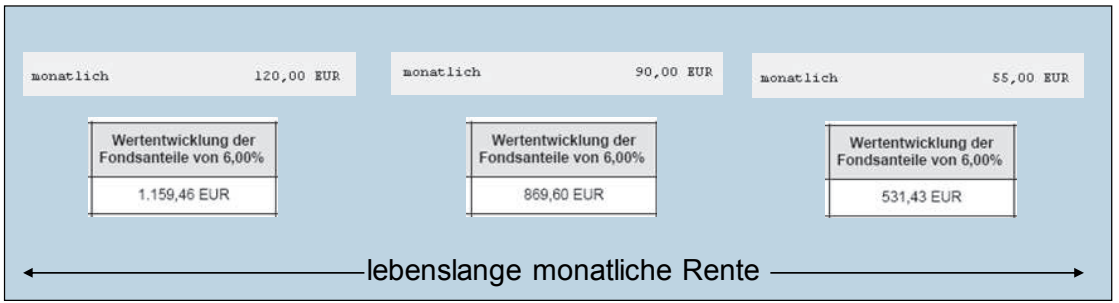




\title{
Chapter 3
}

\section{Investigating the Trust Transfer Process:}

\author{
The Role of Purchase Pals \\ in Interactions with an Online Human Expert
}

This study examines how a purchase pal's trust in an online human expert influences the customer's level of trust in the online human expert and subsequent purchase behavior. Prospect theory is used to explain why the combination of pal's trust in the expert and customer's trust in the pal raise the level of trust perceived by the customer. In an experimental setting, we show that trust transfers in an online transaction from a purchase pal who accompanies the customer to the customer directly and secondly trust transfer only occurs to the extent to which the customer trusts his purchase pal.

Keywords: social presence, trust transfer, physical presence, prospect theory, joint consultation, purchase pal, online human expert 


\subsection{Introduction}

Online sales encounters are increasingly replacing face-to-face encounters. However, customers do not want to miss the social element when shopping online (Wang et al. 2007). Therefore, companies try to replicate the rich experience of offline shopping by adding new features into websites, and by using new media to interact with their customers. For example, ANNA is an avatar with human-like characteristics on IKEA's web site, helping customers with questions during the shopping process. Land's End, a US direct merchant and an early adopter of the internet, offers a feature called "shop with a friend ${ }^{\mathrm{TM}}$ ", which enables a customer to chat with a friend located at a different place while shopping on the website. This tool was included to reflect offline shopping experiences where customers often go shopping with a purchase pal instead of alone. Managers and researchers expect that both avatars and "shop with a friend" increase the social experience and facilitate the customer's trust creation (Nakada 1999; Qiu et al. 2005). However, while these technology-based tools attempt to bring the social element of shopping to the individual customer who is seated in front of his computer, they miss an important element of the "real world": A customer may be physically co-located together with a purchase pal in front of the one single computer and jointly engage in the shopping process.

Still, most companies' online business models and online tools implicitly support customers making decisions in isolation and do not typically take into account (offline) consultations with trusted purchase pals (i.e., friends or family members). Such consultations with purchase pals may enrich the customer's online service experience and may increase the customer's willingness to purchase a specific product or service. Especially when taking a risky decision or buying an unfamiliar product or service for the first time, it seems logical that customers use the friend or family member available at his or her place to get a second opinion before engaging in the transaction. These interactions are currently taking place unnoticed by researchers and managers; the effects of these interactions are unknown and potential benefits are not yet included in companies' business processes to increase sales performance. While purchase pals may influence customer behaviour in various ways, the focus of the current study is on trust transfer. Specifically, the study examines how a purchase pal's trust in an online human 
expert influences the customer's level of trust in the online human expert and subsequently their purchase behaviour.

The role of purchase pals and peers in trust creation has been researched in marketing extensively. However, many studies have focussed on word-ofmouth referral or online review systems, in which purchase pals or peers have first-hand experience with the online vendor (Awad et al. 2008; Sen et al. 2007). Others have identified the importance of "real" friends in business (as opposed to online peers or reviews), yet do not focus on the trust transfer from one party to another (e.g. Grayson 2007). Thus, research has not examined the role of purchase pals in online trust formation where the online human expert or website is unfamiliar to both customer and purchase pal. The current study aims to address this gap.

Drawing from trust transfer and prospect theory, this chapter makes the following contributions: Firstly, it shows that trust transfers in an online transaction from a purchase pal who accompanies the customer to the customer directly. This is surprising, because one would not necessarily expect that trust towards an online human expert unfamiliar to both is transferred via a purchase pal who does not know the salesperson any better than the customer himself. This finding indicates that word-of-mouth is not the only means by which trust is transferred, and thereby adds to trust research by identifying additional pathways to transfer initial trust.

Second, the research argues, and empirically illustrates, that trust transfer only occurs to the extent to which the customer trusts his purchase pal. Therefore, there is a complementary effect between trust in the pal and pal's trust in the online vendor. Thus, if a customer trusts his purchase pal, he or she seems to be more sensitive towards or place more importance in the pal's perception of trust towards the online human expert, and is more likely to internalize the pal's perception.

The chapter is organized as follows: First existing literature on purchase pals and trust is reviewed and summarized in a research model. Afterwards the experimental setup and the findings are described. Finally, the findings and implications are discussed. 


\subsection{Theory and Hypotheses}

\subsubsection{Research model}

The focus of this research is on initial trust formation in joint online service consultations where the customer interacts via technology with an online human expert (e.g. a financial expert, lawyer, medical expert). Specifically, we will investigate the role of purchase pals in joint consultations. For the remainder of this research, "purchase pal" will be defined as a person who is physically co-located with a customer and participates in a joint online consultation session with an online human expert. A joint online consultation session refers to an interaction of an online human expert with two people co-located in one place but separated from the expert, where only one of them is a customer.

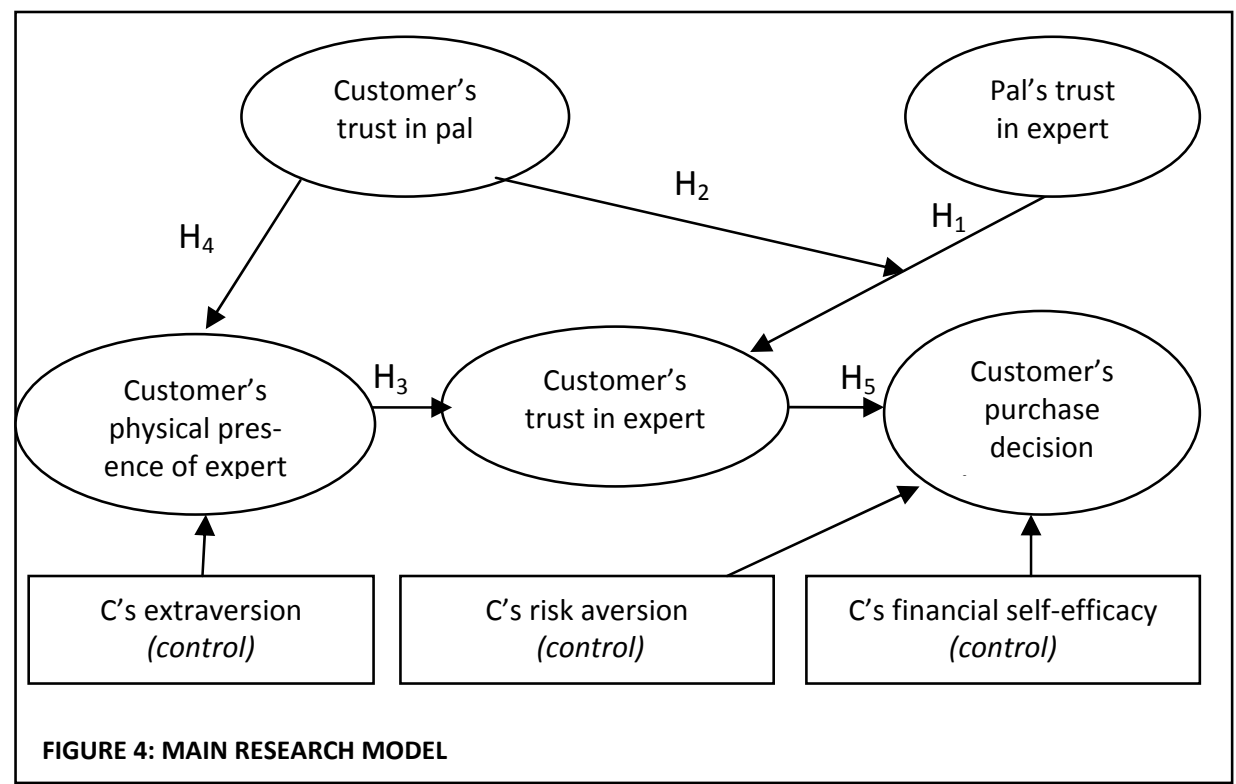

The objective of the research is to examine whether a purchase pal has an effect on the customer's trust in the online human expert. Figure 4 shows the research model. The research model posits that a customer's initial trust in the online human expert will be influenced by the purchase pal's level of trust in the online human expert moderated by the level of trust the customer has in his pal. In addition to the effects of trust transfer from the purchase pal to the customer, we include physical presence as an antece- 
dent of trust in the online human expert since physical presence has been shown to play an important role in trust in a technology-mediated interaction.

\subsubsection{Trust}

The concept of trust has been researched extensively across disciplines for many years. Despite different approaches to conceptualize trust, researchers seem to agree that "the need for trust only arises in a risky situation" (Mayer et al. 1995, p.711). Consequently, the authors define trust as "the willingness of a party to be vulnerable to the actions of another party based on the expectation that the other party will perform a particular action important to the trustor, irrespective of the ability to monitor or control that other party." (Mayer et al. 1995, p.712).

Grabner-Krauter and Kaluscha (2003) characterize electronic commerce as a setting in which the risk of an economic transaction is higher than in traditional shopping, because of uncertainties inherent to the technology as well as uncertainties which result from the lack of personal interaction, and the difficulty to evaluate the seller's ability or willingness to perform. Even with great effort, a customer will be unable to truly verify with certainty that an online transaction is safe. So one could expect that previous experience becomes important, because if a customer had a previous interaction via the internet with a particular well-performing vendor, this customer may expect future interactions with the same vendor to be successful as well. But how does one build up trust to start with a first interaction with an online vendor?

McKnight et al. (1998) found that even in first time interactions, people are able to build up trust towards another person. And surprisingly, the level of initial trust is not necessarily higher in subsequent interactions. Initial trust is defined as "trust in another without firsthand knowledge".

To build high levels of initial trust, individuals seem to process cues other than first-hand knowledge (which they obviously don't have) in such a way that they can reduce the uncertainty and interact with another party even in an otherwise "risky" situation. 
Tanis and Postmes (2003) use the SIDE model (Social Identity model of Deindividuation Effects) to explain the effect that in the presence of very few cues such as basic biographical information or portrait photos, these cues have a drastic impact on impression formation, while objectively they mean very little. Thus, it seems that people grasp at straws to derive trust from whatever information they get.

If a purchase pal is present, one cue online customers can access during a joint online consultation with an online human expert is a purchase pal's perception of the online expert's trustworthiness. The importance of the knowledge on other people's attitude for forming their own attitude has been described in Social Information Processing theory (Salancik et al. 1978). It has also been observed that customers who are shopping with a purchase pal perceive less risk or uncertainty than if they had to make a purchase decision without their pal (Kiecker et al. 1994). Because feeling security while having to trust a third party is one factor contributing to trust (Lewis et al. 1985), we expect that customers are especially prone to trust transfer when they are in a situation where they have to develop an opinion of the trustworthiness of a salesperson they have had no prior experience with. Thus, if a customer's pal is present during the customer's initial interaction with an online human expert (e.g. salesperson), and if this purchase pal perceives the online human expert as trustworthy we expect that the customer will feel more confident trusting the expert as well and perceive less risk in doing so. Conversely, if the purchase pal does not perceive the online human expert as trustworthy, the customer will likely conclude that trusting this expert is risky. Given that an initial online encounter is lean in cues, the customer is likely to be oversensitive to cues that are present and expect that the purchase pal's trust in the online expert will become an important determinant of a customer's own trust assessment resulting in trust transfer from the purchase pal to the customer. We thus propose the following hypothesis:

$H_{1}$ : During a joint consultation, a purchase pal's trust in an online human expert positively influences (transfers to) the customer's trust in the online human expert. 


\subsubsection{Decisions under uncertainty and prospect theory}

Though a customer will take into account a purchase pal's trust in the online human expert as a cue in their own assessment, the credibility of the pal's trust will likely play an important role as to the extent to which the pal's trust will influence the customer's own assessment. In a literature review of five decades' research on source credibility, Pornpitakpan (2004) found that source credibility is an important aspect of persuasion in terms of attitude and behavior change. This suggests that a purchase pal is more likely to influence the customer's trust beliefs in the online human expert if there is a high level of trust between the customer and the purchase pal than if there is a low level of trust between them. Indeed, Ferrin et al. (2006) propose that the trust transfer between two people (e.g., a customer and an online human expert) who are connected via an intermediary (e.g., a purchase pal) may be stronger if the trustor (i.e. customer) trusts in the intermediary (i.e., the pal) via whom trust shall be transferred.

In line with this, research on tie strength has identified that people have more trust in strong ties, and that this trust translates into perceiving the information transmitted via a trusted source as more useful. (Levin et al. 2004). Thus, one can expect that a customer who trusts a purchase pal, and therefore has a strong tie with the pal, is more likely to accept cues about the trustworthiness of a third party such as an online human expert. In other words, findings from tie strength and source credibility literature indicate that the trust transfer as proposed in hypothesis 1 will only happen if the source - in this case the purchase pal - is considered to be trustworthy by the customer.

The reason why the credibility, or trustworthiness, of the pal becomes so important is obvious: A customer has a lot to lose if they place their "trust" where this trust is actually not warranted. Prospect Theory suggests that losses have a greater (negative) effect on preferences than gains. In other words, losses loom greater than gains (Tversky et al. 1991) and thus negative cues will likely be more influential than positive cues. This would suggest that if the customer's purchase pal does not trust the online human expert or if the customer does not trust the purchase pal, the level of customer's level of trust in the online human expert will be low. If the custom- 
er's pal trusts the online human expert AND the customer trusts the purchase pal, then the customer's trust in the online human expert will be high. That is, any negative information with respect to trust (i.e., lack of trust) will hinder the trust development of the customer.

Therefore, we expect an interaction effect between the trust one has in his purchase pal, and the purchase pal's trust in the online human expert. This is reflected in the following hypothesis:

$\mathrm{H}_{2}$ : A customer's trust in a co-located purchase pal moderates the effect of trust transfer such that the effect is stronger the higher the customer's trust in the purchase pal is.

\subsubsection{The role of presence in online trust creation}

In online environments, presence has been shown to be an important antecedent to trust. Social Presence, or presence as it is typically referred to in online environments (Lombard et al. 1997), has been defined as "the degree of salience of the other person in the interaction and the consequent salience of the interpersonal relationship" (Short et al. 1976, p.65.). Though there is an ongoing discussion on the dimensions of presence (Harms et al. 2004; Lessiter et al. 2001), researchers agree on one dimension as being the most critical: physical presence which refers to the perception of being physically together with another person in a technology-mediated interaction.

Pavlou et al. (2007) states that presence "shortens the perceived social distance between buyers and sellers" (p.118). In psychology, the link between physical and social distance has been long established. With the so-called "doll placement technique", researchers ask people to translate a psychological distance by means of dolls into a physical distance (Gerber 1973; Villeneuve et al. 1984). Williams and Bargh (2008) primed people with high or low levels of physical distance, and found that this influences the level of social distance they felt towards other people and places. Thus, physical distance and social distance influence each other.

If physical presence creates the illusion of being together with another person, while in fact one is not together with this person, then one can expect 
that humans will also perceive less social distance to the other party, and subsequently trust the other party more easily. A lack of trust which is caused by the "absence" of the other party (especially in first-time interactions) may thus be reduced.

Prior research has reviewed the impact of presence on trust in online settings extensively. In the context of websites, Gefen et al. (2004) found that presence leads to higher levels of trust. Hassanein (2006) replicated the finding and demonstrated that if a webpage shows pictures of humans, than presence is increased and results in higher levels of trust, too. The link of presence to trust was also confirmed in studies with avatars (Bente et al. 2008; Qiu et al. 2005).

Thus, based on theories from psychology and in line with previous findings in online settings, we believe that a physical presence is positively related to trust, as reflected in the following hypothesis:

$H_{3}$ : A customer's perceived physical presence of the online human expert has a positive impact on trust

\subsubsection{Trust in purchase pal and physical presence with the online human expert}

A customer who engages in a business transaction while having a purchase pal in whom he trusts at his side will experience little social distance towards this trusted pal. The reason for this is, according to construal level theory (Bar-Anan et al. 2006), that the customer shares a lot with the purchase pal, namely they are at that very moment in contact, and the customer trusts his pal. Psychologists also know that social distance can be represented in physical distance (Gerber 1973; Villeneuve et al. 1984). Thus, a customer who feels socially close to the purchase pal should also feel physically close towards this pal. Additionally, construal level researchers have found that people can be primed with one type of distance, and transfer it to another object or person (Williams et al. 2008). In that sense, it can be expected that customer who feels little social distance to a trusted pal will be "primed" with closeness, and thus be able to transfer this feeling of closeness into perceived physical presence with a third party (i.e., the on- 
line human expert). In line with construal level theory we formulate the following hypothesis:

$H_{4}$ : During a joint consultation, a customer's trust in a co-located purchase pal has a positive effect on the customer's perceived physical presence towards the online human expert.

\subsubsection{Trust and purchase decision}

If a customer trusts an online human expert, we expect that the customer consequently takes a purchase decision, such as investing money in specific funds after having received financial advice from a trustworthy expert. Previous research has often captured trusting intentions instead of behavior, despite the fact that these are not perfectly correlated (Kalwani et al. 1982; Morrison 1979). Mayer et al. (1995) wrote that there is "no risk taken in the willingness to be vulnerable (i.e., to trust), but risk is inherent in the behavioral manifestation of the willingness to be vulnerable" (p.724). In other words, the risk only becomes relevant at the moment where one takes an action based on trust, such as a purchase decision. Therefore, this study focuses on actual behavior as reflected in the following hypothesis:

$H_{5}:$ Trust has a positive impact on purchase decision.

\subsection{Methodology}

\subsubsection{Research setting}

Financial products have been described as being an important purchase for customers that requires elaborate decision (Heaney et al. 1999). Recently the financial crisis of $\mathbf{2 0 0 8}$ made people around the globe aware of the fact that a wrong decision can result in a loss of money. Leading journalists argue that the financial crisis is essentially a trust crisis (Dash et al. 2009).

By the end of 2008, Lehman Brothers was bankrupt and the Republic of Iceland was close to bankruptcy, despite that fact that leading rating agencies had rated them shortly before with good A-ratings. Events like these continue to decrease trust in financial institutions. Because financial institutions and individuals do not trust each other anymore, they are not acting 
as rational as they would do if they trusted each other more. Therefore, customers may be skeptical and hesitating to accept advice on complex financial products. Therefore, the context of financial advice was used as a background scenario, to create a setting in which trust plays an important role.

To test the hypotheses, a between-subjects experiment was designed.

\subsubsection{Experimental setup}

\section{Scenario}

Participants were assigned to be a bank customer or a friend (=purchase pal) of the customer. The role of the customer was to invest 500 EUR, and the role of the purchase pal was to help the customer with the financial decision. To strengthen the impact of their decision to the participants, customers had to "invest" 2 EUR to participate, and depending on their performance of the investment product they chose for, the 2 EUR could be lost or customers could actually earn "real" money.

\section{Investment alternatives}

Both customers and purchase pals received the same information, slightly adapted to their respective role. Participants in either role were informed that the customer should decide on how to invest the 500 EUR (for which she had paid EUR 2 when arriving to the experiment). They could choose between a bank deposit with a fixed interest rate or an investment fund, both were existing products by existing financial institutions. For the bank deposit, a screen shot from the bank's webpage was provided, including information on the Deposit Guarantee Scheme which guarantees the first 100.000 EUR investment per accountholder. Therefore, this investment was risk-free.

Alternatively, participants were told that they could invest in an investment fund. However, earnings in this case were not guaranteed. Participants were told that they would have the possibility to speak with a financial advisor about the funds before they had to take a decision. 
From a recent screenshot from the Financial Times and from a real newspaper page of Financial Times Europe, it was clear that stock prices were in free fall. The newspaper was published on the day the data collection started. It included not only on overview with charts of falling share prices, but also a 2-page article on an expected worldwide recession. This way, it was ensured that during their interaction with the advisor, participants had background knowledge and were actually primed with distrust towards investment funds. Secondly, the fact that a real newspaper was used helped to link the experimental setting with the participants "real life".

\begin{tabular}{|c|c|c|}
\hline & Customer & Purchase pal \\
\hline \multicolumn{3}{|l|}{ Initial Investment } \\
\hline Investment & $\begin{array}{c}2 \text { EUR } \\
\text { (which represent } 500 \text { EUR) }\end{array}$ & None \\
\hline $\begin{array}{l}\text { Max. loss } \\
\text { (= investment) }\end{array}$ & $\begin{array}{l}2 \text { EUR investment } \\
\text { (only if they invested in the fund and } \\
\text { the fund made a loss) }\end{array}$ & None \\
\hline \multicolumn{3}{|l|}{ Payments } \\
\hline $\begin{array}{l}\text { Payment if in- } \\
\text { vested in deposit }\end{array}$ & $\begin{array}{l}5 \% \text { interest over } 1 \text { month } \\
=2.08 \text { EUR }\end{array}$ & $\begin{array}{l}25 \% \text { of the customer's } \\
\text { payment }=0.52 \text { EUR }\end{array}$ \\
\hline $\begin{array}{l}\text { Payment if in- } \\
\text { vested in fund }\end{array}$ & $\begin{array}{c}\text { Real return of the Thames River } \\
\text { Bond fund after } 1 \text { month } \\
\text { max. } 8 \text { EUR }\end{array}$ & $\begin{array}{l}25 \% \text { of the customer's } \\
\text { payment = max. } 2 \text { EUR }\end{array}$ \\
\hline $\begin{array}{l}\text { Payment indepen- } \\
\text { dent of decision }\end{array}$ & None & 2 EUR \\
\hline
\end{tabular}

TABLE 8: YIELDS AND INVESTMENT ALTERNATIVES FOR CUSTOMER AND PURCHASE PAL

\section{Payment of participants}

Participant's decision for a specific product impacted the customer's financial reward received for participating in the experiment. The experiment was thus designed to increase the relevancy of the decision for the participant. One month after the experiment, the customer will receive the yield that a 500 EUR investment would have earned in that time. Additionally, the customer will receive their 2 EUR investment. If the customer chooses the investment fund, she runs the risk of losing the 2 EUR investment in case the yield is negative. The purchase pal received $25 \%$ of the customers' 
yield plus 2 EUR for participating (see table 8). The amount of 2 EUR as well as the payment function was chosen to ensure that they were high enough to be relevant for the participants.

\section{Script development, selection of fund and advisors}

The content of the script of the conversations reflected an advice session for an investment fund and was developed based on real information. The fund used in this study was a bond fund which was issued in EUR and consisted mainly of governmental bonds issued by EU countries. Due to the crisis, this fund had performed exceptionally well the month preceding the experiment (13.74\% increase in one month), however, the total increase during the last three years had only been $19.75 \%$. In other words, nearly $70 \%$ of the performance had been generated in only one month, whereas the other $30 \%$ were generated in the preceding 35 months. The chances that the fund would increase another $13 \%$ in the next month was thus very low, with a high risk that the fund would actually stay at that level or even go down. The financial expert's task was thus to persuade the customer that this investment was superior to the deposit, while not giving any wrong information.

The financial experts were recruited among students majoring in finance (six master students, one third-year bachelor student). The experts had thus detailed knowledge on financial products. Still all of them were invited into a training session, in which the bond fund was introduced. They also received information on how to deal with typical customer questions. Also each financial expert practiced a conversation once with another expert while they were in the computer cabins using the software Skype. The advisors were selected among finance master students to ensure they were of roughly the same age, with the same background knowledge.

The financial experts could give feedback on the script they used during this session, and some adaptations were made. Finally the content was scripted, and experts were asked to stick with the script as much as possible. The full-length script is included in the appendix to this chapter.

The financial experts received 4 EUR per conversation plus an additional 2 EUR if the customer bought the fund in the end. 


\section{Procedures: Participant recruitment and the online interaction}

Undergraduate business students of a Dutch university were invited to participate in the experiment in exchange for course credits. This sample was chosen because students have above-average exposure to the internet, experience with e-retailing and are familiar with chat/voip programs such as Skype. That is why students are a popular sample for e-retailing studies (Walczuch et al. 2004). Since the service chosen in this study is financial consultation and the investment of a rather small amount of money, undergraduate business students were selected. Thus, the topic is relevant to the participants, yet are they not too familiar with specific financial products. Consequently, business students represent an ideal sample to study online consultation of financial advice.

Students had to sign up for the experiment on the website for one timeslot together with a friend from the same course. A control group was created for which individual sign-up was allowed. The individual slots for the control group were made available at different points of time during the sign-up period to equally distribute earlier and later subscribers to the experiment across conditions.

All participants that had signed up for individual sessions (control group) were assigned to the role of customers, and among the dyads (main group), one was randomly assigned to be the customer and the other the purchase pal.

Customers had to pay 2 EUR upon arrival, and received a receipt informing them that these 2 EUR represent an investment of 500 EUR. This happened in the presence of their pals. Afterwards the dyads were separated. Customers received written instructions in the hallway, and purchase pals received their written instructions in room 1 (see figure 5).

After having read the instructions (and having met with the financial expert, if applicable), customers were allowed to briefly coordinate with their pals for a short moment, and afterwards both went into room number two of the computer lab, and one dyad occupied one computer cell (see figure 5). Since the financial experts never had to cross the room where the customers were waiting, it was made sure that in fact none of the customers had 
seen an expert before the conversation started. After being seated, the financial experts called the dyads via the Voice over IP (VoIP) program Skype (www.skype.com). Both customer and purchase pal could hear (but not see via video) the financial expert, and both could ask questions or give comments. The expert gave information based on a previously developed script, and answered the questions of both parties. A typical conversation would last about 8-10 minutes.

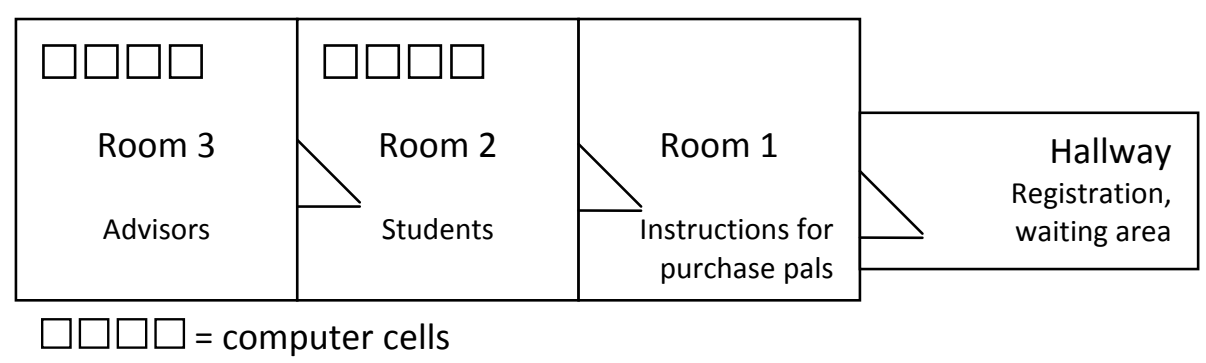

FIGURE 5: FLOOR PLAN OF THE COMPUTER LAB

After the conversation, the purchase pals were placed in a neighboring computer cabin. Both customers and purchase pals found a link on their desktop which they could follow to fill out the questionnaire. All other web pages were blocked, to ensure that the participants would not look up additional information on the bank or the fund.

\subsubsection{Pretest}

Ten students participated in the pre-test. The goal of this pretest was to practice the final script once more with the financial experts, and to see how much time participants needed to read the instructions, have the conversation and complete the final questionnaire. After each session, each participant was asked for feedback. Based on the experience of the pretest, the timing for the main study was designed, and also additional materials for the experimenters were developed to facilitate written instead of verbal communication among the experimenters. 


\subsubsection{Measurement Development}

All principal constructs in this study were statements that could be answered on a 7-point Likert scale anchored at $1=$ Strongly disagree, $4=\mathrm{Neu}$ tral and $7=$ Strongly agree. All items used to measure the constructs can be found in the appendix.

\section{Physical Presence,Trust and purchase decision}

Physical presence was measured with four items, as developed by Schmidt et al. (2008).

Trust was taken from McKnight et al. (2002). The customer's trust in the online human expert, the customer's trust in the purchase pal and the purchase pal's trust in the online human expert is measured with eight questions each to cover the aspects of benevolence, competence and integrity.

Furthermore, we were interested in whether the customers would actually purchase from the financial expert. As there are often discrepancies between self-reported intentions and actual behavior (Chandon et al. 2005; Weijzen et al. 2008), participant's answers to hypothetical questions on trusting intentions may not reflect their actual behavior. Therefore the customers had to decide how they wanted to invest the real money they had to bring to the experiment. They could choose between the investment fund which was promoted by the financial expert, and the bank deposit for which they had received information before the start of the experiment. As such, we captured the participants' actual behavior rather than their trusting intentions.

\section{Additional control variables}

In an interaction, each person has the opportunity to influence the process by his own behavior. An extrovert person may have more influence on the process than an introvert person. Therefore control questions for extraversion were included. This construct was taken from the Big Five personality scale (Benet-Martinez et al. 1998). Four items were selected based on whether they were included in the reduced version BFI-10 (Rammstedt et al. 2007), plus two additional items which loaded well in the English version and among a German sample (Benet-Martinez et al. 1998; Lang et al. 2001). 
Since the investment alternatives among which the respondents could decide differed in risk, risk aversion was included as a control variable for the investment decision. The six measurement items were taken from the CentER Savings Survey as reported by Kapteyn and Teppa (2002).

Financial self-efficacy has been defined as the belief that one is capable of successfully managing the financial events in one's life (Bryant et al. 2006). Since this belief may impact a person's actions and decisions, we will use this concept to control for its impact on the customer's investment decision. Financial self-efficacy is measured with six items as proposed by Bryant et al. (2006).

\subsection{Data Analysis and results}

\subsubsection{Data set}

A total of 144 customers and 102 purchase pals who were enrolled in a business undergraduate program of a mid-size Dutch university participated in the study. Four dyads were excluded, because one (or both) of them filled out the wrong questionnaire, marked the same value throughout the survey, or because the customer and purchase pal were not placed in one single cabin during the conversation (which was done with the rest of the dyads).

Of the remaining 140 customers and 98 purchase pals, $43 \%$ were female, with an average age of 20,85 years, ranging from 18 to 28 ( $S D=1.49)$.

For the analysis, two subsets were drawn from data set. Subset one consists of all customers who participated with a purchase pal, and included all responses given by the customer as well as the items of the pal's trust in the online human expert taken from the pal's survey. The pal's answers were matched to the respective customer who had participated together. This resulted in a sample size of 98 valid responses.

The second data set is used to rule out alternative explanations in the second part of the data analysis. It consists of all customers who participated alone (without a purchase pal), and of customers who participated 
with a pal, but the pal had not previously met with the financial expert. This resulted in 90 observations.

\subsubsection{Construct assessment}

\section{Trust - formative or reflective?}

Prior to conducting the data analysis, we had to decide whether to model trust as reflectively or formatively measured. The measures of trust in this study were taken from Mcknight et al (2002) who measured trust in a reflective way. Trust however consists of the dimensions competence, benevolence and integrity, which can vary independent of each other. That means, a person can be competent while not being benevolent. Therefore, as per the criteria set forth by Jarvis et al (2003), a formative measurement model seems to be more appropriate and we modeled trust as such in our analysis $^{1}$.

Since trust is a second order construct, first a disaggregated model was analyzed to generate factor scores for benevolence, competence and integrity. The resulting factor scores were used as formative indicators for trust in the following analysis. The psychometric properties of these first order dimensions of trust were assessed. The dimensions exhibit good discriminant and convergent validity and internal consistency. Table 9 indicates the weights of each factor score on the respective construct.

\begin{tabular}{|c|c|c|c|}
\hline $\begin{array}{c}\text { Factor score } \\
\text { for... }\end{array}$ & $\begin{array}{c}\text { Customer's trust } \\
\text { in expert }\end{array}$ & $\begin{array}{c}\text { Customer's trust } \\
\text { in purchase pal }\end{array}$ & $\begin{array}{c}\text { Pal's trust in } \\
\text { expert }\end{array}$ \\
\hline Benevolence & 0.353 & 0.456 & 0.424 \\
\hline Competence & 0.340 & 0.284 & 0.328 \\
\hline Integrity & 0.371 & 0.449 & 0.371 \\
\hline
\end{tabular}

TABLE 9: WEIGHTS OF FACTOR SCORES FOR TRUST CONSTRUCTS

\footnotetext{
${ }^{1}$ The model was also run with trust modeled with reflective indicators. The pattern of results remained the essentially the same.
} 


\section{Construct assessment of the overall model}

We used partial least squares (PLS) analysis in SmartPLS (Ringle et al. 2005) to assess the psychometric properties of the scales (measurement model) and to test the structural model.

We provide results for the measurement model for our main sample $(\mathrm{N}=98)$. We performed the same analyses for our control sample (i.e. the subsample of customers without purchase pal or customers who had a pal who did not meet the expert before $(n=90))$. Results from both analyses show very similar psychometric properties. As such, we present the scale validation results for the main sample.

\begin{tabular}{lllllllll}
\hline & Mean (SD) & FSE & PP & E & PT & RA & TiE & TiP \\
\hline FSE & $5.34(1.12)$ & $\mathbf{0 . 8 6 7}$ & & & & & & \\
PP & $3.57(1.46)$ & 0.035 & $\mathbf{0 . 8 8 2}$ & & & & & \\
E & $5.23(.78)$ & -0.064 & 0.164 & $\mathbf{0 . 7 7}$ & & & & \\
PT & $4.82(.88)$ & 0.043 & 0.142 & 0.169 & $\mathbf{0 . 8 8 7}$ & & & \\
RA & $3.63(1.13)$ & 0.208 & -0.210 & 0.006 & -0.123 & $\mathbf{0 . 8 1 7}$ & & \\
TiE & $4.87(1.00)$ & 0.193 & 0.368 & 0.050 & 0.404 & -0.170 & $\mathbf{0 . 9 3 9}$ & \\
TiP & $5.76(.72)$ & 0.300 & 0.259 & 0.111 & 0.149 & 0.090 & 0.432 & $\mathbf{0 . 8 2 5}$
\end{tabular}

Notes: FSE $=$ Financial Self-efficacy, $\mathrm{PP}=$ Physical Presence, $\mathrm{E}=$ Extraversion. $\mathrm{PT}=$ Pal's trust, RA $=$ Risk aversion, $\mathrm{TiE}=$ Trust in Expert, $\mathrm{TiP}=$ Trust in Pal

TABLE 10: CONSTRUCT CORRELATIONS (SQUARE ROOT OF THE AVE ON DIAGONAL)

Validity and reliability: The constructs used in this study are evaluated on their convergent and discriminant validity, as well as on their internal consistency reliability.

Convergent validity: With few exceptions, items loaded very well on their respective constructs with loadings greater than 0.7 (Hulland 1999; Tenenhaus et al. 2005). For extraversion, item 4 had a loading of .688. Since this was close to .7 and the item did not cross-load we retained it in the analysis. For risk aversion and financial self-efficacy, two items on each scale out of the scale's six items had loadings below 0.7 (loadings were lower than .5) in both subsamples. These were removed from the analysis. The final four items for risk aversion include three items which Kapteyn and Teppa (2002) also identified as loading on one factor, thus being consistent with their 
study. Additionally, for convergent validity the average variance extracted (AVE) should be higher than .5, which is the case for all constructs (Hair et al. 2006). Therefore, convergent validity is established for all constructs as used in this study.

\begin{tabular}{|c|c|c|c|c|}
\hline & PP & FSE & $\mathbf{E}$ & RA \\
\hline Cronbach's Alpha & 0.904 & 0.897 & 0.839 & 0.776 \\
\hline $\begin{array}{l}\text { Composite } \\
\text { Reliability }\end{array}$ & 0.933 & 0.924 & 0.888 & 0.852 \\
\hline pp1 & 0.844 & 0.014 & 0.112 & -0.158 \\
\hline pp2 & 0.870 & 0.030 & 0.228 & -0.266 \\
\hline pp3 & 0.926 & 0.043 & 0.168 & -0.182 \\
\hline pp4 & 0.884 & 0.038 & 0.051 & -0.118 \\
\hline fse1 & 0.046 & 0.885 & 0.004 & 0.061 \\
\hline fse2 & 0.087 & 0.843 & 0.063 & 0.149 \\
\hline fse5 & 0.072 & 0.889 & -0.053 & 0.070 \\
\hline fse 6 & -0.033 & 0.852 & -0.160 & 0.313 \\
\hline bfiExtr4REC & 0.090 & -0.141 & 0.688 & 0.047 \\
\hline bfiextr1 & 0.099 & 0.066 & 0.793 & 0.050 \\
\hline bfiextr2 & 0.109 & -0.016 & 0.732 & 0.107 \\
\hline bfiextr3REC & 0.177 & -0.089 & 0.856 & -0.105 \\
\hline risk1REC & -0.172 & 0.186 & 0.005 & 0.871 \\
\hline risk2 & -0.177 & 0.148 & 0.032 & 0.910 \\
\hline risk4 & -0.108 & 0.120 & -0.123 & 0.732 \\
\hline risk5 & -0.258 & 0.271 & 0.088 & 0.740 \\
\hline
\end{tabular}

Notes: FSE $=$ Financial Self-efficacy, $\mathrm{PP}=$ Physical Presence, $\mathrm{E}=$ Extraversion. $\mathrm{PT}=$ Pal's trust, RA = Risk aversion

TABLE 11: COMPOSITE RELIABILITY, CRONBACH'S ALPHA AND CROSS LOADING

Discriminant validity: Good discriminant validity is achieved if the average variance extracted (AVE) per constructs exceeds the correlation shared between the construct and all other constructs (Fornell et al. 1981). This criterion was fulfilled for all constructs (see table 10). Additionally, we investigated the cross loadings (see table 11). All items clearly load on the respective construct, with no relevant crossloadings. Therefore the constructs in this study exhibit good discriminant validity.

Reliability: A reliability analysis was conducted by measuring Cronbach's $\alpha$ and composite reliability. The threshold for both measures is 0.7 , with 
higher numbers indicating good reliability (Hair et al. 2006). This value was very well exceeded for all measures, indicating a good internal consistency of all constructs (Table 11).

\subsubsection{Structural model test}

Hypotheses testing: The results of the hypotheses testing are summarized in figure 6 . To obtain the t-values, the bootstrap procedure with 500 resamples was applied. The results support all the hypotheses of the research model.

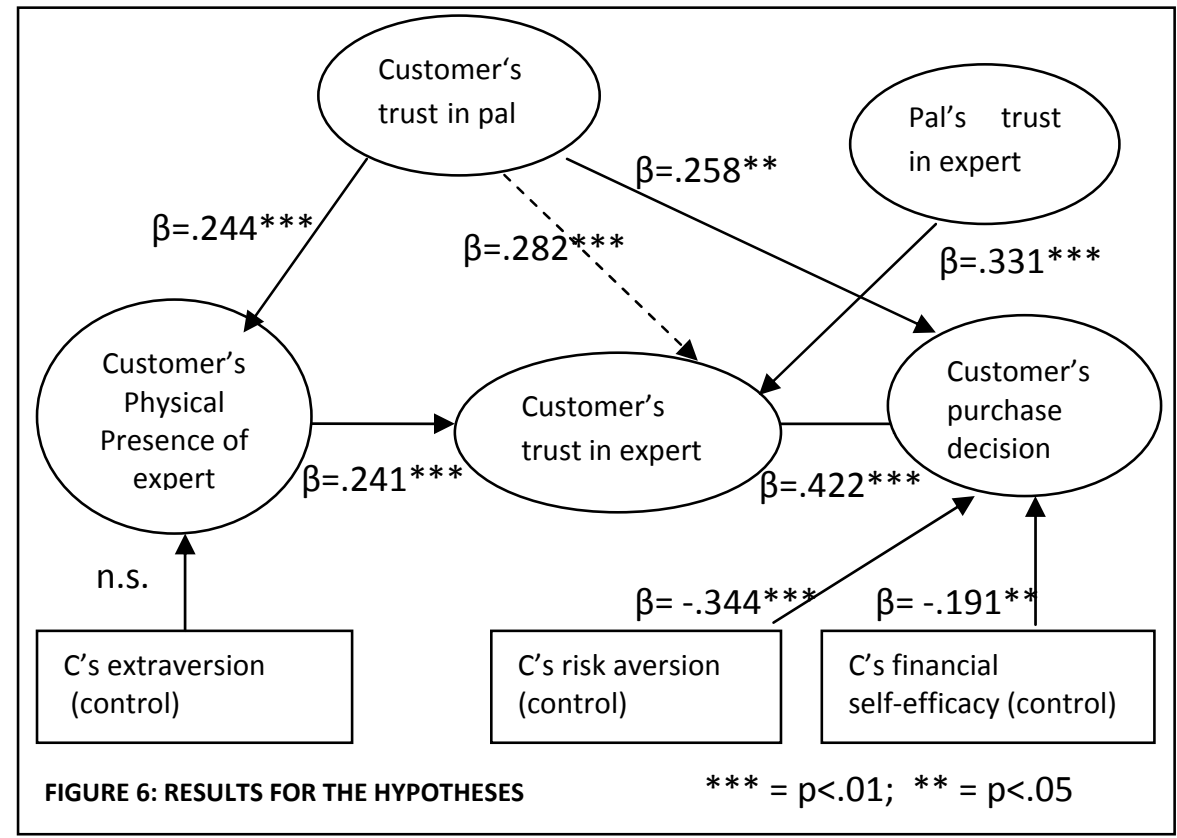

The purchase pal's perception of trust towards the online human expert was positively related to the trust the customer felt towards the expert $(\beta=.331, p=.0001)$. This effect was even stronger if the customer trusts the purchase pal (interaction effect: $\beta=.258, p=.05$ - see figure 7). In that sense, trust is transferred from the purchase pal to the customer, in support of hypothesis 1 and there are complementary effects between trust in the pal and pal's trust in the online human expert supporting hypothesis 2 . To further explore the interaction effects which are graphically shown in figure 8 , we conducted a subsequent ANOVA analysis. Results of the ANOVA (table 12) indicate no statistical difference in trust in the expert across the three 
conditions with at least one low trust construct (that is, low trust in pal high pal's trust in expert; low trust in pal-low pals's trust in expert; high trust in pal-low pal's trust in expert). However, the high-high condition was significantly higher than all of these combinations $(F=6.87, p=0.000)$. Thus, results of this analysis suggest a prospect theory effect as hypothesized in $\mathrm{H} 2$.

\begin{tabular}{|l|c|c|}
\hline P. Pal has... & $\begin{array}{l}\text { low trust in } \\
\text { pal }\end{array}$ & high trust in pal \\
\hline $\begin{array}{l}\text { low trust } \\
\text { in online expert }\end{array}$ & 4.40 & 4.72 \\
\hline $\begin{array}{l}\text { high trust } \\
\text { in online expert }\end{array}$ & 4.93 & $5.50 * * *$ \\
\hline
\end{tabular}

Trust is measured from $1-7,7$ being the highest value. High and low trust conditions were formed based on a median split for each variable. $* * *$ this value is significantly different from all others $(p<0.000)$

TABLE 12: MEAN VALUES FOR CUSTOMER'S TRUST IN ONLINE HUMAN EXPERT

\begin{tabular}{|c|c|c|c|}
\hline $\begin{array}{c}\text { [Dep. Variable: Trust in expert] } \\
\text { Independent Variable }\end{array}$ & Model 1 & $\begin{array}{c}\text { Model 2 (with } \\
\text { interaction) }\end{array}$ & \\
\hline Pal's trust in expert & $0.323^{* * *}$ & $0.331^{* * *}$ & Supporting H1 \\
\hline Customer's trust in pal & $0.323^{* * *}$ & $0.282^{* * *}$ & \\
\hline $\begin{array}{c}\text { Pal's trust in expert x cus- } \\
\text { tomer's trust in pal }\end{array}$ & & $0.258^{* *}$ & Supporting H2 \\
\hline Physical Presence & $0.238^{* * *}$ & $0.241^{* * *}$ & Supporting H3 \\
\hline Adjusted R & $35.8 \%$ & $42.2 \%$ & \\
\hline$\Delta \mathrm{R}^{2}$ & & $6.4 \%$ & \\
\hline $\mathrm{F}$ & & $0.11^{* * *} \mathrm{p}<0.001{ }^{* *} \mathrm{p}<0.01{ }^{*} \mathrm{p}<0.05$ \\
\hline \multicolumn{2}{|r|}{} & \multicolumn{3}{|c|}{} \\
\hline
\end{tabular}

TABLE 13: INTERACTION EFFECT FOR “PAL'S TRUST IN EXPERT” AND “CUSTOMER'S TRUST IN PAL” ON TRUST IN EXPERT

If a customer feels the physical presence of the expert, $s /$ he is more likely to trust the expert $(\beta=.241, p=.001)$. Therefore, hypothesis 3 is supported. If, in addition, the customer trusts the pal who happens to be with her or him during the interaction, the level of physical presence towards the expert is increased $(\beta=.244, p=.001)$. In our study, the presence of the trustworthy purchase pal who joined the customer while the customer had a conversation with the financial expert led to the customer perceiving higher levels of physical presence with the expert. Thus, hypothesis 4 is supported. 


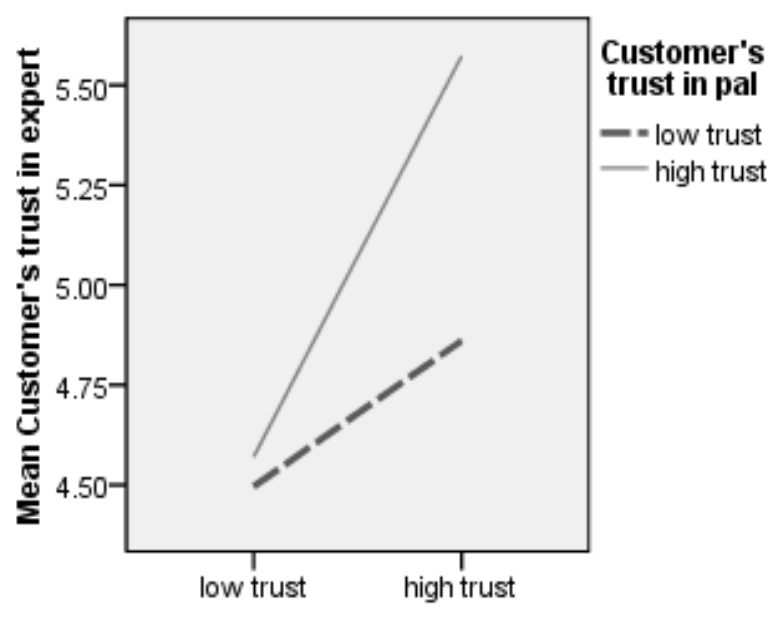

Pal's trust in expert

FIGURE 7: INTERACTION EFFECT "PAL'S TRUST IN EXPERT" * “CUSTOMER'S TRUST IN PAL"

Finally, it was found that the customer's decision is influenced by the level of trust felt towards the online human expert. In this study, a customer would more likely invest the money in a product proposed by the expert when he or she trusted in him, rather than in an alternative, risk-free product which was not presented by the financial expert but for which the customer had received neutral information beforehand. This is line with hypothesis 5.

Control variables: The personality trait of extraversion has no effect on physical presence ( $p>.1)$. Both financial self-efficacy and risk aversion are significantly and negatively related to the investment decision (FSE: $\beta=-$ $.191, p=.005$; risk aversion: $=-.344, p=.0001)$.

Model fit: While there is no single goodness-of-fit measure, the $R^{2}$ values of the endogenous constructs provide an indication on how much variance can be explained with the model. Cohen (Cohen 1988) categorizes $R^{2}$ effect sizes into small (>0.02), medium (>0.13) and large $(>0.26)$. According to this categorization, the effects of trust (0.423) and investment decision (0.379) are large, and physical presence $(0.086)$ has a small $R^{2}$. 


\begin{tabular}{|l|r|r|}
\hline & $\begin{array}{r}\text { AVE / } \\
\text { commu- } \\
\text { nality }\end{array}$ & $\mathbf{R}^{2}$ \\
\hline PP & 0.777 & 0.086 \\
Customer's trust in pal & 0.681 & $0^{*}$ \\
Pal's trust in expert & 0.786 & $0^{*}$ \\
Pal's trust in e *ustomer's trust in pal & 0.372 & $0^{*}$ \\
Customer's trust in expert & 0.882 & 0.423 \\
Purchase decision & $1.000^{*}$ & 0.379 \\
\hline FSE & 0.752 & $0^{*}$ \\
Risk aversion & 0.667 & $0^{*}$ \\
Extraversion & 0.593 & $0^{*}$ \\
\hline & \multicolumn{2}{|c|}{0.296} \\
Average & 0.689 & 0.451 \\
\hline & $=\mathrm{V}(0.689 * 0.296)=$ \\
GoF & \multicolumn{2}{|c|}{0.451} \\
\hline
\end{tabular}

Note: Values marked with a $*$ are not included in the average.

TABLE 14: BASIS FOR CALCULATING THE GOODNESS-OF-FIT OF THE MODEL.

The global Goodness-of-Fit measure was calculated as the square root of the product of the average communality and the average $R^{2}$ (Tenenhaus et al. 2005). The results are presented in table 14 .

While the average communality is formed of all constructs in the model, the average $R^{2}$ is formed of the endogenous constructs only (Schepers et al. 2005). Cohen (1988) proposes that Goodness-of-Fit criteria for small, medium and large effect sizes are $0.1,0.25$ and 0.36 respectively. For the current model, the goodness of fit is 0.451 , indicating a good fit of the model to the data.

\subsubsection{Test for alternative explanations}

In order to identify whether the effects described were not in fact caused by the simple presence of a purchase pal but rather they were caused by trust of the pal in the online human expert, the second sample described on our methodology section is used to rule out this alternative explanation. Half of this sample included customers who had no purchase pals and thus participated in the conversation alone. The other half of the sample had a purchase pal, but this pal had not met the expert beforehand. A total of $\mathrm{n}=90$ participants were in either of the two conditions. 
The question at hand was whether the presence of a purchase pal leads to higher levels of

a) physical presence or

b) trust in the online human expert.

Therefore, an alternative model with direct links from pal (yes or no) to physical presence and trust was created. The analysis was performed with SmartPLS, following the same procedure as above both for scale validation and for the structural model. Results of the analysis are presented in Figure 8.

The results indicate that the mere presence of a purchase pal does not significantly influence physical presence or trust. Therefore, we rule out physical presence of a purchase pal as a rival explanation for our results. Please note that the relationships between physical presence, trust and investment decision (as well as the control variable relationships) show the same patterns as the main sample for the study, providing additional empirical evidence supporting the relevant hypotheses proposed in the study.

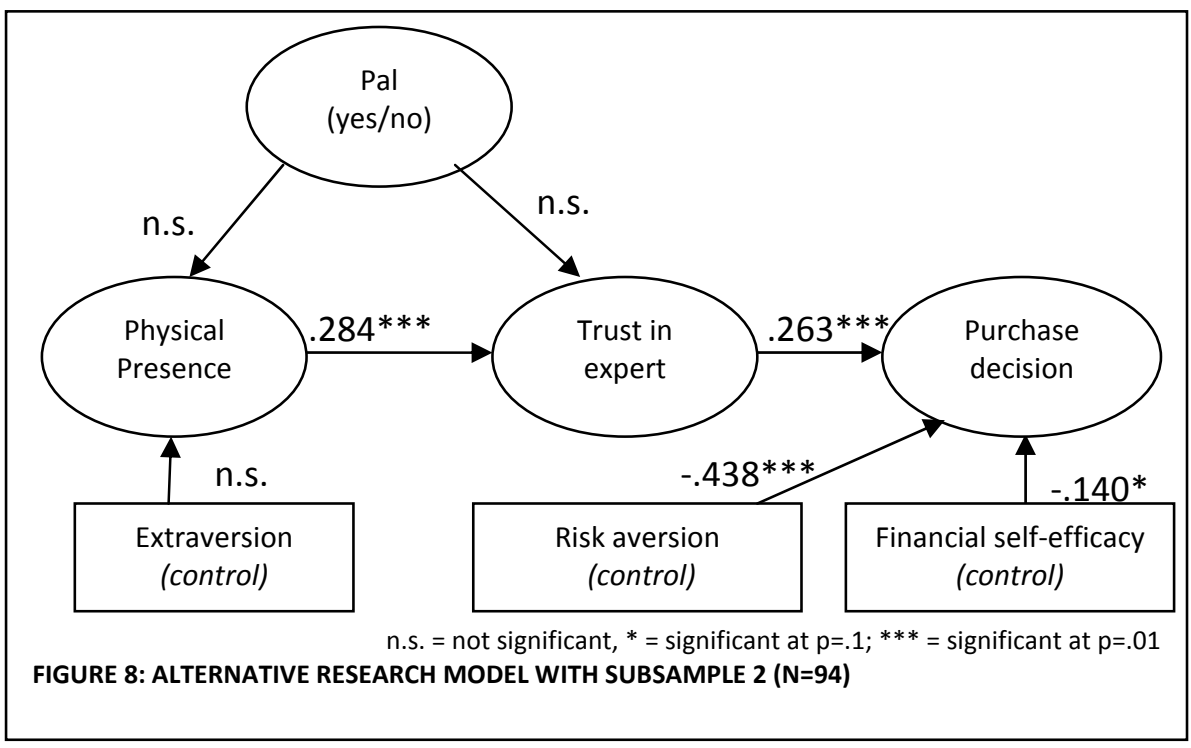




\subsubsection{Post-hoc test: Impact of purchase pal on customer's trust in the expert}

The results above indicate that initial trust is increased if the customer interaction with the financial expert occurs in the presence of a purchase pal whom the customer trusts AND the pal trusts the expert. However, would a pal's involvement be detrimental to the online consultation if the pal does not trust the expert or the customer does not trust the pal? That is, would it reduce the level of trust a customer would otherwise have in the expert in the absence of the pal?

Therefore, a couple of independent sample t-tests were executed, comparing customers who had no purchase pal $(n=42)$ with all customers who had a pal whom they did not trust $(n=81)$, or where the pal did not trust the expert $(n=73)$, or where both customer's trust in the pal and pal's trust in the expert were high $(n=32)$.

Customer who had not pal with them had an average trusting value in the expert of 4.89 (on a likert scale from 1-7). This value was not significantly different from customers who had a pal they did not trust in (mean $=4.67$ ). This indicates that having a pal who is not trustworthy to the customer is not detrimental to the customer's perceived trust in the online human expert. However, in case the customer trusts the pal but the pal does not trust the online human expert, a slightly negative effect on the customer's trust can be observed (mean=4.53, $\mathrm{p}<.05$ ). From a company perspective, thus, it is preferable if customers bring no purchase pal to bringing a purchase pal who does not trust in the online human expert. However, if both the customer's trust in the purchase pal and the pal's trust on the online human expert is high, there is a great positive impact in the customer's trust in the online human expert (mean $=5.57, \mathrm{p}<0.001$ ).

\subsubsection{Limitations}

Before we discuss the implications of the study, we need to acknowledge some of the limitations. The experimental setup was designed to be as realistic as possible to the subjects to reduce experimental artefacts. The fact that customers had to invest "real" money, the original newspaper and the payment which was calculated four weeks after the end of the experiment 
based on real performance created experimental realism with the subjects. Several subjects asked the expert or the experimenters after the sessions whether the financial experts were paid for selling the funds and whether the experts would invest the money in reality. However, there may be limitations to mundane realism (that is, whether the experiment resembles a real world situation) because the financial experts used in this experiment were not real financial advisors. They were master students majoring in finance, having experience with and passion for financial products. Additionally, they received a sales training and detailed product information in the investment funds. Having trained experts enabled the researchers to control the experts more than that had been the case in a field setting. Second, the "friends" who had to sign up together for this study may not always have been real friends but rather study colleagues who knew each other. Therefore, customers may have trusted these pals less than they may trust a close friend. However, this was intentional to increase the variability in trust and enables us to conclude that trust in the pal matters for trust transfer.

Finally, the use of students as subjects sometimes gives rise to concerns on external validity of the experiment. However, research on student surrogates shows that students make very similar investment decisions as accounting specialists (Liyanarachchi et al. 2005). Furthermore, there is no theoretical reason to believe that trust transfer occurs in a different manner in this sample. Nonetheless, the study should be replicated with other populations, with other technologies besides VoIP, and in other online settings (other than financial consultation) to assess generalizability of results.

\subsection{Discussion and Contributions to theory}

\subsubsection{Online trust transfer in the presence of trusted pals}

This chapter examines the role of purchase pals on trust transfer in a technology-mediated interaction between a customer and an online human expert. Though previous research has explored online review systems and (online) word of mouth, in which trust is transferred because someone else had an experience with a specific product or service, customers may be ac- 
companied by purchase pals who also experience the service for the first time. For offline shopping, the effect of a purchase pal's competence on susceptibility to being influenced has been demonstrated (Mangleburg et al. 2004), however, for online shopping we are not aware of any study which would focus on trust transfer in a joint shopping experience during a first-time interaction for both customer and friend.

By drawing upon prospect theory (Tversky et al. 1991; Tversky et al. 1992), social presence theory (Short et al. 1976) and the SIDE model (Tanis et al. 2003), we develop a theoretical model and find empirical support on how a purchase pal's trust in an online human expert influences (transfers to) customer's trust in the online human expert $\left(\mathrm{H}_{1}\right)$. This effect is moderated by the level of trust a customer has in the purchase pal such that a pal's trust in the online human expert is transferred only if the customer trusts the pal $\left(\mathrm{H}_{2}\right)$. Additionally we find that physical presence has a positive impact trust in the online human expert $\left(\mathrm{H}_{3}\right)$, and that a customer's trust in a pal has a positive impact on physical presence with the online human expert $\left(\mathrm{H}_{4}\right)$. Finally, we demonstrated that trust in the online human expert results in a purchase decision based on the advice the customer received from the online human expert $\left(\mathrm{H}_{5}\right)$.

One may argue that some of the effects found in this chapter may be allocated to the sheer presence of a purchase pal rather than in trust transfer per se. However, we ruled out this explanation by presenting an alternative research model. In the alternative model, customers who had a purchase pal during the interaction were compared to customers who participated individually in the online consultation. While all hypotheses and all control variables were found to be equally significant, thus confirming the findings from the main study, the presence of the purchase pal was not related to either physical presence or trust. ${ }^{2}$ We can therefore rule out that the presence of a purchase pal has impacted our findings.

\footnotetext{
${ }^{2}$ In the alternative model, the constructs of "pal's trust in the expert" and "customer's trust in pal" could not be included because there was obviously no such information available for customers without pal. Thus, all hypotheses related to either of these constructs could not be confirmed in the alternative model
} 
The study leads to a better theoretical understanding of how trust is transferred from a purchase pal to a customer in mediated interactions. While previous research on transferring trust or a positive reputation has focused on direct referrals such as word of mouth (Stuteville 1968; Villanueva et al. 2008) or direct links between companies or webpages (Stewart 2003), we find that trust can be transferred even if there are no direct link between the between the person who transfers trust (i.e., the purchase pal) and the online human expert. The reason why trust still is transferred is that in a cue-lean environment, any minor cue becomes very important. Thus, in the absence of cues available from the online human expert, the customer relies on the purchase pal to figure out, and the customer himself additionally evaluates whether or not to trust the pal who is with him. It is obviously easier to evaluate the purchase pal's trustworthiness, because one has previous knowledge and more cues from the purchase pal. This may be an unconscious process, because there is no rational as to why one should rely on a purchase pal who has no more information. ${ }^{3}$

This study extends our understanding on trust transfer, in that some of the assumptions made (e.g. a pal having to know the online human expert or product) are not required for trust to be transferred. These findings enable researchers to understand the process of trust-transfer in a wider range of situations.

\subsubsection{Managerial implications}

Acquiring new customers is an important aspect of organizational growth. As such, managers are confronted with finding new ways of acquiring customers to enrich their portfolio of customer acquisition methods. While many companies have implemented referral systems in which customers can persuade a friend to do business with a company in return for loyalty points or cash, few efforts have been made to explore alternative ways of

\footnotetext{
${ }^{3}$ We also tested whether or not a previous offline meeting of the online human expert and the purchase pal had an impact on the trust transfer, and arranged an offline meeting for $50 \%$ of the purchase pals. We found that even though the customer was aware that the friend had met the online human expert, this meeting did not affect any of the constructs used in this study. Thus, it is the trust one has in the purchase pal, rather than rationale that a purchase pal has or has not more information.
} 
gaining new customers' trust. We propose an additional way in which companies can benefit from trust transfer towards new customers.

Our research shows that customers are more likely to trust an online human expert (e.g. financial advisor) if they are accompanied by a purchase pal who trusts the online human expert even if the purchase pal has no prior experience with the online human expert. This sheds new light on customer referral programs. Companies may reward their existing customers when they refer a new customer (whom they are friends with, thus who consider each other to be trustworthy) and agree to have the first consultation session together with him or her. This way, trust may get transferred more easily from the existing customer, who serves as a purchase pal, to the new customer.

While our research shows that trust transfers even if the purchase pal has no prior experience with the online human expert, it is difficult to predict whether a purchase pal without prior experience will indeed trust the online human expert upon his or her first interaction. Therefore, advising dyads where both have no prior experience with the online human expert bears the risk that the purchase pal transfers low levels of trust to a potential new customer. But on the other hand, there is the chance that a purchase pal who trusts in the online human expert on first sight may increase the customer's trust in the online human expert. Therefore, companies who actively encourage customers to bring a friend or their spouse to join them in their first interaction need to be aware that this is a double-edged sword, which may increase the customers trust, but may also reduce the level of trust the customer experiences compared to being advised in a "normal" online consultation without purchase pal.

Offering joint consultations requires additional tools and changes in a company's business procedures. First of all, online human experts need to be prepared to speak with two people at the same time, and may need to keep two people actively involved in a conversation. Second, companies need to think of rewards they want to offer to new dyads or an existing customer who brings in a purchase pal. These new programs need to be integrated with existing customer acquisition programs and promoted adequately. And 
third, additional tools may be necessary to enable the online human expert's communication with a dyad. These may be software changes to link a customer's data set with the one of another person (e.g. purchase pal), or new software to enable communication with a group where expert, customer and purchase pal are all in different locations.

\subsubsection{Future Research}

Several directions for future research emerge from our study. First, customer and purchase pal were placed in the same room using the same computer during this advice session. Future researchers may attempt to replicate these findings with a purchase pal who interacts with the customer from a remote location. While there is no reason to expect that the customer will have less trust in the purchase pal who is at a remote location, it may be more difficult to experience the trust transfer.

Second, this research only investigated the use of audio communication with the online human expert. Based on the SIDE model (Social Identity model of Deindividuation Effects) by Tanis and Postmes (2003) and the Social Information Processing Theory (Salancik et al. 1978), we know that in the absence of media cues, people grasp at a straw and tend to (over) interpret cues they get from elsewhere, such as the impression their purchase pal has on the online human expert. Thus, this condition seems to facilitate the trust transfer process. The impact of trust transfer may be different if the contact towards the online human expert is made via a "richer" medium such as video call, and the purchase pal can only be contacted with an equally rich or even "poorer" medium. The question arises whether the purchase pal's impact can be substituted for cues that the customer receives from the online human expert through richer media. Following the SIDE argumentation, there should be less doubt about the online human expert if more cues are transmitted, thus there is less potential to over-interpret cues transferred by the purchase pal. However, based on the Social Information processing Theory, other people's attitudes always influence, thus a pal's perception on trust should influence the customer even if he has more cues about the online human expert. In that sense, future research should investigate which of these theories is more appropriate to explain trust transfer under rich media conditions. 
Third, the trust transfer process investigated in this study serves as an additional mechanism portfolio managers can use to start trustful relationships with new customers. This study shows that participating in a conversation with a trustworthy purchase pal will be beneficial to the customer's level of initial trust if the pal trusts the online human expert. However, we cannot compare the effects of trust transfer during joint sessions to other types of customers' referrals in which a friend gives reference but does not join a customer's first interaction. Research on purchase pals has proposed that having a pal who helps with a purchase decision may help to gain certain benefits for certain customers (Kiecker et al. 1994). Future studies should examine the relative effectiveness of this kind of referrals compared to other methods, and conditions under which each of these is appropriate. It is currently unknown whether the nature of the customer, or the nature of the product, or whether other contingencies determine the effectiveness of this trust transfer process compared to other mechanisms.

Finally, this research did not focus on the detailed process of trust transfer. We do not know whether customer and purchase pal spoke directly about the trustworthiness of the online expert or whether trust was conveyed in more subtle and maybe non-verbal terms. Future research may thus explore the details on this trust transfer. 


\subsection{Appendix A - questionnaire items}

(Items with a * are reversely coded)

\section{Physical Presence}

1. When we started the conversation, it felt as if the advisor had entered the room.

2. I forgot the advisor was not in the same room as I

3. I felt as if the advisor and I were located in the same room.

4. When we ended the conversation, it felt as if the advisor had left the room.

Trusting beliefs (McKnight et al. 2002)

Benevolence of the advisor

1. I believe that the advisor acts in my best interest.

2. If I required help, the advisor would do his best to help me.

3. The advisor is interested in my well-being, not just in his own.

4. The advisor cares for me (Ganesan 1994; Ganesan et al. 1997)

Competence of the advisor

1. The advisor is competent and effective in providing financial advice.

2. The advisor performs his role of giving financial advice very well.

3. Overall, the advisor is a capable and proficient financial advisor.

4. In general, the advisor is very knowledgeable about financial products. Integrity of the advisor

1. The advisor is truthful in his dealings with me.

2. I would characterize the advisor as honest.

3. The advisor would keep his commitments.

4. The advisor is sincere and genuine.

Benevolence, competence and integrity of the friend

As above, but the words "the advisor" were replaced with "my friend".

The friend's perception of benevolence, competence and integrity of the advisor For benevolence and competence, the words "me" or "my" where replaced with "my friend" or "my friend's".

Competence was measured as above, with no changes in wording.

Big Five Inventory - Extraversion (Benet-Martinez et al. 1998)

1. I am talkative

2. I am outgoing, sociable

3. I tend to be quiet*

4. I am reserved* 
Financial self-efficacy (Bryant et al. 2006)

1. I am good at managing my money

2. I am satisfied with my ability to manage my money

3. Compared to other people, I think I do pretty well at making financial decisions - excluded in the analysis

4. I am pretty skilled at making financial decisions - excluded in the analysis

5. I budget my money very well

6. I use my money very carefully

Risk aversion (Kapteyn et al. 2002)

1. I am willing to run the risk of losing money if there is also a chance that I will make money*

2. I find it more important to invest safely and to get a guaranteed return than to take risks in order to possibly get a higher return

3. If I believe an investment will vary profit, I am willing to borrow money for it* - excluded in the analysis

4. Investing in stocks is something I would not do, since it is too risky

5. I want to be sure that my investments are safe

6. I am increasingly convinced that I need to take more financial risks if I wanto to improve my financial position* - excluded in the analysis

\section{Manipulation check}

Did your friend speak to the advisor today while you were waiting for the study to begin?
a) Yes, before the Skype conversation started
b) No, they did not speak with each other
c) I don't know 


\subsection{Appendix B - experimental scripts and handouts}

\subsubsection{Advisors' script}

Hello, can you hear me?

Ok perfect. My name is xxx, (I just had the pleasure to meet your friend $x x x$ ). I am a $\left(3^{\text {rd }} 4^{\text {th }}\right)$ year Bachelor / Master student, and my specialization is finance. I am very interested in financial markets and investment products. This is why I would like to advice you on this topic.

- In order to give you an advice, I would first like to know how much money you want to invest? (500 EUR)

- And are you willing to take some risks to get more return, or do you prefer relatively save investments?

OK, for this amount I think that a bond funds is ideal, because there are funds available that have a very high performance (and are save at the same time).

\section{Have you experience with investments funds?}

No - that is no problem, I will start to explain from the basics then $\rightarrow$ A

Yes - ok, then you know what I am talking about $\rightarrow$ A

\section{A) Introduction capital market and funds}

Well, as you know, you can save money in a savings account in a bank for a fixed interest rate. But most people want to achieve a higher interest on their savings. In investment funds, you can get very high interest rates, and you can access your money whenever you like.

Well the capital market is known to outperform bank savings. That means, in the long run, your money will always have a higher rent on the capital market than if you put your money in the savings account.

For example, it is easily possible to earn on the capital market in 1 month more money than you would earn in a bank account in 2 years.

But there is no guarantee on such a performance. So it is important to understand the product, before you take a decision if you want to invest.

\section{Do you know what a bond fund is?}

Yes: Ok, then I will present you one fund that is performing excellent at the moment $\rightarrow$ C 
No: OK, then I will explain it to you $\rightarrow$ B

\section{B) Explanation Bond and bond funds}

A bond is a long-term debt of a company or government, which is sold to an investor and can be traded on the capital market. That means, if a company or government needs money, it can issue a bond. The company or government promises to pay a certain rent each year, and at the end of for example 30 years, the company pays the money back. This bond can be traded on the capital market. That means, you can buy the right that a certain company or government pays interest to you and that the company will pay back the total credit at the end of the 30 years.

Since these bonds are traded on capital markets, the prices do change based on demand and offer, or they change if the interest rate on the market changes, or if the economic situation of a country changes, but they are a lot more stable than share prices.

But should the company get bankrupt, you have a problem, because they cannot pay back the money they promised.

An investments funds that invests in bonds has bought several different bonds. So in case one company gets bankrupt, you still have the interest from all the other bonds in the funds. So a bond funds is a way to reduce the risk that the company gets bankrupt.

\section{Do you have any more questions what a bond fund is?}

No - ok, then I will introduce you one fund that I would recommend to you.

\section{C) Introduction Thames River Performance}

I have prepared some materials for you. In the folder on your table you will find screenshots from the webpage of the Financial Times with the performance of the Thames River Euro Global bond fund. This is one bond fund, which performs very high and still has a very low level of risk.

If you look at the end of the page, there is a section "cumulative performance". Did you find that? Well there is information how much the fund has performed in the past. For example, during the last month, the fund has performed 13.74 EUR! That means, if you had invested 500 EUR one month ago, you would have earned 68.70 EUR in one month! So nearly 70 EUR within 1 month! If you had invested in a bank account with $5 \%$ interest per year, you would need nearly 3 years to get this amount. 
But you have probably also heard of the financial crisis. If you have a look at the page titled "1 year performance", you can see what the financial crisis is doing. Have you found the page?

Well you can see 3 lines in the graph. The red line is the Thames River bond fund. The green line is the US government bonds. As you know, the dollar is week, and the US economy is struggling a lot, so this is why the US government bonds are not doing very well. And below, you can see a grey line, which is the company share values of the 100 top European blue chip companies (very big companies). They have made about $50 \%$ loss within 1 year.

\section{D) Rating and Risk}

So you see it is also possible to lose money on the capital market. But maybe you are wondering why this bond is not affected at all by the crisis.

Well, this fund invests mainly in bonds that are issued by Governmental institutions of European Countries (about 2/3), and the rest is invested in other highly developed countries (OECD countries - Organisation for Economic Cooperation and Development - highly developed countries). Most of these bonds are issued in Euros (over 70\%), so the impact of the weak dollar is also reduced. This explains the very good performance even though many companies suffer from financial crisis. This fund does not depend so much on banks, but on European governments.

Any financial product that is traded on the capital market has a different risk, so there are independent rating agencies that evaluate funds. So in the folder I prepared, you will find a page with Fund Rating. The Financial Times rated this fund as having a very low risk and a very high performance. Did you find this sheet?

Standard and Poors, which is one of the biggest rating agencies rated this fund with a double $A$.

\section{Are you familiar with the rating categories of Standard and Poors?}

No $\rightarrow E$

Yes $\rightarrow \mathrm{F}$

\section{E) Ratings}

Well Standard and Poor's evaluate companies and bonds on whether they are risky or not. They do NOT evaluate whether the performance is high or low. The best category is Triple A, and this grade is mainly given to governments in very stable countries. The Thames River Global bond fund holds $93 \%$ of bonds in this very best 
category. But they also have some bonds that are graded lower, so the overall rating is Double A. This is a very good rating and means that Standard and Poor's think that there is very little risk in this bond.

\section{F) Past performance}

If you have a look at the sheet called "1 year performance", you will see what the low risk means. Do you have this page open? The fund basically did not have any losses within 1 year. You can also see, that the performance is changing, so for example in September, the graph went down a bit but this was compensated with the high performance in the rest of the month. So it is not possible to predict how much money you can earn exactly with this fund, but is anyhow one of the safest options with the highest performance that exist currently on the capital market.

\section{G) Conclusion}

Well our time is nearly over. I hope I could give you an overview over this fund.

My recommendation is to invest in this fund, because financial times rated the fund with 5 out of 5 stars for performance, and standard and poor's rated this fund with AA as very save. The performance was nearly $14 \%$ in the last month, and that is better than the best European companies have performed with their share prices.

\section{Do you have any further questions?}

Ok, then you will now be able to invest your money into this fund. You will receive a link with the questionnaire right now.

Thank you for coming, have a nice day.

Bye.

\section{Answers to the financial crises:}

The fund does not invest in real estate or shares, only governmental bonds are included.

The fund operates in Euros, and the majority of the bonds is issued in Euros. Therefore, the impact of a weak dollar is reduced

Well, as you can see, the crisis started like 6 months ago, and the funds still performing very well 


\subsubsection{Instructions customers}

You just paid 2 EUR to participate in this study. These 2 EUR represent an investment of 500 EUR.

Your task is to invest this money during the next 4 weeks. After 4 weeks, we will pay you the interest that an investment of 500 EUR would have earned. We also will refund the 2 EUR you paid, but only if you did not make a loss with you investment.

There are 2 possibilities to invest.

\section{A) Bank deposit}

One is a deposit at the Economy Bank. The Economy bank is part of the BNP Paribas, which is one of the biggest financial institutions in the world. The Economy Bank is subject to the Dutch Deposit Guarantee Scheme, which means that the first 100.000 EUR investment per customer will be guaranteed, even if the bank should experience financial problems. That means that should the Economy Bank be affected from the current financial crisis during the next 4 weeks, this deposit is safe. The current interest on an investment for 1 month is $5 \%$ per year. For a 500 EUR investment, you would receive 2.08EUR interest after 4 weeks.

If you decide to invest into the deposit, you will receive your 2 EUR investment plus 2.08 EUR interest 4 weeks after this experiment is over.

B) Investment fund

The alternative is to invest into an investment fund. For this investment, you will have the opportunity to speak with a financial advisor. This conversation will take place with SKYPE, and your friend will be with you during this session. You are allowed to ask for his advice or opinion during the session, as long as you speak in English.

Investment funds represent company shares or bonds which are traded on a daily basis on the capital market. The prices go up and down, depending on demand and offer, on the currency exchange rate and the interest rate, on company performance and expectations of future growth or economic development of a company, industry or country.

The current financial crisis has caused that share prices worldwide have gone down by $40 \%$ on average - but that does not mean that they lose value every single day. 
There may be days or even weeks in which there are no losses occurring. In many Germany the Netherlands, UK and other countries, banks have crashed or would have collapsed without the support of their governments.

Iceland is the first country which is (nearly) bankrupt due to the crisis. The head of the International monetary funds IMF, Dominique Strauss-Kahn, expects that the economy recovers only at the end of 2009. At the moment, many countries are preparing for a recession.

If you decide to invest into the investment funds, you will receive the increase of value that 500 EUR would have earned after 4 weeks (with a maximum of 8 EUR in case the increase in value is higher than that). In case the fund made a loss, you will not receive anything. The 2 EUR will only be returned to you in case you did not make a loss with the investment fund.

Please have a look at the screenshot of the Economy bank for the offer of the deposit, and at the Financial times webpage for and overview over some UK-based European funds.

\subsubsection{Instructions friends}

Your friend just paid 2 EUR to participate in this study. These 2 EUR represent an investment of 500 EUR.

Your task is to help your friend to take a decision on how to invest this money during the next 4 weeks. After 4 weeks, we will pay him/her the interest that an investment of 500 EUR would have earned. We also will refund the 2 EUR he/she paid, but only if he/she did not make a loss with the investment.

You will receive 2 EUR for participating in this study. Furthermore, you will receive $25 \%$ of your friend's payment, which is specified below.

There are 2 possibilities to invest.

\section{A) Bank deposit}

One is a deposit at the Economy Bank. The Economy bank is part of the BNP Paribas, which is one of the biggest financial institutions in the world. The Economy Bank is subject to the Dutch Deposit Guarantee Scheme, which means that the first 100.000 EUR investment per customer will be guaranteed, even if the bank should experience financial problems. That means that should the Economy Bank be affected from the current financial crisis during the next 4 weeks, this deposit is safe. 
The current interest on an investment for 1 month is $5 \%$ per year. For a 500 EUR investment, he /she would receive 2.08EUR interest after 4 weeks.

If he/she decides to invest into the deposit, he/she will receive the 2 EUR investment that he/she paid plus 2.08 EUR interest 4 weeks after this experiment is over. You will receive 52cts in addition to your payment of EUR 2.

B) Investment fund

The alternative is to invest into an investment fund. For this investment, your friend will have the opportunity to speak with a financial advisor. This conversation will take place with SKYPE, and you will be with your friend during this session. You are allowed to ask questions during the sessions and give advice to your friend, as long as you speak in English.

Investment funds represent company shares or bonds which are traded on a daily basis on the capital market. The prices go up and down, depending on demand and offer, on the currency exchange rate and the interest rate, on company performance and expectations of future growth or economic development of a company, industry or country.

The current financial crisis has caused that share prices worldwide have gone down by $40 \%$ on average - but that does not mean that they lose value every single day. There may be days or even weeks in which there are no losses occurring. In many Germany the Netherlands, UK and other countries, banks have crashed or would have collapsed without the support of their governments.

Iceland is the first country which is (nearly) bankrupt due to the crisis. The head of the International monetary funds IMF, Dominique Strauss-Kahn, expects that the economy recovers only at the end of 2009. At the moment, many countries are preparing for a recession.

If he/she decides to invest into the investment funds, he/she will receive the increase of value that 500 EUR would have earned after 4 weeks (with a maximum of 8 EUR in case the increase in value is higher than that). In case the fund made a loss, he/she will not receive anything. The 2 EUR which represent his/her investment will only be returned in case he/she did not make a loss with the investment fund. You will receive $25 \%$ of the increase in value ( $\max 25 \%$ of 8 EUR $=\mathbf{2}$ EUR), or nothing in case the fund makes a loss after 4 weeks. 
Please have a look at the screenshot of the Economy bank for the offer of the deposit, and at the Financial times webpage for and overview over some UK-based European funds. 
Handout 1 - part of friends' information

\section{Top 10 European funds (page 1/2)}

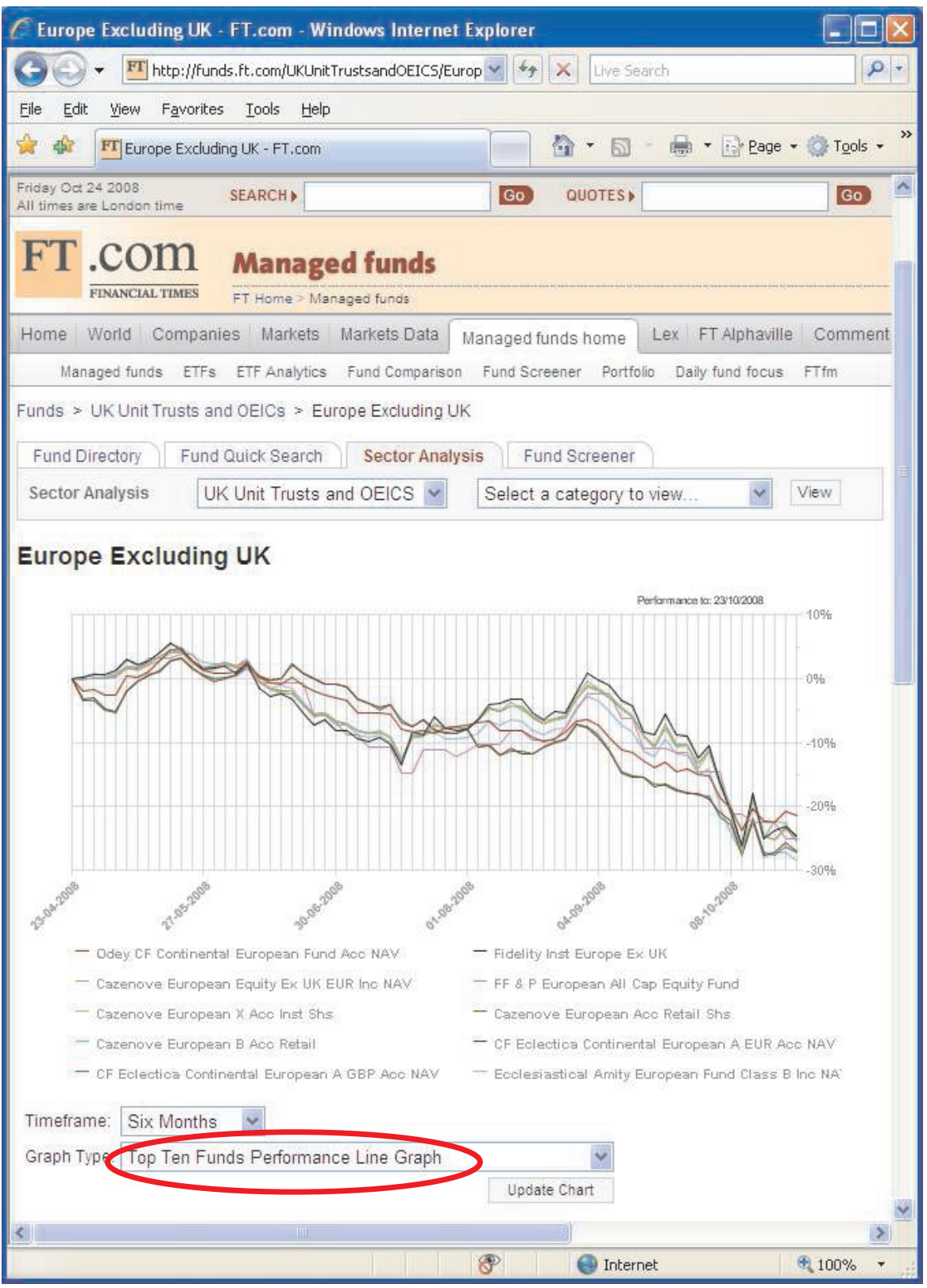




\section{Top 10 European funds (page 2/2)}

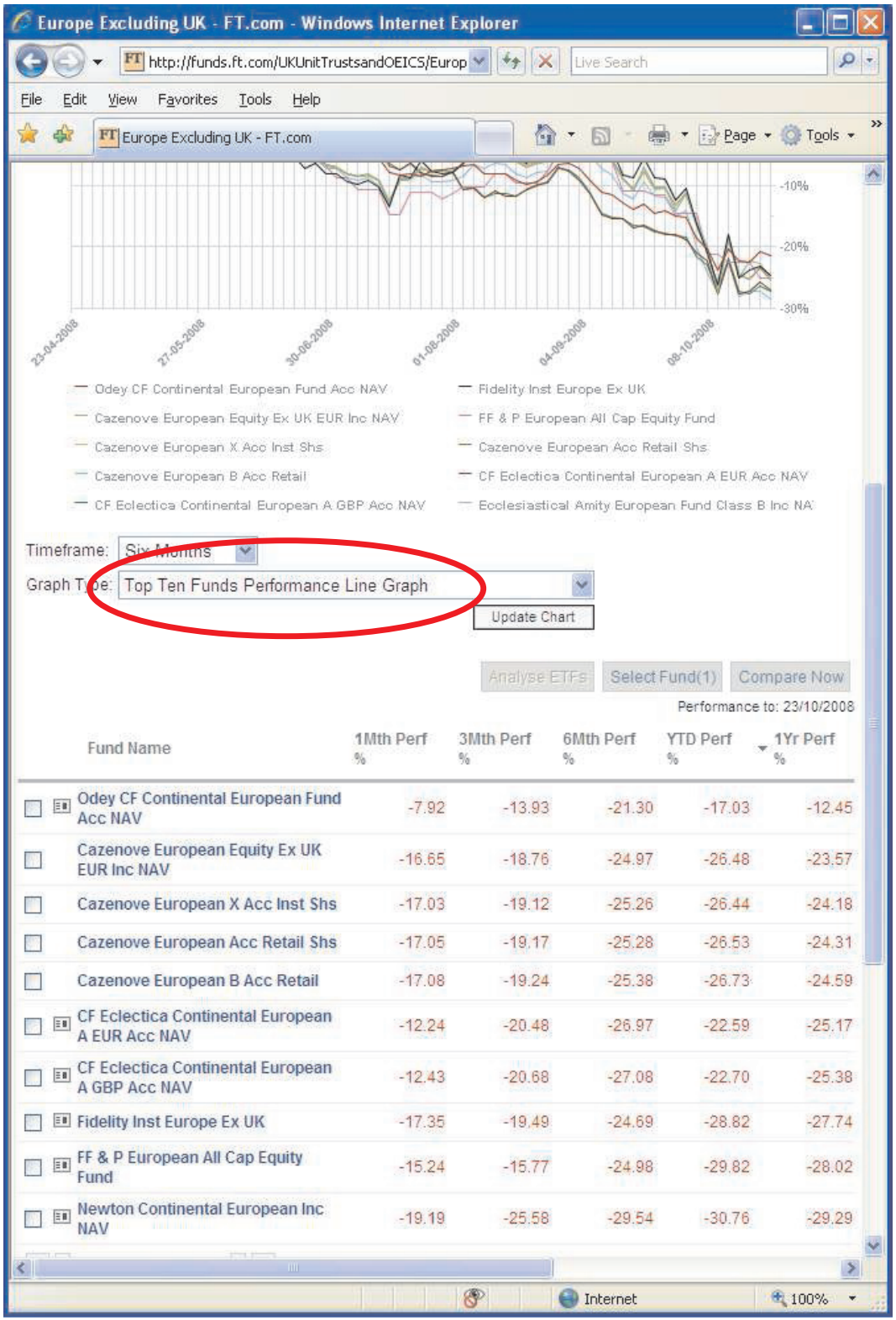




\section{Some ABN Amro funds}

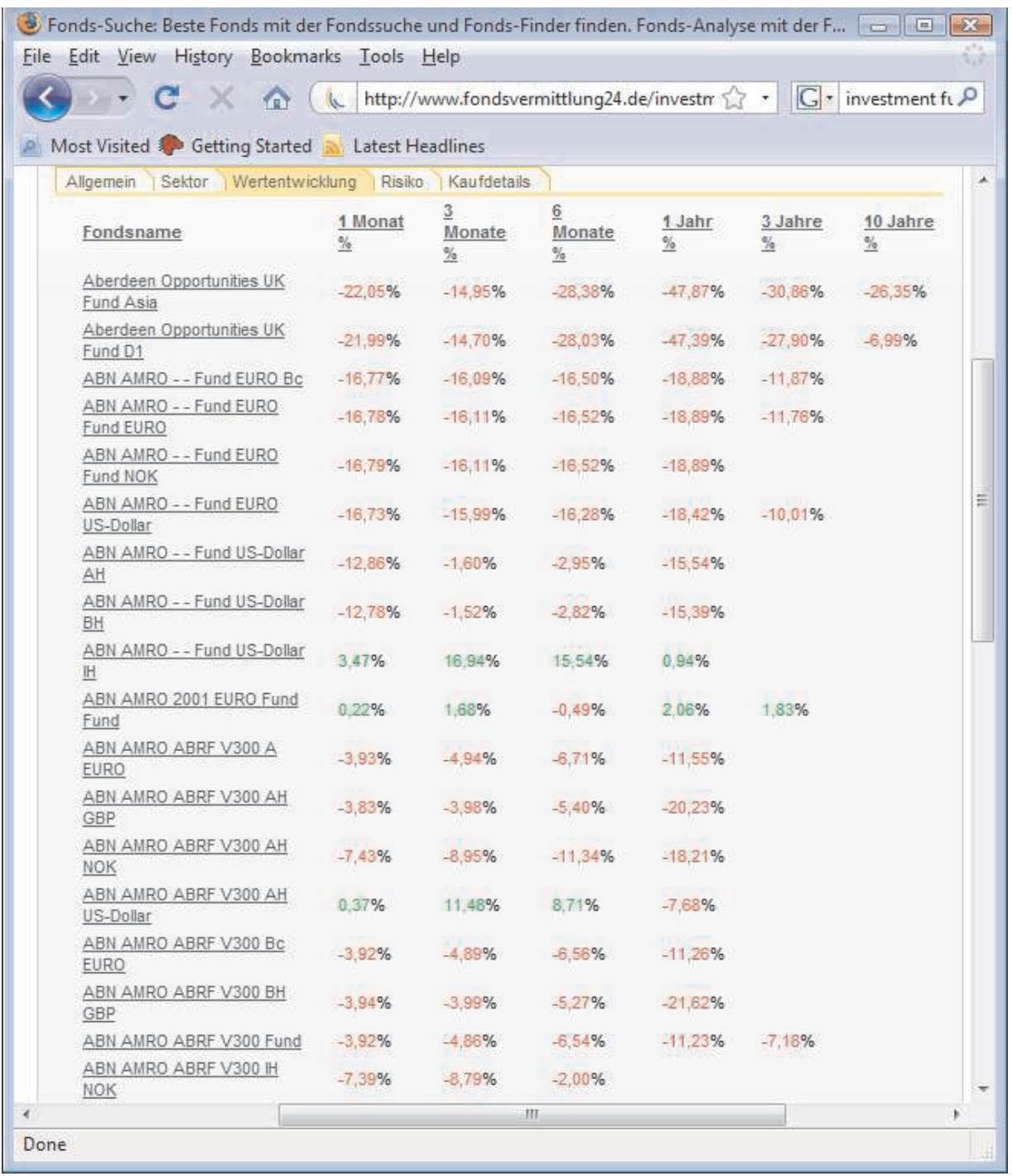




\section{Some Deutsche Bank funds}

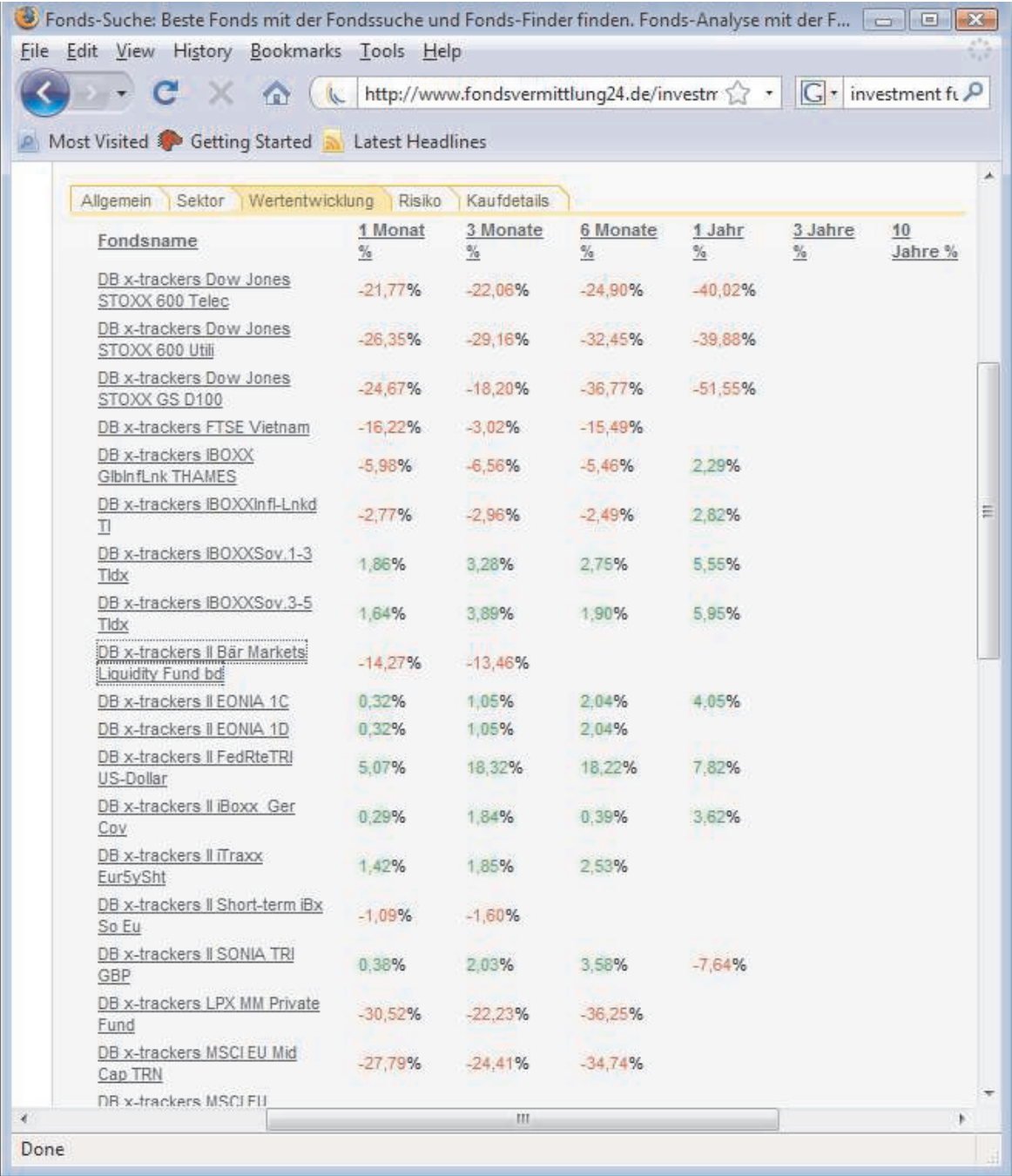




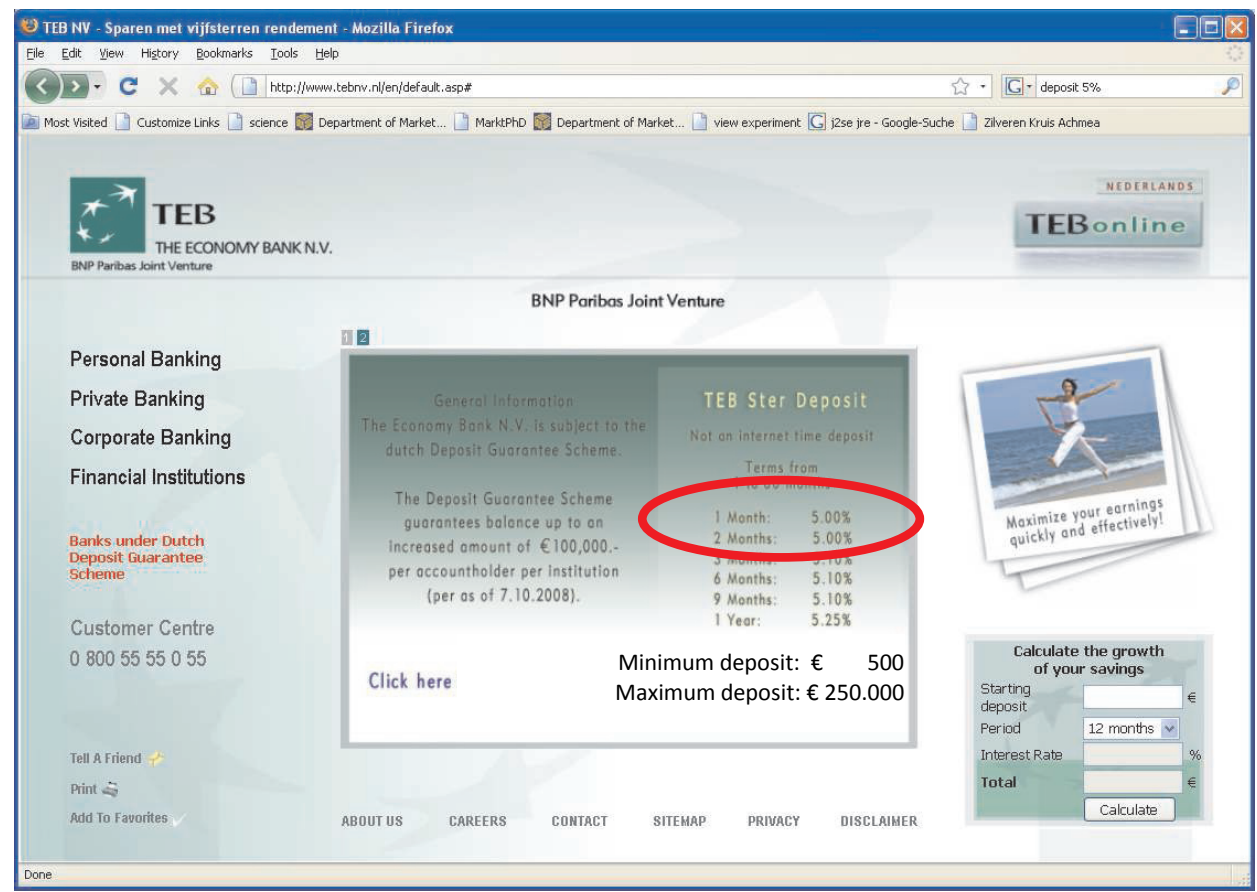

Calculation of interest for the Economy Bank Deposit

\begin{tabular}{|c|c|c|c|}
\hline $\begin{array}{c}\text { Investment } \\
\text { (capital) }\end{array}$ & $\begin{array}{c}\text { Interest rate } \\
\text { per year }\end{array}$ & $\begin{array}{c}\text { Interest } \\
\text { earned per } \\
\text { year }\end{array}$ & $\begin{array}{c}\text { Interest } \\
\text { earned per } \\
\text { month }\end{array}$ \\
\hline $500 €$ & $5 \%$ & $25 €$ & $2.08 €$ \\
\hline & & & \\
\hline
\end{tabular}


Handout 3 - information for session with expert

\section{1 month performance}

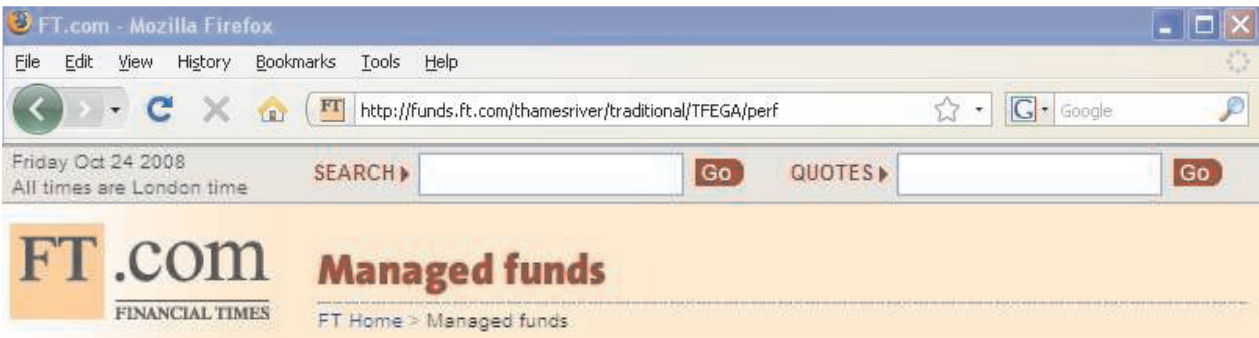

Thames River Euro Global Bd EUR Acc NAV

\begin{tabular}{l|l|l|l|l|l|l} 
Summary & Performance & Risk & History & Ratings & News & Assets \& Holdings
\end{tabular}

Fund Performance and Charting

At a glance

Cumulative and Discrete Performance

Charting Information

Performance From: $23-09-2008$ to: $23-10-2008$

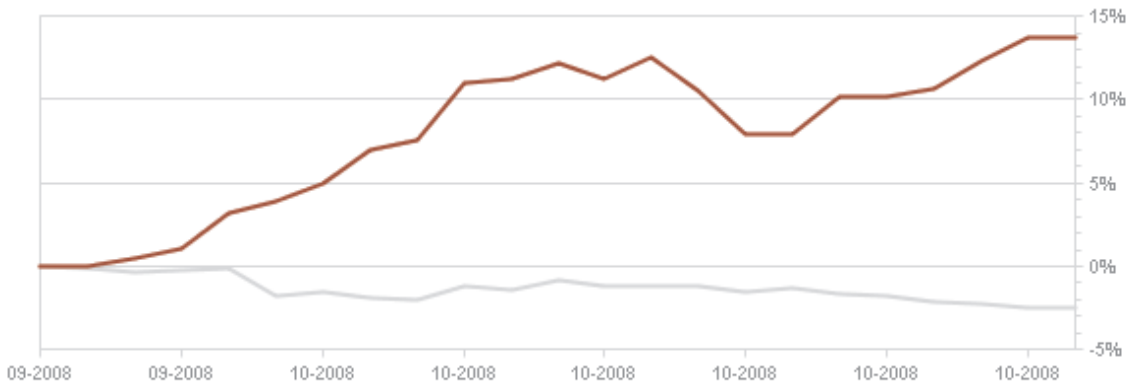

- Thames River Euro Global Bd EUR Aco NAV

- ML Global Gov Bond Index II 1-3 YRS(USD] 


\section{3 month performance}

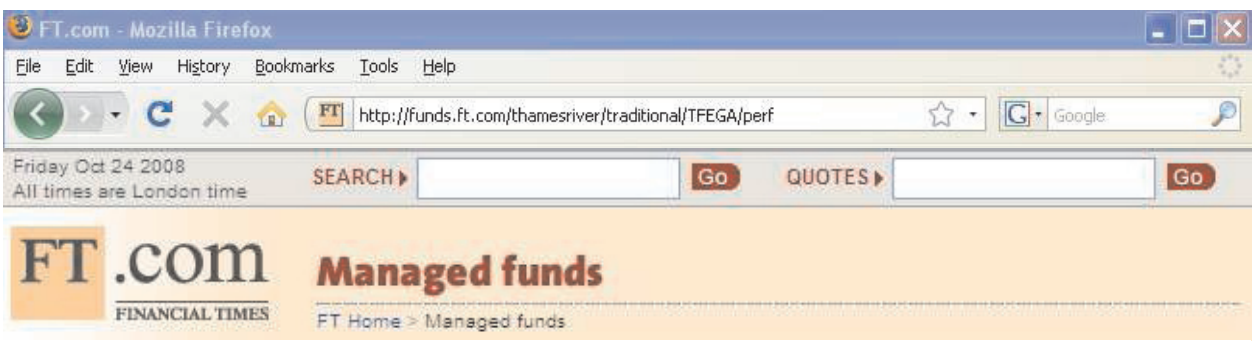

Thames River Euro Global Bd EUR Acc NAV

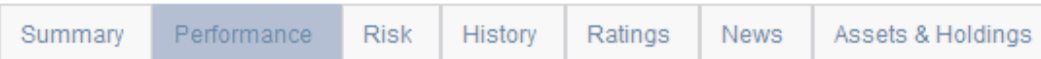

Fund Performance and Charting

At a glance

Cumulative and Discrete Performance

Charting Information

Performance From: 23-07-2008 to: 23-10-2008

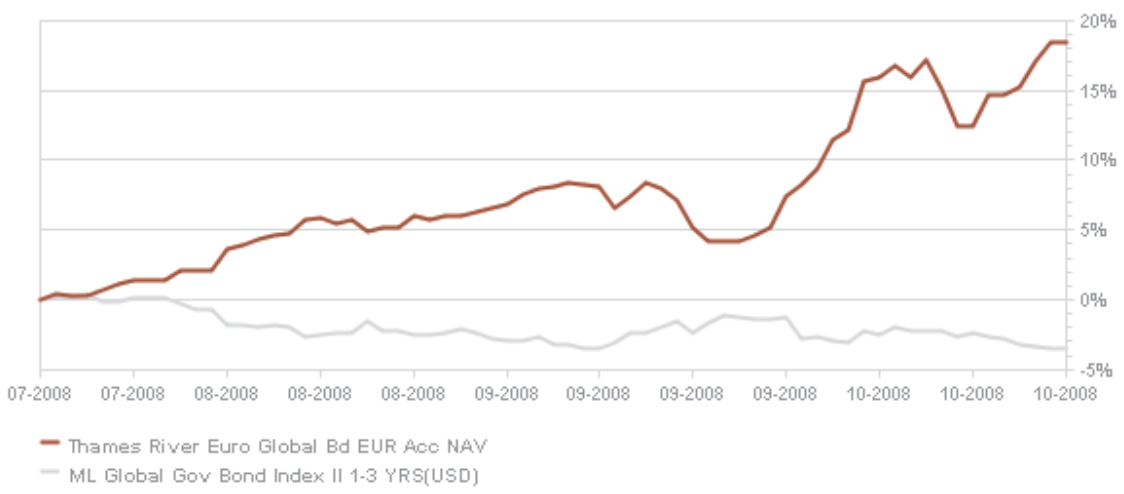

\section{$\%$ Return}

Thames River Euro Global Bd EUR Acc NAV

1 MTD 3 MTD 6 MTD 1 Year 3 Year 5 Year YTD

$+13.74+18.47+16.56+18.13+19.75 \quad-+16.22$


Handout 3 - information for session with expert

\section{1 year performance}

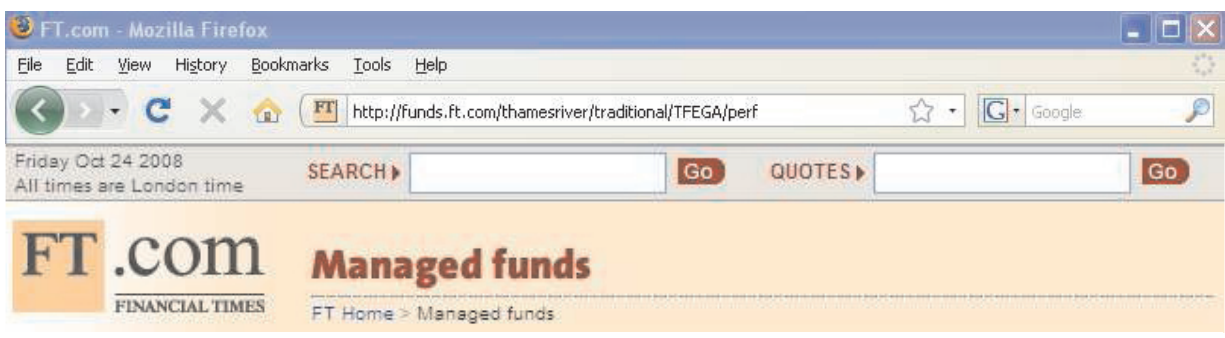

\section{Thames River Euro Global Bd EUR Acc NAV}

\begin{tabular}{|l|l|l|l|l|l|l}
\hline Summary & Performance & Risk & History & Ratings & News & Assets \& Holdings \\
\hline
\end{tabular}

Fund Performance and Charting

At a glance

Cumulative and Discrete Performance

Performance From: $23-10-2007$ to: $23-10-2008$

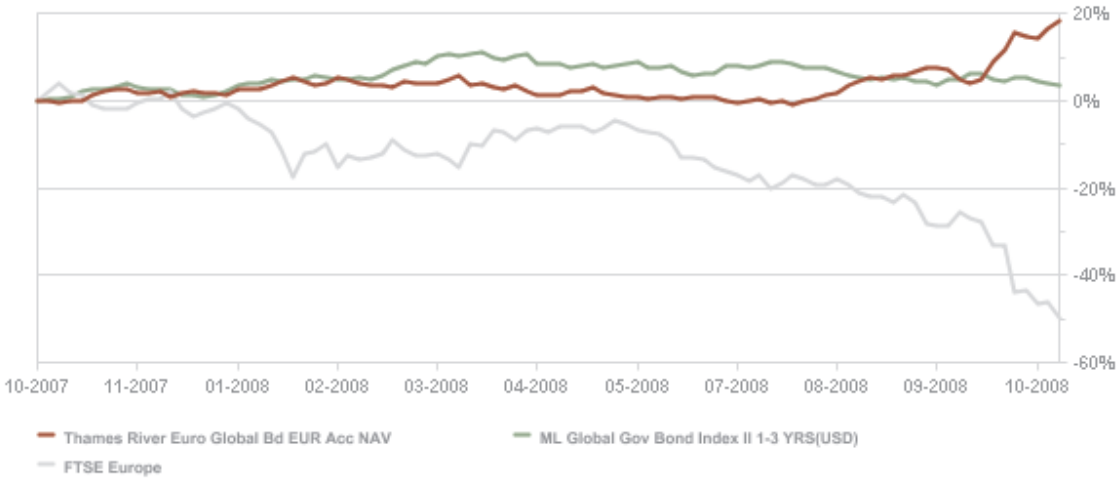

CUMULATIVE PERFORMANCE

Performance to: 23/10/2008

$\%$ Return

Thames River Euro Global Bd EUR Acc NAV
1 MTD 3 MTD 6 MTD 1 Year 3 Year 5 Year $\quad$ YTD

$+13.74+18.47+16.56+18.13+19.75 \quad-+16.22$ 
Handout 3 - information for session with expert

(3) Thames River Euro Global Bd EUR Acc NAV - FT.com - Mozilla... $\square \square$ File Edit View History Bookmarks Iools Help
Di Most Visited $\square$ Customize Links $\square$ science 8 Department of Market... प MarktPhD "
FT Fund Ratings

FT Risk Profile

Risk Profile Risk Level

Euro International

very low

FT Performance

FT 3.5YR adjusted

Charge Rating

$+9.38 \%$

$\square \square \square \square \square$

October 2008

\section{STANDARD \&POOR'S}

$<$ 

Chapter 4

\section{Conclusion}




\subsection{Synopsis}

Customers increasingly use the internet to communicate and to do business online. They require customized, innovative services and convenient ways to interact with companies anytime and anywhere. These interactions of customers and companies in the internet are called online service encounters. Service encounters are critical for customers as well as for companies, because they determine whether or not a customer will buy and consequently be satisfied and return or engage in positive word-of-mouth.

Albeit customers and companies do not meet physically during an online service encounter, they may experience a sense of closeness, a feeling that has been described as social presence by researchers. This social presence is a known antecedent to trust, and trust is crucial when customers take a purchase decision based on an online service encounter.

The research of this dissertation was driven by the importance customer put on personal advice when engaging in a service encounter versus company's interest to reduce expensive face-to-face meetings. Advising customers personally via an online human expert is thus a way to combine the benefits of human contact with the advantages of cost- and time-efficient advice via the internet.

This dissertation started with an overview on the major concepts and theories used or tested in the studies: social presence theory, trust, adaptive structuration theory, the SIDE model (Social Identity model of Deindividuation Effects) and prospect theory. Adaptive Structuration Theory was used to extract new antecedents to trust and social presence that had not been studied before. The SIDE model was used to explain why these factors may be relevant, and prospect theory was applied to understand a specific case of inconsistent clues.

We extended these arguments and studied online encounters between a customer and an online human expert in different settings. Thereby we investigated several factors that are under a company's influence to exploit the maximum benefit for both customers and companies. Throughout this dissertation, we were guided by the principal of contributing value to the 
different theories presented in the introduction, as well as to managers by specifically focusing on factors that can be influenced by companies and are theoretically meaningful.

In chapter 1, we specified that the overall aim of this dissertation was to uncover antecedents of customer trust in initial encounters with online human experts and a given medium in the context of complex services. Additionally we formulated specific objectives for the individual chapters. In chapter 2, the focus was on different interaction styles, the interaction history and the process of social presence as antecedents to customer trust. Chapter 3 dealt with the effect of a purchase pal and the conditions under which trust can be transferred within a triad.

\begin{tabular}{|l|l|l|}
\hline Subject & Chapter $\mathbf{2}$ & Chapter $\mathbf{3}$ \\
\hline Theoretical Background & $\begin{array}{l}\text { How to create social } \\
\text { presence and trust? }\end{array}$ & $\begin{array}{l}\text { Can trust be trans- } \\
\text { ferred? }\end{array}$ \\
& $\begin{array}{l}\text { theory, social presence } \\
\text { theory }\end{array}$ & $\begin{array}{l}\text { Trust transference, } \\
\text { prospect theory, social } \\
\text { presence theory, SIDE } \\
\text { model }\end{array}$ \\
\hline Data & Experiment & Experiment \\
\hline Interaction media & Video call via Skype & Voice call via Skype \\
\hline Interaction structure & $\begin{array}{l}\text { Dyad (customer and } \\
\text { online human expert) }\end{array}$ & $\begin{array}{l}\text { Triad (customer, pur- } \\
\text { chase pal and online } \\
\text { human expert) }\end{array}$ \\
\hline
\end{tabular}

TABLE 15: MAIN CHARACTERISTICS OF THE STUDIES

The studies used different theoretical backgrounds, media and set-ups. Table 15 summarizes the main characteristics of the research in this dissertation.

In this chapter, we will tie together the results of the chapters. First, the main conclusions of the chapters will be presented in relation to the objectives they addressed. Subsequently, an integrated perspective will be presented. This chapter will end with suggestions for further research. 


\subsection{Main conclusions of the chapters}

\subsubsection{Chapter 2}

The questions with respect to dyadic online service encounters between a customer and an online human expert were: 1) what are alternative ways to create social presence, specifically inspired by adaptive structuration theory, and 2) how can the process by which social presence leads to trust be described in detail? An adjunct question to the second objective was 3) how can social presence be defined and measured in the context of dyadic online encounters?

The last question was answered first by defining social presence as consisting of two dimensions, namely physical and emotional presence. These dimensions are different from conversational involvement, and a scale of four items is developed per dimension. With respect to the first question, we conclude that a prior face-to-face meeting of a customer and an expert enhances the level of physical presence the customer perceived when interacting with this expert online. Additionally, we conclude that the interaction style applied by the online human expert also leads to higher level of physical presence. The second question was answered by showing that physical presence increases emotional presence, emotional presence increases conversational involvement which subsequently leads to higher levels of trust.

This chapter contributes to theory by linking social presence theory to two new antecedents taken from adaptive structuration theory. Additionally the idea of a process inherent to adaptive structuration theory was extended to specifically investigate the process by which social presence is created. The findings of the chapters support the idea that group features such as interaction style and interaction history are a relevant source of structure that impact an interaction. Furthermore, the idea of interaction as a process was successfully replicated by identifying the process and elements of social presence. In that sense, adaptive strucutration theory contributed to two important aspects of social presence theory. 


\subsubsection{Chapter 3}

In chapter 3, we studied triadic interactions of a customer and a purchase pal sharing one computer screen during an interaction with an online human expert. The questions guiding chapter 3 were 1) can trust be transferred from a purchase pal to a customer? and 2) can trust transfer also happen under conditions in which the purchase pal has no prior experience with the online human expert?

The findings of this chapter can be summarized as follows: Trust can be transferred from a purchase pal to a customer even in first-time interactions, were the purchase pal has no prior experience with the online human expert. However, in order for trust to be transferred, the customer needs to trust the purchase pal, and only then he will assimilate the purchase pal's trust perceptions towards the online human expert.

In terms of theoretical contributions, these findings support the relevancy of antecedent taken from adaptive structuration theory, namely the presence of a third person added to a dyad does influence the outcome of an interaction. Second, this chapter provides support for the SIDE model by investigating two small cues relevant to trust transfer, namely purchase pal's evaluation of the expert's trustworthiness (to be more specific: the customer's perception of the purchase pal's evaluation of the expert's trustworthiness), and the customer's evaluation of the purchase pal's trustworthiness. The findings support the idea that customers grasp at straws to derive an impression on the expert. And finally, prospect theory could be supported by extending it to the trust transfer process. Because losses loom greater than gains, customers want to avoid putting trust in an online human expert if either the pal does not trust in the expert, or if the customer does not trust in the pal. If one of the cues is reflects low trustworthiness, customers will immediately react by not trusting in the online human expert. 


\subsection{An integrated perspective}

The two empirical chapters explore different antecedents of trust using different theoretical settings. In this section, we will discuss the consequences of our findings for management and research of service encounters with customers and online human experts.

\subsubsection{Maximizing the power of service encounters with online human experts}

Both studies show one thing for sure: virtual interaction with an online human expert works. Customers are able to build up trust and take decisions based on the advice they received. Thus, companies are encouraged to continue the virtualization of customer-sales encounters.

However, some aspects require more detailed attention. In the past, much research has focused on designing applications that are as realistic as possible. Thus, bigger screens and increased video and audio quality aimed at creating the (optical) illusion of speaking to a real human being. These developments were supported by the idea of social presence theory, which argued that richer media were more likely to create a feeling of social presence and thus the customer felt more physically present to the human expert. It was believed that only then trust could be created as in a real human-to-human interaction (for a more detailed description and references, see chapter 2). Although media richness is indeed related to social presence and trust, it is expensive to invest heavily in technology, and it may even be impossible to ensure that all customers have access to e.g. video calls. Consequently, there is a need to identify additional ways to create social presence and trust, to ensure trust creation in situations where media richness cannot be influenced. Thus, Adaptive Structuration Theory (DeSanctis et al. 1994) was used to extract three additional factors, namely interaction history, interaction style, and the presence of a purchase pal in a triadic interaction.

The findings of this dissertation indicate that media richness and social presence are not the only antecedents to trust. The more general necessity customers have may be the need for clues about the online human expert. 
These may be high-quality visual clues as proposed by social presence and media richness theory. However, the SIDE model (Social Identity model of Deindividuation Effects) argues that in the absence of clues that may be provided in real face-to-face interactions, people take whatever clue they can get about the other party to form an impression about important aspects such as trustworthiness (Tanis et al. 2003).

The SIDE model helps to bring the findings of this dissertation in line. In chapter 2, we found that the interaction history between a human expert and the customer is one important clue for the customer. This is obvious, because it is a kind of first-hand experience the customer had with that human expert. Additionally, we found that the expert's interaction style forms significant clue. A more interactive communication style creates the feeling of being more appreciated and being physically closer to the online human expert. The third clue discovered in this dissertation (chapter 3 ) is that trust in the co-located purchase pal also creates the illusion of having more physical presence with the online human expert. In addition, prospect theory is used to explain why the purchase pal's trust in combination with the customer's trust in the purchase pal increases the customer's perceived level of trust with the inline human expert.

The importance of these clues is explained using theories from different areas. While previous research has focused on very prominent information such as media richness or peer's word of mouth, this dissertation shows by means of experiments that even minor information such as a different interaction style or a pal's initial trust (that is, the pal has no experience with the online human expert) had a significant impact on social presence or trust. Thus, the theories used in these studies seem to be very strong so that they come into effect even with subtle clues. It can be concluded that all of these clues seem to help reducing the uncertainty inherent to interactions with online human experts, or help to create a feeling of presence with these experts.

We hope that this dissertation helps to change the perspective researchers and managers take when evaluating service encounters with online human experts: Even in situations of low media richness and absence of word of mouth (e.g due to the pal's lack of experience), this dissertation identifies 
three additional clues to increase social presence and trust in interactions with an online human expert.

\subsubsection{Re-defining Social Presence}

A second common theme in the chapters of this dissertation is the focus on social presence.

In chapter 2, one focus is on the conceptualization of this construct and its sub dimensions (namely physical presence and emotional presence). Additionally, social presence is clearly delineated from conversational involvement, a construct often confounded as being one dimension of social presence.

This dissertation showed that the different sub-dimensions are clearly related, namely are they elements of a process that evolves like a chain reaction, in which physical presence helps to create emotional presence which subsequently leads to conversational involvement.

Also new antecedents to physical presence were discovered - interaction history, interaction style and trust in a co-located purchase pal. These antecedents are in line with adaptive structuration theory (DeSanctis et al. 1994), which predicts that factors inherent to the humans involved in an online interaction shape the ongoing interaction and it's outcome.

Both of these chapters highlight the importance of social presence for studies of human-to-human contact. Since social presence contributes to the level of trust felt by the customer, and trust relates to critical outcomes for companies (see chapter 1 ), it is difficult to understand why researchers have used the construct of social presence mainly in studies with avatars, virtual worlds and websites, as opposed to settings such as service encounters with human-to-human contact (see chapter 2).

This dissertation provides a clear definition of social presence, a short measurement tool for physical and emotional presence in human online encounters as well as insights in additional antecedents to social presence and trust during online encounters, such as interaction style, interaction history and trust in a co-located friend. In the following chapter, we will present suggestions on how these findings can be used for further research. 


\subsubsection{Suggestions for further research}

We provided specific directions of further research at the end of each chapter. This concluding paragraph will focus on more general directions of further research in the area of human-to-human personal advice via the internet.

First of all, adaptive structuration theory (DeSanctis et al. 1994) argues that several sources of structure influence an interaction simultaneously. However, most research has only focused on one source of structure. Studies using media richness or social presence theory have mainly argued that technology features impact the outcome of a mediated interaction, and this dissertation has evaluated the impact of the dyad / triad, beyond investigating the impact of the medium. Future research should thus study possible interaction effects between different sources of structure by investigating media richness and features of dyad/triads/groups simultaneously. Likewise, future research may compare which source of structure actually has the greatest impact on trust or other outcome variables of interest.

Second, adaptive structuration theory proposes that during an interaction new structures are developed inherent to the specific combination of task, media used and the group who participates in an interaction. Future research may thus specifically focus on the complex effects one interaction has on the next interaction. For this, a longitudinal study may be providing further insights into how the impact of the different sources of structure changes over time.

Third, based on chapter 2 we concluded that the interaction history of the dyad had an impact on social presence and subsequently on trust. From chapter 3 we learned that trust can be transferred within a triad. Further research may thus explore how trust can be transferred depending on the interaction history of a triad. It is unclear whether an interaction history of the purchase pal strengthens the trust transfer towards the customer without previous experience with the online human expert. We may assume that in the opposite case, a customer who has an interaction history with the online human expert will not be easily influenced by a purchase pal without any prior experience with the online human expert. However, what happens if both of them have an interaction history? And how does trust 
get transferred when customer and purchase pal made different experiences with the same online human expert? Future research should thus explore more in depth how trust gets transferred in situations where the interaction history is different than in the studies executed in this dissertation.

Finally, this dissertation focuses on the customer perspective. While the customer perspective is crucial since it directly relates to critical outcomes such as trust and purchase behavior, also the employee's perceptions may impact a customer's score on the outcome variable. The Actor-Partner Interdependence Model - APIM (Kenny et al. 1999) argues that within a dyad, each partner's score for a independent variable impacts the own score for the outcome variable that relates to the independent variables, but also the other party's score on that outcome variable. However, in chapter 3 not a dyad but a triad participated in a conversation. Thus, the APIM may explain the effect of trust transfer between customer and purchase pal, but how does APIM relate to the relationship of the purchase pal and the online human expert or the online human expert and the customer? How and what does get transferred between these parties? Thus, future research should also consider the employee. This may be yet another variable to be influenced by a company: If employee perceptions can be changed due to specific trainings, the customer's perceptions may be impacted as well. 


\section{References}

ABN AMRO "Proef met teleportatie in nieuwe Self-service Bankshop in Eindhoven [Trial of Teleportation in the New Self-service Bankshop in Eindhoven]," ABN AMRO, 2004.

Ambady, N., and Rosenthal, R. "Half a minute: Predicting teacher evaluations from thin slices of nonverbal behavior and physical attractiveness," Journal of Personality and Social Psychology (64:3) 1993, pp 431-441.

Awad, N.F., and Ragowsky, A. "Establishing Trust in Electronic Commerce Through Online Word of Mouth: An Examination Across Genders," in: Journal of Management Information Systems, M.E. Sharpe Inc., 2008, pp. 101-121.

Bar-Anan, Y., Liberman, N., and Trope, Y. "The association between psychological distance and construal level: Evidence from an implicit association test," Journal of Experimental Psychology: General (135:4) 2006, pp 609-622.

Barfield, W., Baird, K.M., and Bjorneseth, O.J. "Presence in virtual environments as a function of type of input device and display update rate," Displays (19) 1998, pp 91-98.

Barki, H., and Hartwick, J. "Rethinking the Concept of User Involvement," MIS Quarterly (13:1) 1989, pp 53-63.

Barua, A., Konana, P., Whinston, A.B., and Fang, Y. "An Empirical Investigation of Net-Enabled Business Value," MIS Quarterly (28:4) 2004, pp 585-620.

Bekkering, E., and Shim, J.P. "i2i Trust in Videoconferencing," Communications of the ACM (49:7) 2006, pp 103-107.

Benet-Martinez, V., and John, O.P. "Los Cinco Grandes Across Cultures and Ethnic Groups: Multitrait Multimethod Analyses of the Big Five in Spanish and English," Journal of Personality \& Social Psychology (75:3) 1998, pp 729-750.

Bente, G., Rüggenberg, S., Krämer, N.C., and Eschenburg, F. "Avatar-Mediated Networking: Increasing Social Presence and Interpersonal Trust in Net-Based Collaborations," Human Communication Research (34:2) 2008, pp 287-318.

Bielski, L. "Telepresence: costly, but very cool," ABA Banking Journal (100:4) 2008, pp 50-52.

Biocca, F., Burgoon, J., Harms, C., and Stoner, M. "Criteria and Scope Conditions for a Theory and Measure of Social Presence," PRESENCE 2001: The 4th Annual International Workshop on Presence, Philadelphia, PA, USA at Temple University, 2001a.

Biocca, F., Harms, C., and Burgoon, J. "Toward a More Robust Theory and Measure of Social presence: Review and Suggested Criteria," Presence: Teleoperators \& Virtual Environments (12:5) 2003, pp 456-480.

Biocca, F., Harms, C., and Gregg, J. "The Networked Minds Measure of Social presence: Pilot Test of the Factor Strucuter and Concurrent Validity," PRESENCE 2001: The 4th Annual International Workshop on Presence, Philadelphia, PA, 2001b.

Bitner, M.J., Booms, B.H., and Mohr, L.A. "Critical service encounters: The employee's viewpoint," in: Journal of Marketing, American Marketing Association, 1994, p. 95. 
Bitner, M.J., Brown, S.W., and Meuter, M.L. "Technology Infusion in Service Encounters," in: Journal of the Academy of Marketing Science, 2000, p. 138.

Bohnet, I., and Frey, B.S. "The sound of silence in prisoner's dilemma and dictator games," Journal of Economic Behavior \& Organization (38:1) 1999, pp 43-57.

Bos, N., Olson, J., Gergle, D., Olson, G., and Wright, Z. "Effect of Four ComputerMediated Communication Channels on Trust Development," CHI 2002, Minneapolis, Minnesouta, USA, 2002, pp. 135-140.

Bradley, G., Sparks, B., and Nesdale, D. "Doctor Communication Style and Patient Outcomes: Gender and Age as Moderators," Journal of Applied Social Psychology (31:8) 2001, pp 1749-1773.

Brosig, J., Ockenfels, A., and Weimann, J. "Information and Communication in Sequential Bargaining," in: Discussion Papers on Strategic Interaction, Max Planck Institute of Economics, Strategic Interaction Group, 2003-09, Jena, Germany, 2003.

Bryant, S.M., Stone, D.N., and Wier, B. "Financial Attitudes: Implications for Personal Financial Planning Services (PFPSs) and Financial Literacy," 2006.

Bugg Holloway, B., and Beatty, S.E. "Satisfiers and Dissatisfiers in the Online Environment: A Critical Incident Assessment," in: Journal of Service Research, 2008, pp. 347-364.

Buller, M.K., and Buller, D.B. "Physicians' communication style and patient satisfaction," Journal of Health and Social Behavior (28:4) 1987, pp 375-388.

Burgoon, J.K., Bonito, J.A., Bengtsson, B., Ramirez, A.J., Dubar, N.E., and Miczo, N. "Testing the Interactivity Model: Communication Processes, Partner Assessments, and the Quality of Collaborative Work," Journal of Management Information Systems (16:3) 2000, pp 33-56.

Burgoon, J.K., Buller, D.B., White, C.H., Afifi, W., and Buslig, A.L.S. "The Role of Conversational Involvement in Deceptove Interpersonal Interactions," Personality and Social Psychology Bulletin (25:6) 1999, pp 669-686.

Burgoon, J.K., Newton, D.A., Walther, J.B., and Baesler, E.J. "Nonverbal Expectancy Violations and Conversational Involvement," Journal of Nonverbal Behavior (13:2) 1989, pp 97-119.

Cassel, C., Hackl, P., and Westlund, A.H. "Robustness of partial least-squares method for estimating latent variable quality structures," Journal of Applied Statistics (26:4) 1999, pp 435-446.

Cegala, D.J., Savage, G.T., Brunner, C.C., and Conrad, A.B. "An Elaboration of the Meaning of Interaction Involvement: Toward the Development of a Theoretical Concept," Communication Monographs (49) 1982, pp 229-248.

Chandon, P., Morwitz, V.G., and Reinartz, W.J. "Do Intentions Really Predict Behavior? Self-Generated Validity Effects in Survey Research," Journal of Marketing (69:2) 2005, pp 1-14.

Cho, J. "The mechanism of trust and distrust formation and their relational outcomes.," Journal of Retailing (82:1) 2006, pp 25-35.

Churchill Jr, G.A. "A Paradigm for Developing Better Measures of Marketing Constructs," Journal of Marketing Research (JMR) (16:1) 1979, pp 64-73.

Cisco "Virtual Expert Management," 2008. 
Cohen, J. Statistical Power Analysis for the Behavioral Sciences Lawrence Erlbaum Associates, Hillsdale, NJ, 1988.

Coker, D.A., and Burgoon, J. "The Nature of Conversational Involvement and Nonverbal Encoding Patterns," Human Communication Research (13:4) 1987, pp 463494.

Commission, E. "E-Communications Household Survey," in: Special Eurobarometer, 2008.

Coyle, J.R., and Thorson, E. "The Effects of Progressive Levels of Interactivity and Vividness in Web Marketing Sites," Journal of Advertising (30:3), Fall2001 2001, pp 65-77.

Cyr, D., Hassanein, Head, m., and Ivanov "The role of Social Presence in establishing Loyalty in E-service Environments," Interacting with computers (19:1) 2007, pp 43-56.

Czepiel, J.A. "Service Encounters and Service Relationships: Implications for Research," in: Journal of Business Research, 1990, pp. 13-21.

Daft, R.L., Lengel, R.H., and Trevino, L.K. "Message Equivocality, Media Selection, and Manager Performance: Implications for Information Systems," MIS Quarterly (11:3) 1987, pp 354-366.

Dash, E., and Bajaj, V. "Credit, and trust, needed to end financial crisis," in: The New York Times, New York, 2009.

Derks, D., Bos, A.E.R., and von Grumbkow, J. "Emoticons and Social Interaction on the Internet: The Importance od Social Context," Computers in Human Behavior (23:1) 2007, pp 842-849.

Derks, D., Fischer, A.H., and Bos, A.E.R. "The role of emotion in computer-mediated communication: A review," Computers in Human Behavior (24:3) 2008, pp 766785.

DeSanctis, G., and Poole, M.S. "Capturing the Complexity in Advanced Technology Use: Adaptive Structuration Theory," Organization Science (5:2) 1994, pp 121147.

Dion, P.A., and Notarantonio, E.M. "Salesperson Communication Style: The Neglected Dimension in Sales Performance," Journal of Business Communication (29:1) 1992, pp 63-77.

Duncan, T., and Moriarty, S.E. "A Communication-Based Marketing Model for Managing Relationships," Journal of Marketing (62:2) 1998, pp 1-13.

Fabri, M., and Moore, D. "Is Empathy the Key? Effective Communication via Instant Messaging," 11th EATA International Conference on Network Entities, St. Pölten, Austria, 2005.

Ferrin, D.L., Dirks, K.T., and Shah, P.P. "Direct and indirect effects of third-party relationships on interpersonal trust," Journal of Applied Psychology (91:4) 2006, pp 870-883.

FocusMoney "Deutsche befürchten Altersarmut," 2007.

Fornell, C., and Larcker, D.F. "Structural Equation Models With Unobservable Variables and Measurement Error: Algebra and Statistics," Journal of Marketing Research (JMR) (18:3) 1981, pp 382-388. 
Frey, B.S., and Bohnet, I. "Cooperation, Communication and Communitarianism: An Experimental Approach," The Journal of Political Philosophy (4:4) 1996, pp 322336.

Ganesan, S. "Determinants of long-term orientation in buyer-seller relationships," Journal of Marketing (58:2) 1994, p 1.

Ganesan, S., and Hess, R. "Dimensions and Levels of Trust: Implications for Commitment to a Relationship," Marketing Letters (8:4) 1997, pp 439-448.

Gefen, D., Benbasat, I., and Pavlou, P.A. "A Research Agenda for Trust in Online Environments," Journal of Management Information Systems (24:4), Spring2008 2008, pp 275-286.

Gefen, D., and Straub, D.W. "Consumer trust in B2C e-Commerce and the importance of social presence: experiments in e-Products and e-Services," Omega (32:6) 2004, pp 407-424.

Gerber, G.L. "Psychological distance in the family as schematized by families of normal, disturbed, and learning-problem children," Journal of Consulting and Clinical Psychology (40:1) 1973, pp 139-147.

Gerhard, M., Moore, D., and Hobbs, D. "Close Encounters of the Virtual Kind: Agents Simulating Copresence," Applied Artificial Intelligence (19:3 \& 4) 2005, pp 393-412.

Grabner-Kräuter, S., and Kaluscha, E.A. "Empirical research in on-line trust: a review and critical assessment," International Journal of Human-Computer Studies (58) 2003, pp 783-812.

Grayson, K. "Friendship Versus Business in Marketing Relationships," in: Journal of Marketing, American Marketing Association, 2007, pp. 121-139.

Gremler, D.D., and Brown, S.W. "The loyalty ripple effect," in: International Journal of Service Industry Management, 1999, p. 271.

Gremler, D.D., Gwinner, K.P., and Brown, S.W. "Generating positive word-of-mouth communication through customer-employee relationships," in: International Journal of Service Industry Management, 2001, p. 44.

Gupta, P., Yadav, M.S., and Varadarajan, R. "How Task-Facilitative Interactive Tools Foster Buyers' Trust in Online Retailers: A Process View of Trust Development in the Electronic Marketplace," in: Journal of Retailing, 2009, pp. 159-176.

Hair, J.F., Black, W.C., Babin, B.J., Anderson, R.E., and Tatham, R.L. Multivariate Data Analysis, (6th edition ed.) Prentice Hall, New Jersey, USA, 2006.

Harms, C. "The Effects of Media Type and Personal Relationship on Perceptions of Social Presence," in: Department of Communication, Michigan State University, East Lansing, 2004.

Harms, C., and Biocca, F. "Internal Consistency and Reliability of the Networked Minds Social Presence Measure," PRESENCE 2004: The 7th Annual International Workshop on Presence, Valencia, Spain, 2004.

Hassanein, K., and Head, M. "The Impact of Infusing Social Presence in the Web Interface: An Investigation Across Product Types," International Journal of Electronic Commerce (10:2) 2006, pp 31-55. 
Havitz, M.E., and Mannell, R.C. "Enduring Involvement, Situational Involvement, and Flow in Leisure and Non-leisure Activities," Journal of Leisure Research (37:2), 2005 2nd Quarter 2005, pp 152-177.

Heaney, J.-G., and Goldsmith, R.E. "External information search for banking services," International Journal of Bank Marketing (17:6/7) 1999, p 305.

Heeter, C. "Being There: The subjective experience of presence," Presence: Teleoperators \& Virtual Environments (1:2) 1992, pp 262-271.

Hian, L.B., Chuan, S.L., Trevor, T.M.K., and Detenber, B.H. "Getting to Know You: Exploring the Development of Relational Intimacy in Computer-mediated Communication," Journal of Computer-Mediated Communication (9:3) 2004.

Howcroft, B., Hewer, P., and Durkin, M. "Banker-Customer Interactions in Financial Services," Journal of Marketing Management (19:9/10) 2003, pp 1001-1020.

Hulland, J. "Use of partial least squares (PLS) in strategic management research: A review of four recent," Strategic Management Journal (20:2) 1999, p 195.

Hwang, H.S., and Lombard, M. "Understanding Instant Messaging: Gratifications and Social Presence," Presence: 2006: The 9th Annual International Workshop on Presence, Cleveland, Ohio, 2006, pp. 50-56.

Hwang, H.S., and Park, S. "Being Together: User's Subjective Experience of Social Presence in CMC Environments " in: Human-Computer Interaction. Interaction Design and Usability, J.A. Jacko (ed.), Springer, Berlin / Heidelberg, 2007, pp. 844853.

IBM "Putting the "retail "into retail banking," 2006.

Ijsselsteijn, W., Ridder, H.d., Freeman, J., Avons, S.E., and Bouwhuis, D. "Effects of Stereoscopic Presentation, Image Motion, and Screen Size on Subjective and Objective Corroborative Measures of Presence," Presence (10:3) 2001, pp 298-311. Ijsselsteijn, W.A., and Riva, G. "Being There: The Experience of Presence in Mediated Environments," in: Being There: Concepts, Effects and Measurements of User Presence in Synthetic Environments, G. Riva, F. Davide and W.A. Ijsselsteijn (eds.), los Press, Amsterdam, The Netherlands, 2003, pp. 4-16.

Insko, B.E. "Measuring Presence: Subjective, Behavioral and Physiological Methods," in: Being There: Concepts, Effects and Measurement of User Presence in Synthetic Environments, G. Riva, F. Davide and W.A. Ijsselsteijn (eds.), los Press, Amsterdam, The Netherlands, 2003, pp. 110-119.

Jarvenpaa, S.L., Tractinsky, N., and Saarinen, L. "Consumer Trust in an Internet Store: A Cross-Validation," Journal of Computer-Mediated Communication (5:2) 1999.

Kalwani, M.U., and Silk, A.J. "On The Reliability and Predictive Validity of Purchase Intention Measures," in: Marketing Science, INFORMS: Institute for Operations Research, 1982, p. 243.

Kapteyn, A., and Teppa, F. "Subjective Meausres of Risk Aversion and Portfolio Choice," in: CentER Discussion Paper, Tilburg, 2002, pp. 1-38.

Keaveney, S.M. "Customer switching behavior in service industries: An exploratory study," in: Journal of Marketing, American Marketing Association, 1995, p. 71. 
Kenny, D.A., and Cook, W. "Partner effects in relationship research: Conceptual issues, analytic diificulties, and illustrations," Personal Relationships (6:4) 1999, pp 433-448.

Khalifa, M., and Shen, N. "System Design Effects on Social Presence and Telepresence in Virtual Communities," Proceedings of the 24th International Conference on Information Systems, Washington, DC, USA, 2004, pp. 12-15.

Kiecker, P., and Hartman, C.L. "Predicting Buyers' Selection of Interpersonal Sources: The Role of Strong Ties and Weak Ties," Advances in Consumer Research (21:1) 1994, pp 464-469.

Kim, T., and Biocca, F. "Telepresence via Television: Two Dimensions of Telepresence May Have Different Connections to Memory and Persuasion," Journal of Computer-Mediated Communication (3:2) 1997.

Kumar, N., and Benbasat, I. "Para-Social Presence and Communication Capabilities of a Web Site," e-Service Journal (1:3) 2002, pp 5-24.

Lang, F.R., Lüdtke, O., and Asendorpf, J. "Testgüte und psychometrische Ä quivalenz der deutschen Version des Big Five Inventory (BFI) bei jungen, mittlalten und alten Erwachsenen. [Validity and psychometric equivalence of the German version of the Big Five Inventory in young, middle-aged and old adults.]," Diagnostica (47:3) 2001, pp 111-121.

Lessiter, J., Freeman, J., Keogh, E., and Davidoff, J. "A Cross-Media Presence Questionnaire: The ITC-Sense of Presence Inventory," Presence: Teleoperators \& Virtual Environments (10:3) 2001, pp 282-297.

Levin, D.Z., and Cross, R. "The Strength of Weak Ties You Can Trust: The Mediating Role of Trust n Effective Knowledge Transfer," Management Science (50:11) 2004, pp 1477-1490.

Lewis, J.D., and Weigert, A. "Trust as a social reality," Social Forces (63:4) 1985, pp 967-985.

Li, H., Daugherty, T., and Biocca, F. "Impact of 3-D Advertising on Product Knowledge, Brand Attitude and Purchase Intention: The Mediating Role of Presence," Journal of Advertising (16:3) 2002, pp 43-57.

Liyanarachchi, G.A., and Milne, M.J. "Comparing the investment decisions of accounting practitioners and students: an empirical study on the adequacy of student surrogates," Accounting Forum (Elsevier) (29:2) 2005, pp 121-135.

Lombard, M., and Ditton, T. "At the Heart of It All: The Concept of Presence," Journal of Computer-Mediated Communication (3:2) 1997.

Lombard, M., and Ditton, T.B. "Measuring Presence: A Literature-based Approach to the Development of a Standardized Paper-and-Pencil Instrument," PRESENCE 2000: The 3rd Annual International Workshop on Presence, Delft, the Netherlands, 2000.

Maguire, K.C., and Connaughton, S.L. "Relational Presence in Distance Interdependent Relationships," Presence 2006: The 9th Annual International Workshop on Presence, Cleveland, Ohio, 2006, p. 35.

Mangleburg, T.F., Doney, P.M., and Bristol, T. "Shopping with friends and teens' susceptibility to peer influence," in: Journal of Retailing, 2004, pp. 101-116. 
Mayer, R.C., Davis, J.H., and Schoorman, F.D. "An Integrative Model of Organizational Trust," in: Academy of Management Review, Academy of Management, 1995, pp. 709-734.

McKnight, D.H., Choudhury, V., and Kacmar, C. "Developing and Validating Trust Measures for e-Commerce: An Integrative Typology," Information Systems Research (13:3) 2002, pp 334-359.

McKnight, D.H., Cummings, L.L., and Chervany, N.L. "Initial Trust Formation in New Organizational Relationships," in: Academy of Management Review, Academy of Management, 1998, pp. 473-490.

Meehan, M. "Physiological Reaction as an Objective Measure of Presence in Virtual Environments," in: Department of Computer Science, University of North Carolina, Chapel Hill, 2001.

Mensink, D. "SNS bank bepaalt koers in hypotheekland [SNS bank determines the the way to go in the area of mortgages]," E-commerce (6:4) 2007, pp 34-35.

Mesch, G., and Talmud, I. "The Quality of Online and Offline Relationships: The Role of Multiplexity and Duration of Social Relationships," Information Society (22:3) 2006, pp 137-148.

Meuter, M.L., Bitner, M.J., Ostrom, A.L., and Brown, S.W. "Choosing Among Alternative Service Delivery Modes: An Investigation of Customer Trial of Self-Service Technologies," Journal of Marketing (69:2) 2005, pp 61-83.

Meuter, M.L., Ostrom, A.L., Roundtree, R.I., and Bitner, M.J. "Self-Service Technologies: Understanding Customer Satisfaction with Technology-Based Service Encounters," Journal of Marketing (64:3) 2000, pp 50-64.

Mikropoulos, T.A., Tzimas, E., and Dimou, G.E. "Objective Presence Measures through Electric Brain Activity," PRESENCE 2004: The 7th Annual International Workshop on Presence, Valencia, Spain, 2004.

Morgan, R.M., and Hunt, S.D. "The Commitment-Trust Theory of Relationship Marketing," Journal of Marketing (58:3) 1994, p 20.

Morrison, D.G. "Purchase Intentions and Purchasing Behavior," in: Journal of Marketing, American Marketing Association, 1979, pp. 65-74.

Mühlbach, L., Bocker, M., and Prussog, A. "Telepresence in Videocommunications: A Study on Stereoscopy and Individual Eye Contact," Human Factors (37:22) 1995, pp 290-305.

Naisbitt, J. Megatrends: Ten new directions transforming our lives Warner Books, New York, 1982.

Nakada, G. "Customer service with a digital smile," J@pan Inc.:2) 1999, p 7.

Norton, R.W., and Miller, L.D. "Dyadic Perception of Communication Style," Communication Research (2:1) 1975, pp 50-67.

Ou, C.X.J., Davison, R.M., Pavlou, P.A., and Li, M.Y. "Leveraging Rich Communication Tools: Evidence of Online Trust and Guanxi in China," ICIS 2008 Proceedings Paper 66, Paris, France, 2008.

Parasuraman, A., Zeithaml, V.A., and Berry, L.L. "A Conceptual Model of Service Quality and Its Implications for Future Research," in: Journal of Marketing, American Marketing Association, 1985, pp. 41-50. 
Pavlou, P.A., Huigang, L., and Yajiong, X. "Understanding and Mitigating Uncertainty in Online Exchange Relationships: A Principal - Agent Perspective " MIS Quarterly (31:1) 2007, pp 105-136.

Pornpitakpan, C. "The Persuasiveness of Source Credibility: A Critical Review of Five Decades' Evidence," in: Journal of Applied Social Psychology, 2004, pp. 243-281.

Qiu, L., and Benbasat, I. "Online Consumer Trust and Live Help Interfaces: The Effects of Text-to-Speech Voice and Three-Dimensional Avatars," International Journal of Human-Computer Interaction (19:1) 2005, pp 75-94.

Queisser, M. "Pensions in Germany," in: Policy Research Working Paper Series, The World Bank, Washington, USA, 1996.

Rammstedt, B., and John, O.P. "Measuring personality in one minute or less: A 10item short version of the Big Five Inventory in English and German.," Journal of Research in Personality (42) 2007, pp 203-212.

Reynolds, K.E., and Beatty, S.E. "Customer Benefits and Company Consequences of Customer-Salesperson Relationships in Retailing," Journal of Retailing (75:1), Spring99 1999, pp 11-32.

Ringle, C.M., Wende, S., and Will, S. "SmartPLS 2.0 (M3) Beta," Hamburg, 2005.

Rosch, E. "Cognitive Reference Points," Cognitive Psychology (7) 1975, pp 532-547.

Salancik, G.R., and Pfeffer, J. "A Social Information Processing Approach to Job Attitudes and Task Design," in: Administrative Science Quarterly, Administrative Science Quarterly, 1978, pp. 224-253.

Sarel, D., and Marmorstein, H. "Marketing online banking services: The voice of the customer," Journal of Financial Services Marketing (8:2) 2003, pp 106-118.

Schepers, J., Wetzels, M., and De Ruyter, K. "Leadership Styles in Technology Acceptance: Do Followers Practice What Leaders Preach?," Managing Service Quality (15:6) 2005, pp 496-508.

Schmidt, C., and Zultan, R.i. "The Uncontrolled Social Utility Hypothesis Revisited," Economics Bulletin (3:33) 2005, pp 1-7.

Schmidt, M., Walczuch, R.M., and Ruyter, K.d. "B2C Advice on Complex Service Products via Video Calls: Explanations from Social Presence and Adaptive Structuration Theory," AMCIS 2008 Proceedings, 2008, p. Paper 25.

Schubert, T.W., Friedmann, F., and Regenbrecht, H.T. "The Experience of Presence: Factor Analytic Insights," Presence: Teleoperators \& Virtual Environments (10:3) 2001a, pp 266-281.

Schubert, T.W., Friednman, F., and Regenbrecht, H.T. "The Experience of Presence: Factor Analytic Insights," Presence: Teleoperators \& Virtual Environments (10:3) 2001b, pp 266-281.

Schwyhart, W.R., and Smith, P.C. "Factors in the job involvement of middle managers," Journal of Applied Psychology (56:3) 1972, pp 227-233.

Selnes, F., and Hansen, H.v. "The Potential Hazard of Self-Service in Developing Customer Loyalty," Journal of Service Research (4:2) 2001, p 79.

Sen, S., and Lerman, D. "Why are you telling me this? An examination into negative consumer reviews on the Web," in: Journal of Interactive Marketing (John Wiley \& Sons), 2007, pp. 76-94. 
Sheng-Hsun, H., Wun-Hwa, C., and Ming-Jyh, H. "Robustness testing of PLS, LISREL, EQS and ANN-based SEM for measuring customer satisfaction," Total Quality Management \& Business Excellence (17:3) 2006, pp 355-371.

Short, J., Williams, E., and Christie, B. The Social Psychology of Telecommunications John Wiley \& Sons, London, 1976.

Siehl, C., Bowen, D.E., and Pearson, C.M. "Service Encounters as Rites of Integration: An Information Processing Model," Organization Science (3:4) 1992, pp 537555.

Slingsby, B.T., Yamada, S., and Akabayashi, A. "Four Physician Communication Styles in Routine Japanese Outpatient Medical Encounters," Journal of General Internal Medicine (21:10) 2006, pp 1057-1062.

Söderlund, M., and Rosengren, S. "Revisiting the smiling service worker and customer satisfaction," in: International Journal of Service Industry Management, 2008, pp. 552-574.

Steuer, J. "Defining Virtual Reality: Dimensions Determining Telepresence," in: Communication in the Age of virtual Reality, F. Biocca and M.R. Levy (eds.), Lawrence Erlbaum Associates, Hillsdale, New Jersey, 1995.

Stewart, D.W., and Pavlou, P.A. "From Consumer Response to Active Consumer: Measuring the Effectiveness of Interactive Media," Journal of the Academy of Marketing Science (30:4), Fall2002 2002, pp 376-396.

Stewart, K.J. "Trust Transfer on the World Wide Web," in: Organization Science, INFORMS: Institute for Operations Research, 2003, pp. 5-17.

Straub, D., and Karahanna, E. "Knowledge Worker Communications and Reciepient Availability: Toward a Task Closure Explanaition of Media Choice," Organization Science (9:2) 1998, pp 169-175.

Stuteville, J.R. "The Buyer as a Salesman," in: Journal of Marketing, American Marketing Association, 1968, pp. 14-18.

Tanis, M., and Postmes, T. "Social Cues and Impression Formation in CMC," Journal of Communication (53) 2003, pp 676-693.

Teleportel "Private Banking en Andere Toepassingen Binnen de Bank [Private Banking and Other Applications within the Bank]," Teleportel, 2009.

Tenenhaus, M., Vinzi, V.E., Chatelin, Y.-M., and lauro, C. "PLS path modelling," Computational Statistics \& Data (48:1) 2005, pp 159-205.

Tversky, A., and Kahneman, D. "Loss Aversion in Riskless Choice: A ReferenceDependent Model,," in: Quarterly Journal of Economics, MIT Press, 1991, pp. 1039-1061.

Tversky, A., and Kahneman, D. "Advances in Proppect Theory: Cumulative Representation of Uncertainty," Journal of Risk and Uncertainty (5) 1992, pp 297-323.

Tyre, M.J., and Orlikowski, W.J. "Windows of Opportunity: Temporal Patterns of Technological Adaptation in Organizations," Organization Science (5:1) 1994, pp 98-118.

Venkatesh, V., and Johnson, P. "Telecommuting Technology Implementations: A Within- and Between-Subjects Longitudinal Field Study," Personnel Psychology (55:3) 2002, pp 661-687. 
Villanueva, J., Yoo, S., and Hanssens, D.M. "The Impact of Marketing-Induced Versus Word-of-Mouth Customer Acquisition on Customer Equity Growth," in: Journal of Marketing Research (JMR), American Marketing Association, 2008, pp. 4859.

Villeneuve, C., and Roy, L. "Psychological distance in 'clinic' and control families," Canadian Journal of Behavioural Science/Revue canadienne des sciences du comportement (16:3) 1984, pp 216-223.

Walczuch, R., and Lundgren, H. "Psychological antecedents of institution-based consumer trust in e-retailing," in: Information \& Management, 2004, pp. 159-177.

Waller, D., and Bachmann, E.R. "The Borderline of Science: On the Value of Factor Analysis for Understanding Presence," Presence (15:2) 2006, pp 235-244.

Walther, J.B., and Burgoon, J.K. "Relational Communication in Computer-Mediated Interaction," Human Communication Research (19:1) 1992, pp 50-88.

Walther, J.B., Loh, T., and Granka, L. "Let me count the ways: The Interchange of Verbal and Nonverbal Cues in Computer-Mediated and Face-to-Face Affinity.," Journal of Language and Social Psychology (24:1) 2005, pp 35-65.

Wang, L.C., Baker, J., Wagner, J.A., and Wakefield, K. "Can a Retail Web Site Be Social?," in: Journal of Marketing, American Marketing Association, 2007, pp. 143157.

Weijzen, P.L.G., de Graaf, C., and G.B., D. "Discrepancy Between Snack Choice Intentions and Behavior. ," Journal of Nutrition Education and Behavior (40:5) 2008, pp 311-316.

Williams, K.C., and Spirio, R.L. "Communication Style in the Salesperson-Customer Dyad," Journal of Marketing Research (22:4) 1985, pp 434-424.

Williams, L.E., and Bargh, J.A. "Keeping One's Distance: The Influence of Spatial Distance Cues on Affect and Evaluation," Psychological Science (19:3) 2008, pp 302-308.

Witmer, B.G., Jerome, C.J., and Singer, M.J. "The factor structure of the presence questionnaire," Presence: Teleoperators and Virtual Environments (14) 2005, pp 298-312.

Witmer, B.G., and Singer, M.J. "Measuring Presence in Virtual Environments: A Presence Questionnaire," Presence: Teleoperators \& Virtual Environments (7:3) 1998, pp 225-240.

www.internetwoldstats.com "Internet Usage in European Union," 2009.

Yadav, M.S., and Varadarajan, P.R. "Understanding product migration to the electronic marketplace: A conceptual framework," in: Journal of Retailing, 2005, pp. 125-140.

Yoo, Y., and Alavi, M. "Media and Groep Cohesion: Relative Influences on Social Presence, Task Participation, and Group Consensus," MIS Quarterly (25:3) 2001, pp 371-390.

Yoon, S.-J. "The Antecedents and Consequences of Trust in Online-Purchase Decisions," Journal of Interactive Marketing (John Wiley \& Sons) (16:2), Spring2002 2002, pp 47-63.

Zaichkowsky, J.L. "Measuring the Involvement Construct," Journal of Consumer Research (12:3) 1985, pp 341-352. 
Zeithaml, V.A., Berry, L.L., and Parasuraman, A. "The Behavioral Consequences of Service Quality," in: Journal of Marketing, American Marketing Association, 1996, pp. 31-46. 



\section{Curriculum Vitae}

Mirjam Schmidt (1981) was born in Hesse, Germany. She obtained a diploma for a vocational training at Frankfurt (Bankkauffrau IHK, 2002) and worked at the risk control department of one of Germany's biggest banks. In 2004 she received her bachelor in Business Administration at Frankfurt School of Finance and Management (formerly Hochschule für Bankwirtschaft).

In 2005, Mirjam graduated with a master's degree from the business research program in Maastricht (M.phil). Afterwards she worked for the German chamber of industry and commerce in Caracas, Venezuela.

Mirjam was employed as a PhD Candidate at both the department of Marketing \& Supply Chain Management and the department of Accounting \& Information Management from 2006. During this time, she conducted research projects, was involved in teaching and supervised master theses. 